Portland State University

PDXScholar

Spring 6-7-2017

\title{
Grassroots Resistance in the Sustainable City: Portland Harbor Superfund Site Contamination, Cleanup, and Collective Action
}

Erin Katherine Goodling

Portland State University

Follow this and additional works at: https://pdxscholar.library.pdx.edu/open_access_etds

Part of the Environmental Studies Commons

Let us know how access to this document benefits you.

\section{Recommended Citation}

Goodling, Erin Katherine, "Grassroots Resistance in the Sustainable City: Portland Harbor Superfund Site Contamination, Cleanup, and Collective Action" (2017). Dissertations and Theses. Paper 3613.

https://doi.org/10.15760/etd.5505

This Dissertation is brought to you for free and open access. It has been accepted for inclusion in Dissertations and Theses by an authorized administrator of PDXScholar. Please contact us if we can make this document more accessible: pdxscholar@pdx.edu. 
Grassroots Resistance in the Sustainable City:

Portland Harbor Superfund Site

Contamination, Cleanup, and Collective Action

by

Erin Katherine Goodling

A dissertation submitted in partial fulfillment of the requirements for the degree of

Doctor of Philosophy

in

Urban Studies

Dissertation Committee:

Nathan McClintock, Chair

Sy Adler

Lisa K. Bates

Veronica Dujon

Portland State University

2017 
(C) 2017 Erin Katherine Goodling 


\begin{abstract}
How does progressive change happen in so-called sustainable cities? In this dissertation, I present findings from a three year-long ethnographic investigation of grassroots organizing in Portland, Oregon, a city at the leading edge of the green urbanism movement. This research centered on an extended case study of the Portland Harbor Community Coalition (PHCC). PHCC is an alliance of grassroots groups working to ensure that cleanup of the Portland Harbor Superfund Site benefits those who have been most impacted by pollution. In this dissertation, I develop three main empirical findings. First, despite depoliticized (sustainability) discourse permeating the harbor cleanup planning process, which excluded impacted communities from and minimized disparate impacts resulting from contamination and cleanup, there has not necessarily been a green growth machine operating in the way that we would expect. Instead, a classic status quo growth machine has indirectly pushed depoliticized sustainability discourse, and benefited from it at the expense of vulnerable residents -- even in a paradigmatic sustainable city. Second, in contrast to the "just green enough" strategies put forth in previous research, there are, in fact, grassroots groups who are demanding robust environmental improvements as part of broader social and environmental justice outcomes. PHCC takes an "oppositional community development" approach in attempting to transcend the green development-displacement dialectic. This approach has entailed being strategically confrontational some of the time, and engaging through more established participation channels at other times. Third, individual and collective historicized learning has played a key role in PHCC's efforts to re-politicize the cleanup
\end{abstract}


planning process in three ways: it helped coalition members connect their personal experiences to the harbor; it helped coalition members build a political analysis of the cumulative and inter-generational ways that harbor pollution has impacted different groups; and a collectively produced historical narrative ultimately contributed to the coalition's moderate success in pushing public agencies to be more responsive to impacted communities.

More broadly, this research draws attention to the historical contingencies, organizing approaches, challenges, and transformations experienced by ordinary people coming together to fight for a more just sustainability. It suggests that in order to develop a fuller understanding of urban socio-ecological change processes - and to make meaningful contributions to change in an era of environmental crisis, extreme housing instability, racial violence, and other forms of oppression - scholars must pay attention to those working on the front lines of change, themselves, in broader historical context. 
For Roy Pascoe, who loved and fought for the Willamette River and its people. 


\section{Acknowledgements}

This research was made possible through generous financial and in-kind support of Portland State University's (PSU) Institute for Sustainable Solutions; an Ernie Bonner Equity Planning Scholarship; a PSU Laurel's Fellowship; the PSU Library Special Collections Dissertation Fellowship; and two Maurie Clark Dissertation Fellowships. Additionally, this material is based upon work supported by National Science Foundation IGERT Grant \#0966376: “Sustaining Ecosystem Services to Support Rapidly Urbanizing Areas". Any opinions, findings, and conclusions or recommendations expressed in this material are those of the authors and do not necessarily reflect the views of the National Science Foundation.

I owe a long list of people an enormous debt of gratitude for their support throughout this project. First and foremost, I want to thank the members and supporters of the Portland Harbor Community Coalition (PHCC). This research - and more importantly the grassroots collective action that is the central topic of this dissertation would not have happened without those who have dedicated so much hard work and love to PHCC. Many people are named in this dissertation, and many remained unnamed. I owe Cassie Cohen, PHCC's founder, particular thanks for her patient support of this project. And I am also so lucky to know Steve Goldstein, who has willingly loaned me his ear and shared decades of accumulated wisdom. I can only hope that the words on these pages help to amplify in some small way the knowledge and perspectives of those working on the front lines to make cities more just. 
Second, I cannot thank the members of my dissertation committee enough for their belief in this project and their help making it come to fruition. Nathan McClintock, the chair of my committee, took me under his wing soon after we both arrived at PSU. When I first contacted Nathan, I had never read, let alone written, an academic article. He patiently helped me channel the critical perspective and facilitation skills I had developed over the previous decade as a youth worker and high school teacher, and not only learn to navigate the world of academia, but also to connect the world of research with on-theground social change work. Sy Adler has also offered invaluable support since I began at PSU. More than anyone, Sy has pushed me to think historically, connecting the past to the present. At first, Sy's system of dog-earring the corners of my drafts terrified me; I'd walk into his office, and immediately see that nearly every page needed attention. Sy's consistency made it easy to trust him, however, and I have been so lucky to receive his counsel. I look up to Lisa Bates as the quintessential phronetic scholar. Equally at ease tackling a complicated spatial statistics problem and talking story with teenagers, Lisa is a role model for the kind of researcher that I aspire to be. Throughout this project, she reminded me that my first order of business is to maintain my commitment to PHCC members and their work. Our two-hour long conversations always left me with renewed dedication to making sure this project eventually lands on the ground in a way that matters for those doing this work day in and day out. The first day I met Veronica Dujon, she reminded a room full of students how critical it is to continually ask three questions: who wins? Who loses? Who decides? Ever since, I have endeavored to make these questions central to my own work. I have benefited enormously from Veronica's 
guidance around the ethics and logistics of doing ethnographic research, and feel so lucky that she agreed to remain on my committee even when her work took her far beyond the walls of PSU.

Sincere appreciation is also due to colleagues and mentors at PSU and other institutions. Classmates - now friends - who have helped shape my thinking in valuable ways include Amy Coplen, Anandi van Diepen-Hedayat, Betsy Breyer, Cameron Herrington, Claire Bach, Diana Denham, Fiona Gladstone, Jamaal Green, Jen Turner, Khanh Pham, Kenya Dubois, Marissa Matsler, Mary Ann Rozance, Max Ritts, Melanie Malone, Mike Simpson, Pam Phan, Paul Manson, Tara Goddard, Sam Stritzl, and Z Grabowski. Three classmates/colleagues - Anthony Levenda, Ellie Harmon, and Dillon Mahmoudi - deserve extra special thanks; I am confident I would not have finished this without the friendship and support you all have given. Ellie, especially went above and beyond, biking and taking the bus to the east side of town to write alongside me on so many occasions; reading draft upon draft; and helping me stay focused with emoticon texts. And I have benefited enormously from the formal and informal guidance of so many faculty members at PSU and elsewhere, including Alan Yeakley, Amy Lubitow, Carl Abbott, Connie Ozawa, Greg Schrock, Henrik Ernstson, Isabelle Anguelovski, Jason Jurjevich, Jennifer Allen, Jennifer Dill, Karen Gibson, Marisa Zapata, Moriah McSharry McGrath, Naomi Adiv, Nik Heynen, Paula Carder, Richard White, and Thad Miller. Additionally, I cannot thank the faculty and staff leaders of PSU's IGERT program enough for their deep commitments to interdisciplinary research and student-centered 
approach to learning, especially Darrell Brown, Dave Ervin, Elise Granek, and Kim Heavener.

Finally, I owe my family members giant hugs of appreciation. Alan and Sharon Horton gave me the gift of time to write and Kai the gift of time adventuring with his grandparents three mornings a week, for over a year during the research and writing of this dissertation; I don't know how we'd do it without you. Veronica, Jared, Julian, and Valentina are like extended family members, especially for Kai. My parents, Jesse and Cecilia Goodling, and siblings, Peter and Emilie, continue to offer the same unconditional love as they have since I can remember; I cannot begin to imagine life without your support. Last but definitely not least, Joe and Kai: you guys help me stay grounded and make sure I feel loved, every single day. Thank you. 


\section{Table of Contents}

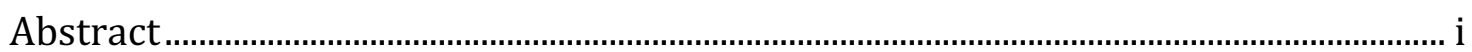

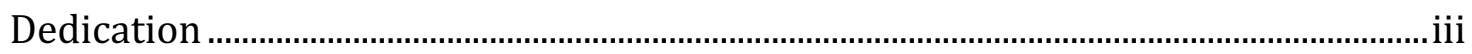

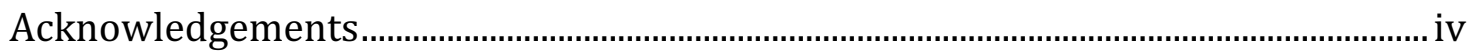

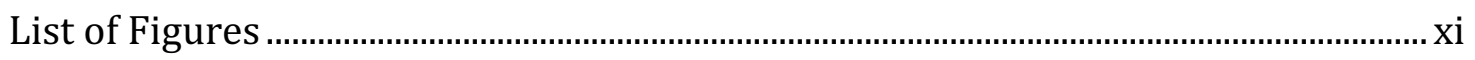

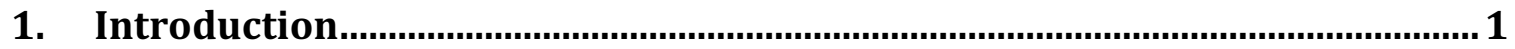

The Production of a Paradigmatic Sustainable City ……........................................... 11

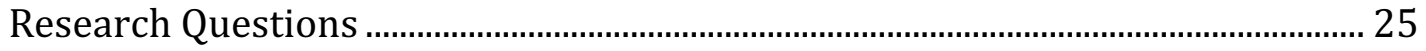

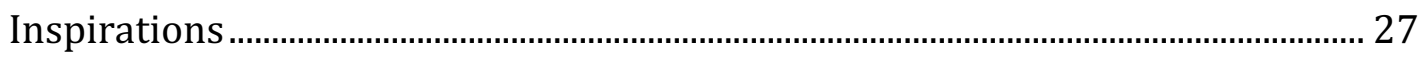

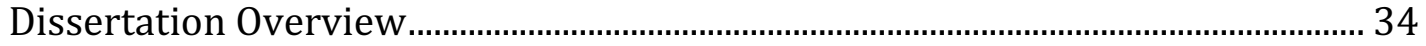

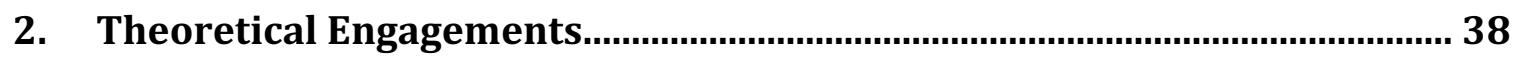

Uneven Development in/of the Sustainable City .................................................... 38

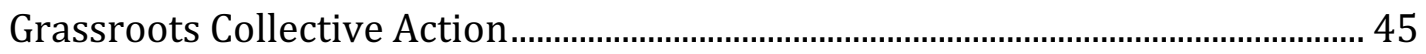

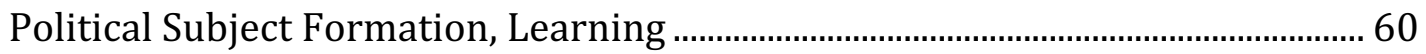

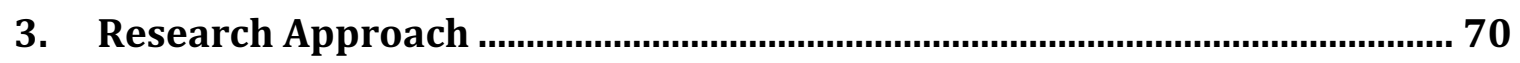

Research Design: Extended Case Method ................................................................... 70

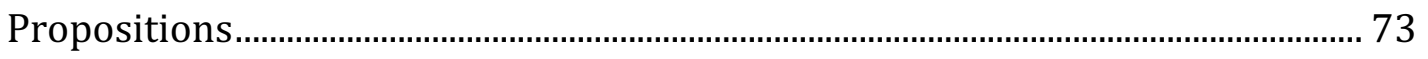

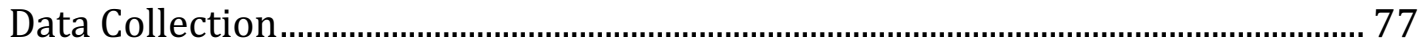

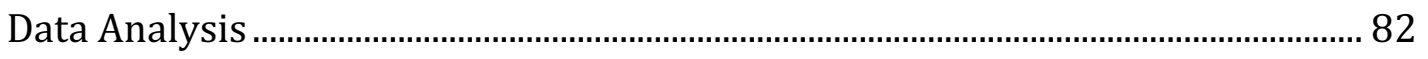

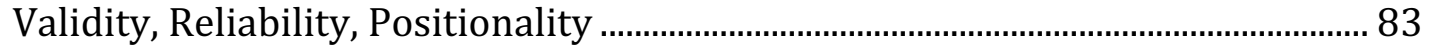

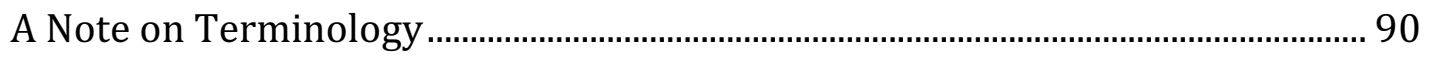

viii 
4. 'Little Bugs in the Mud': Origins and Rise of the Portland Harbor

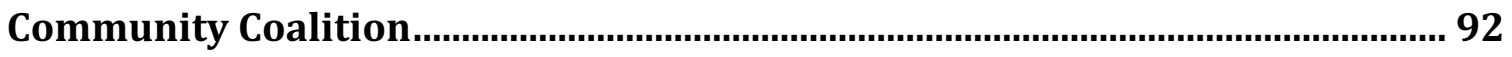

Polluter Pays...for Outreach: Antecedents to PHCC................................................... 93

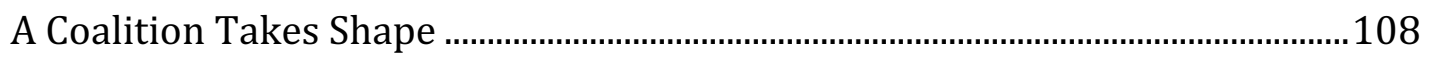

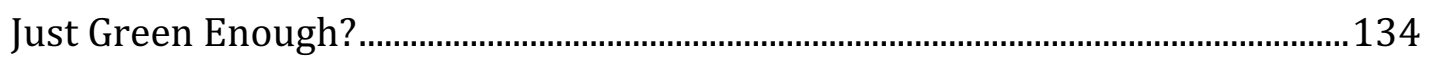

5. A Public Opinion Poll ... and a Webinar!: Holding Public Agencies

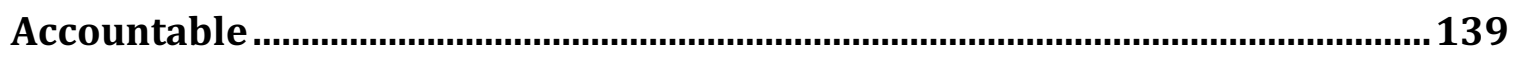

Oppositional Community Development, PHCC-Style...............................................141

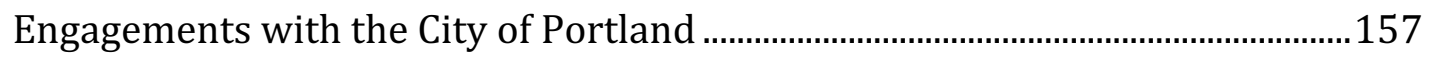

Engagements with the Environmental Protection Agency …………………….....182

Challenging Public Agencies, Making Space for Marginalized Voices...................199

6. Taking Collective Action: Historicized Learning ……................................ 203

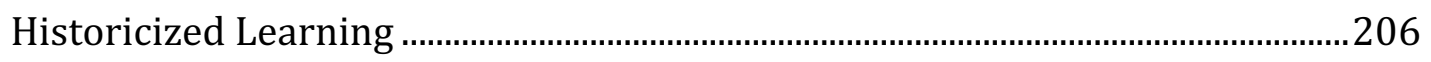

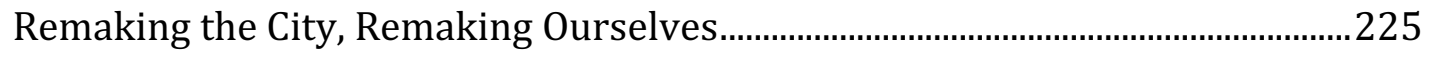

7. Discussion \& Conclusion: Green City Rising....................................................229

Theorizing Sustainability Postpolitics and the (Green) Growth Machine .........235

Theorizing Collective Action in the Green City …………….......................................245

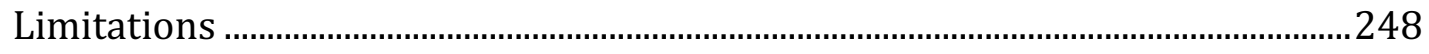

Avenues of Future (Engaged) Inquiry …………………………...........................252

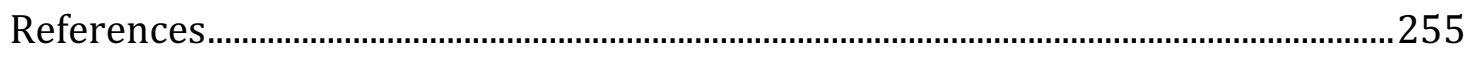

Appendix A: Staying Safe \& Healthy on the Rivers....................................................22 


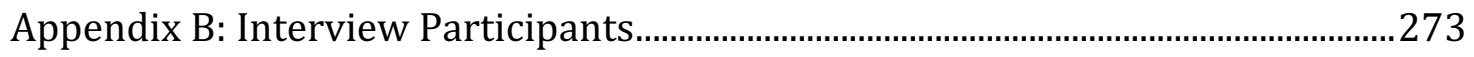




\section{List of Figures}

Figure 1. Rahsaan Muhammad leads community members in condemning the Environmental Protection Agency's Proposed Plan for the Portland Harbor Superfund Site in June 2016. (Photo by Eli Mangold.)

Figure 2. The Portland Harbor Superfund Site and surrounding area. (Map by Dillon Mahmoudi.)

Figure 3. Centerfold of PHCC's four-page Testimony Guide, from summer 2016.

Figure 4. Three scales of analysis address different but overlapping scales and corresponding sets of theoretical concerns and empirical questions. While investigation of each scale could stand alone, the ECM holds them together in one coherent research project. 


\section{INTRODUCTION}

On a grey June morning in 2016, Rahsaan Muhammad stood tall behind a portable podium, addressing fifty people who had gathered on the sidewalk in front of the Portland Municipal Services Building in Portland, Oregon:

We are here today representing over a dozen organizations ... that are saying NO! We want a comprehensive cleanup ... What they are proposing is truly insufficient. We are talking about a site that is ten miles long, over 22,000 acres. We're talking about dredging that needs to be done, shorelines that need to be cleaned up ... There are a lot of opposers talking about "We're going to have to lose jobs to clean up the harbor" ... and we're here to say uh-uh. No-no-no. There are billions of dollars that have already been pocketed by corporations like Bayer CropScience, Chevron, Gunderson, Exxon, BP, Shell, Schnitzer Steel, Toyota, the US Navy, just to name a few-and we all can look at their records and what they make yearly and see that that 750 [million dollars] that you all are playin' with, tryin' to clean up the harbor, is really an insult and a joke. We are here, men, women, and children, ALL different nations - make no mistake about this - this coalition is representative of ALL the communities of color, ALL the Native tribes ... We are ALL on 
board with cleaning up our harbor at the expense of those who are responsible for polluting the harbor. ${ }^{1}$

The crowd clapped and cheered, raising fists in the air. Reporters cocked digital recorders toward Rahsaan, scribbling on little notepads (see Figure 1). Meanwhile, inside the Portland Building, as it is colloquially called, staff members from the Environmental Protection Agency (EPA) prepared for the first public hearing following the release of the Portland Harbor Superfund Site: Superfund Proposed Plan (EPA, 2016).

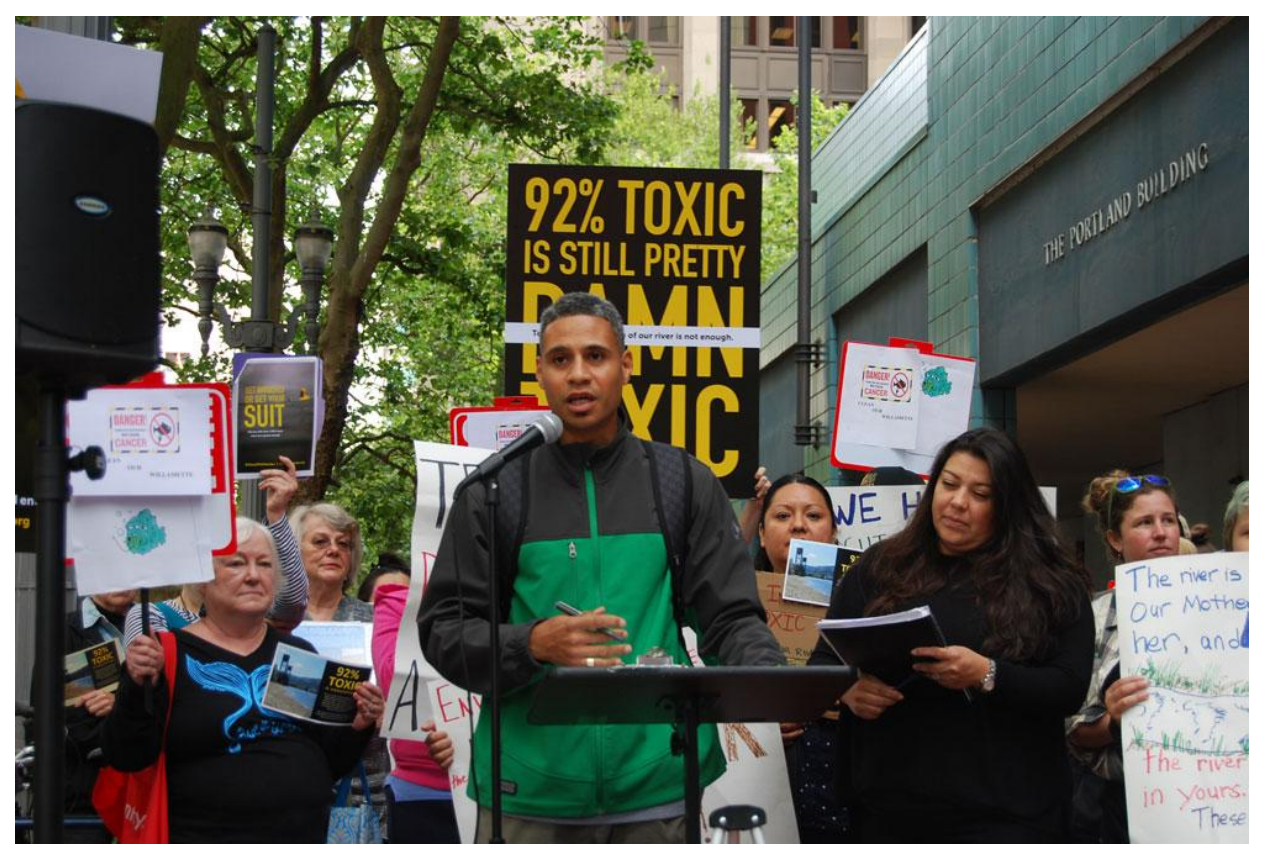

Figure 1. Rahsaan Muhammad leads community members in condemning the Environmental Protection Agency's Proposed Plan for the Portland Harbor Superfund Site in June 2016. (Photo by Eli Mangold.)

${ }^{1}$ Emphasis added to reflect the inflections in Rahsaan's voice. 
As Rahsaan spoke, I shifted my eight-month-old son, Kai, from one hip to the other, posing for a photo with two other mamas and their babies. The Oregon Health Authority (OHA) warns nursing mothers and children against consuming even one bite of "resident" fish, or those fish living fulltime in the Portland Harbor, including catfish, bass, and carp. No amount is considered safe for babies and youngsters with stilldeveloping immune systems, nor for adults with compromised health. The OHA advises all others to eat no more than eight ounces of resident fish per month, or a piece about the size of a deck of cards (Oregon Health Authority, 2017).

Whereas migratory fish, such as salmon, only live beneath Portland's iconic bridges for parts of their lives, resident fish spend their whole lifespans eating a daily diet of the benthic organisms living in mud at the bottom of the river. These organisms, in turn, eat polychlorinated biphenyls, or PCBs, as well as a host of other toxic substances buried in the river's sediment. Banned by Congress in 1979, and one of the most potent of the over 100 contaminants found in the harbor, PCBs are odorless, tasteless, man-made chemicals that were used in the manufacture of transformers, electrical equipment, thermal insulation, plastics, paint, motors, hydraulic systems, and other household and industrial goods for decades. PCBs do not break down over time, and those buried in the Willamette's sediment have been bio-accumulating in the bodies of small organisms and fish - as well as in the bodies of people who eat the fish - for years. Those who subsist on fish from the harbor are estimated to face cancer risks nearly 100 times higher than the EPA's guidelines (EPA, 2013; Mesh, 2012). 
In 2000, the EPA deemed approximately eleven miles of the Willamette River to be so toxic that cleanup warranted federal oversight. The contaminated area in question stretches from the Broadway Bridge in downtown Portland almost to the Willamette's confluence with the Columbia River (see Figure 2). Under the federal Comprehensive Environmental Response, Compensation, and Liability Act (CERCLA) process, commonly known as Superfund, federal natural resource agencies, states, and Tribes have authority to recover natural resource damages caused by release of hazardous substances. CERCLA also allows these entities to evaluate and negotiate cleanup plans, and to mandate follow-through on remediation of some of the most toxic sites in the US. Over 150 "potentially responsible parties" (PRPs) are implicated in paying for the Portland Harbor's cleanup. In addition to those that Rahsaan named, other notable PRPs include multinational companies worth billions of dollars, such as Conoco Phillips, Freightliner Corporation, Kinder Morgan, and Union Pacific Railroad. Companies run by local barons of real estate and industry, such as Harsch Investment Properties and Zidell Marine Corporation, are also on the hook. The City of Portland, the US Army Corps of Engineers, and a handful of other public agencies are considered PRPs as well, as are several mom-and-pop businesses that shuttered years ago. With an original estimated cleanup price tag spread of between $\$ 451$ million and $\$ 9.5$ billion, depending on cleanup methods used, the Portland Harbor Superfund Site is considered one of the most complex of all those listed under CERCLA (EPA, 2013; EPA, 2016). ${ }^{2}$

\footnotetext{
${ }^{2}$ In January, 2017, the EPA released its final Record of Decision, detailing a cleanup plan
} 


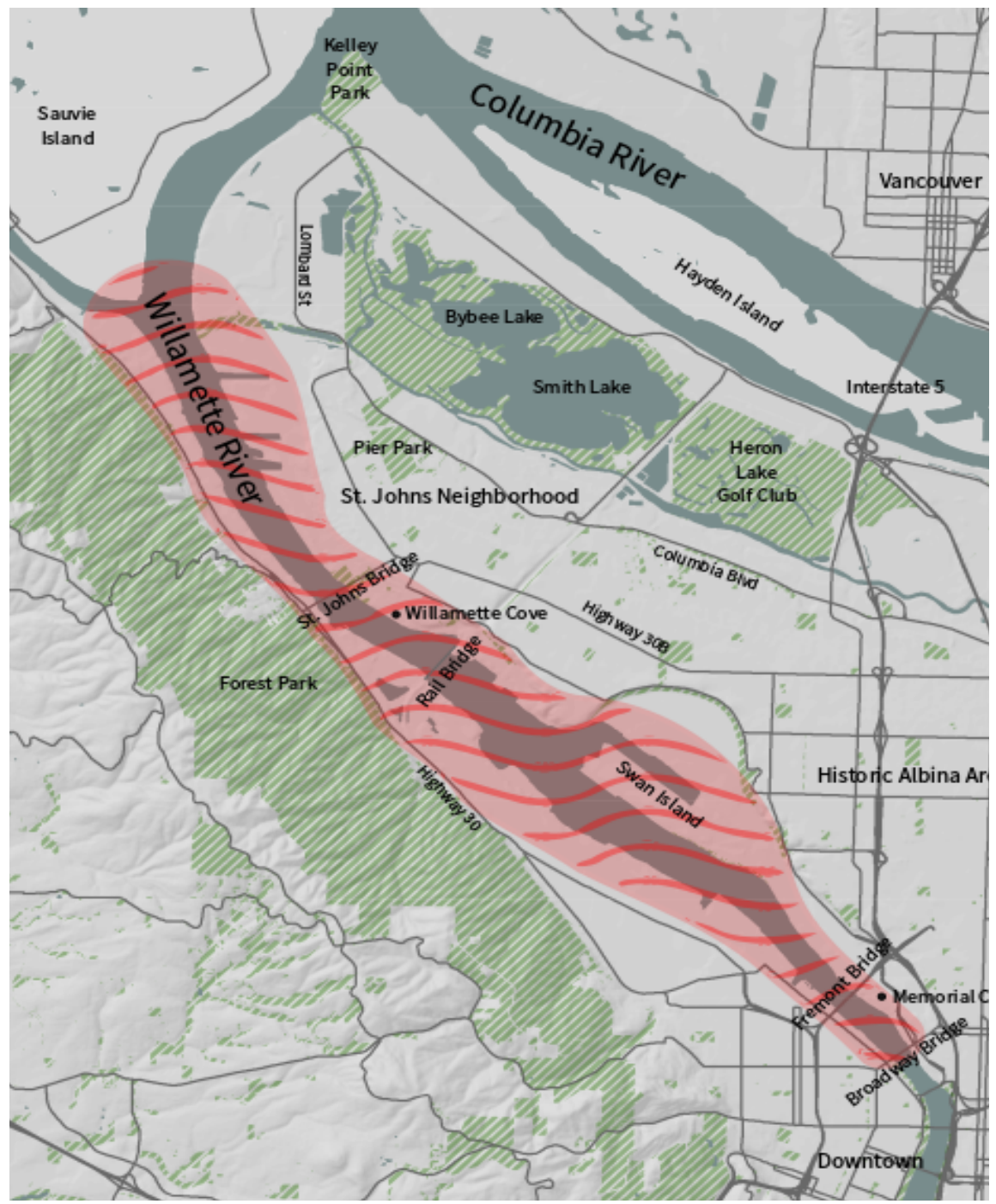

Figure 2. The Portland Harbor Superfund Site and surrounding area. (Map by Dillon Mahmoudi.)

with an officially estimated cost of $\$ 1.04$ billion. Other agencies, however, predict the total cost will actually end up closer to $\$ 2$ billion. 
The possibility of a future in which the Portland Harbor's resident fish can never be safely consumed, and the imperative that polluters pay to redress this situation, weighed heavily on our minds that morning in front of the Portland Building. The " $\$ 750$ million" Rahsaan mentioned is an approximate reference to the EPA's projected cost (\$746 million) of carrying out the remediation activities detailed in the Proposed Plan released in June 2016. The Proposed Plan relied mainly on a "monitored natural recovery" (MNR) approach as opposed to requiring more aggressive methods, such as dredging, for more acres of the cleanup. The estimated cost was therefore at the low end of the range in the list of alternatives put forth by the EPA earlier in the cleanup planning process. Community and environmental groups expressed extreme dissatisfaction with the Proposed Plan. The Audubon Society of Portland (2016:6), for instance, called MNR "a 'do nothing' option" that is "unsupported by science"; "predicated on the expectation that contaminants will degrade over time," MNR "ignores the historic record, which shows that decades after this site was contaminated, contaminated sediments continue to remain exposed." In essence, many of the most dangerous contaminants found in the Portland Harbor, such as PCBs, DDT, heavy metals, dioxins, and furans, take many, many years to degrade, making MNR an inadequate remedy for lifting warnings against consuming resident fish (deFur, 2016). The EPA's Proposed Plan effectively told people who eat from the river that they will forever put themselves at risk of developing cancer and other diseases for which there are no known cures.

Representing the Portland Harbor Community Coalition (PHCC), those of us gathered with Rahsaan stood united on behalf of the tens of thousands of people who 
have depended on the river for not only food, but also shelter, employment, recreation, and spiritual sustenance, for years, decades, centuries. In some ways, the crowd resembled the original Rainbow Coalition. Operating in Chicago in the late 1960s, the Black Panther Party, the Puerto Rican Young Lords, and the white Young Patriots joined forces to combat racialized oppression. In the introduction to Hillbilly Nationalists, Urban Race Rebels, and Black Power: Community Organizing in Radical Times, Sonnie and Tracy (2011:10) write, "We studied these organizations because we believe they engaged honestly with the complexities of racialized capitalism in the United States." While PHCC - the focus of this dissertation - is a much different kind of organization, operating in a different time and place than the original Rainbow Coalition, the coalition's members are also in the midst of honest engagements with the complexities of racialized capitalism in the present moment. The case of PHCC therefore offers important insights into how cities might become more welcoming, affordable, and just spaces for the years to come.

In the hour prior to the press conference, two middle-aged white men smoking the stubs of hand-rolled cigarettes walked over from Right 2 Dream Too, one of Portland's self-run houseless rest areas. They chatted with a handful of white Sierra Club volunteers, most of whom began their activism careers in the years of Rachel Carson. A half-dozen Latina mothers watched their elementary and middle school-aged children march around on the sidewalk in mock-but-real-protest, holding signs bearing colorful drawings of dead fish and slogans such as Tenemos Derecho a Saber - We Have the Right to Know. Graduate students - my classmates - wandered down from Portland State 
University's campus, wondering what all the commotion had to do with the ecosystem services theories they read about in academic journals. Rahsaan, sporting Air Jordan sneakers, greeted a Black man wearing an embroidered Islamic dishdasha with a handshake and a hug, uttering "Salaam". An African-American woman shook hands with a man and his teenage sons who had immigrated to Portland from Iraq a decade prior. A half-dozen twenty-something-year-old representatives from urban Native-serving organizations, tenant advocacy groups, and environmental justice collectives stood off to the side, chatting about recent anti-displacement policy planning meetings. Rose Longoria, the Yakama Nation Fisheries' Regional Superfund Cleanup Projects Coordinator, also arrived to speak during the press conference.

For Rahsaan and those of us standing with him in solidarity, the Proposed Plan would do little to redress the more than a century of "slow violence" (Nixon, 2011) inflicted upon people via exposure to pollution and a host of other vectors of oppression related to the Portland Harbor. Indeed, Ruth Wilson Gilmore's (2007:28) definition of racism as "the state-sanctioned and extralegal exposure of group-differentiated vulnerability to premature death" is relevant not only in her investigation of California's prison system, but also in cases of environmental degradation and cleanup (Dillon and Sze, 2016). ${ }^{3}$ A confluence of circumstances related to the harbor have harmed and

${ }^{3}$ Dillon and Sze (2016:1) examine the "constriction of breath" through asthma rates in San Francisco's Hunter's Point neighborhood as well as in the murder of Eric Garner, a Black man killed by police in New York City after uttering the phrase "I can't breathe". Put side by side, these cases of withheld air reflect the "uneven environmental 
continue to threaten Portland's most vulnerable residents. Those of us gathered on the sidewalk were particularly concerned about the wellbeing of the thousands of people who rely on the river for protein. We were also worried about shipyard workers' exposure to toxins, as well as the countless houseless people living in tents pitched in lead- and dioxin-laced soil on the river's banks. For this reason, PHCC demanded a thorough cleanup. But at the same time, we were also preoccupied about how the harbor cleanup, itself, might threaten the lives and livelihoods of already-marginalized people. We were concerned about low- and middle-income households in neighborhoods adjacent to the river, which face the rising rents, displacement, and other consequences of gentrification that have become all too common in waterfront redevelopment projects. And PHCC members had questions related to jobs: Who would be employed in cleanup work, and how much would they be paid? What percentage of cleanup contracts would go to women and/or minority-owned firms? Would members of underrepresented groups be given priority in cleanup-related job training programs, and would protocols and technologies keep workers' bodies safe? Additional concerns encompassed the removal of toxins: Where would workers dispose of refuse? Would diesel trucks carrying sludge away from the harbor be required to use the most effective air filters available? PHCC's Testimony Guide, which served as a rubric for PHCC members and supporters to use when testifying about the Proposed Plan in summer 2016, outlines the breadth of the coalition's concerns (see Figure 3).

conditions" in which Black/African American communities live, and they also assert "the humanity of a population for whom human-ness, and life, has been historically denied." 


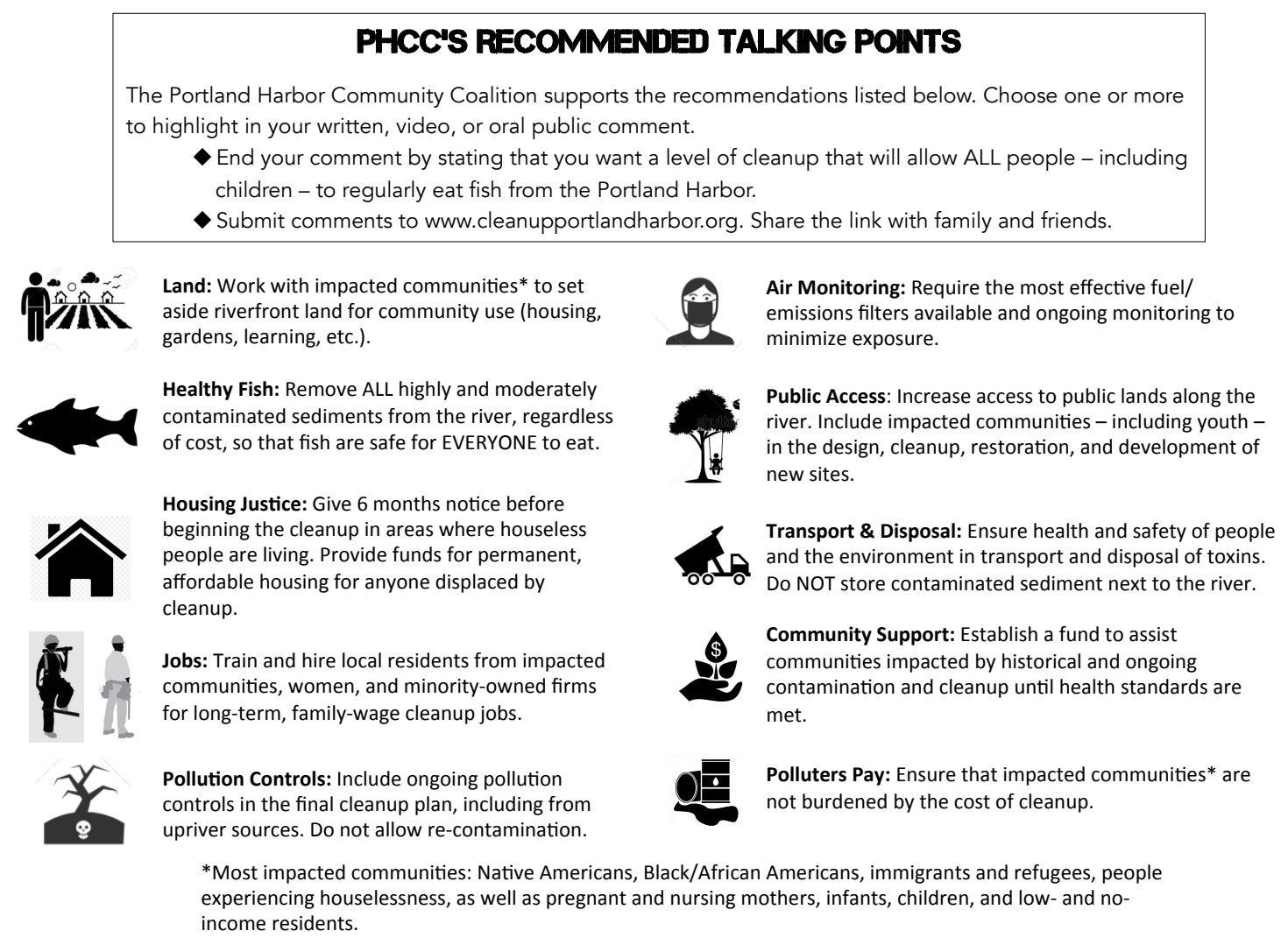

Figure 3. Centerfold of PHCC's four-page Testimony Guide, from summer 2016.

Testifying and submitting comments during the EPA's official comment periods

is the formal channel through which the general public can weigh in on Superfund cleanup plans. In the case of the Portland Harbor, the 90-day comment period that lasted from June $8^{\text {th }}$ to September $6^{\text {th }}, 2016$ was the official forum through which PHCC members and others submitted testimony. Instead of finding ways to authentically include impacted communities in the planning process over the previous sixteen years, however, PHCC members viewed public agencies' outreach as tokenizing. As we will see in the 
chapters to come, Rahsaan's euphemistic dubbing of the Proposed Plan as "insufficient" could be applied to the entire sixteen-year-long planning process.

In short, during the press conference that morning on the sidewalk, PHCC members were concerned with those who have suffered in the past, who suffer in the present, and who, barring precise measures instituted and enforced by public agencies to ensure otherwise, will continue to suffer at the hands of "growth coalition actors" (Logan and Molotch, 2007) - including PRPs - in the years to come. Pellow (2016:223) puts it bluntly: what we are talking about in cases like the Portland Harbor, for which, to PHCC members, the EPA's Proposed Plan demonstrated little regard for the lives of people actually affected by contamination and cleanup, is an attitude of "expendability of human and non-human populations facing socioecological threats from states, industries, and other political economic forces." PHCC members are working hard to challenge this stance.

\section{The Production of a Paradigmatic Sustainable City}

Since the 1990s, sustainability boosters have peddled the win-win-win promise of the " 3 Es": environmental improvement, economic growth, and social equity (Campbell, 1996). But it is by now well established that the greening of cities has actually widened socioeconomic divisions along interconnected lines of race and class (Gould and Lewis, 2016; Pulido, 2016), through a process that Hern (2016:18) calls "the core of capitalism's durability - its agility and malleability." Checker (2011:212) defines "eco-gentrification" as the "convergence of urban redevelopment, ecologically minded 
initiatives and environmental activism in an era of advanced capitalism." (Ecogentrification involves the wholesale eviction of lower-income residents from newly greened neighborhoods - disproportionately communities of color and often those who have suffered from the effects of past pollution. Perhaps the most dramatic and destructive outcome of the sustainable city movement, the fracturing of communities and disruption of families and people's lives is part and parcel of gentrification. Without specific provisions to mitigate rising rents, the development of eco-villages, walkable neighborhoods, bicycle infrastructure, urban farms, and waterfront parkways push those with fewer resources further to the margins (Bunce, 2009; Dooling, 2009; Goodling, Green, and McClintock, 2015; Quastel, 2009; Tretter, 2013; Zavestoski and Agyeman, 2014). And yet, sustainable city disparities are not going unchallenged. ${ }^{4}$ There exist pockets of localized actors, including planners, policymakers, and grassroots activists, working hard to reverse these trends. Sometimes using a chisel and other times a sledgehammer, on occasion a sickle and now and again a fist, these actors employ a range of tactics and strategies, not without contradiction, in their efforts to move cities toward what Agyeman (2013) calls a more just sustainability (Anguelovski, 2011; Checker, 2011; Curran and Hamilton, 2012; Goodling and Herrington, 2014; Pearsall, 2013). The

\footnotetext{
${ }^{4}$ I use "sustainable city" and "green city" interchangeably to refer to those municipalities identified by any number of sustainability-promoting organizations (e.g., SustainLane.org) and/or whose identities (e.g., as displayed on municipal websites) revolve in large part around sustainability, environmentalism, and/or green development initiatives - regardless of the actual outcomes of such approaches.
} 
growing prevalence and power of these groups, but also their precariousness, begs their close examination by urban scholars.

\section{Portland's Uneven (Green) Development}

Portland is a city at once at the forefront of urban greening efforts, as well as home to a grassroots movement of people working to ensure that marginalized residents shape and benefit from so-called sustainable development. Lonely Planet named Portland one of its top twenty destinations of 2017 on account of the city's "eco-friendly activities", such as hanging out on the waterfront (Sullivan, 2016). Portland's climate action plan, the first of its kind in the US, recently helped the city earn a spot in a list of the ten municipalities worldwide doing the most to address climate change (Metcalfe, 2016). Widely heralded as one of the world's foremost "green cities" (Knox and Florida, 2014), as the bike capital of the US (Duffy, 2014), and as a "mighty gastropolis" (Brooks, Bosker, and Gelber, 2012) due to the city's farm-to-table food scene, Portland is a paradigmatic sustainable city in almost every sense.

Portland's appeal is not limited to tourists and its well-heeled residents. Policymakers and planners from around the world seek to emulate the green image cultivated in the "City of Roses" (Slavin and Snyder, 2011). Programs such as First Stop Portland introduce delegates from other cities to Portland's miles of bike lanes and light

rail, walkable neighborhoods, and urban growth boundary intended to prevent sprawl and protect farmland. During a recent visit, Indianapolis Mayor Gregory Ballard, declared, "You have been leaders in these [sustainability] things, but other cities like us are 
catching up. And we need you to lead us to the next great initiative. So, get on it!" (First Stop Portland, 2014).

But as in cities across North America, Portland's green façade hides a murkier reality, one that sustainability-themed tours of the city often overlook. Notably, despite Portland's reputation for environmental progressivism, the river running through this world-renowned sustainable city is actually one of the dirtiest in the country. Over a century of shipbuilding, ship-breaking, manufacturing, and light and heavy industry have left a legacy of non-point source pollution buried in the sand and sediment (HillegasElting, 2009). ${ }^{5}$ This is the contamination that qualified the Portland Harbor for CERCLA listing.

It is important to note, however, that the Willamette River was once even more polluted than it is today. Without the efforts of public health experts, sanitary engineers, conservationists, and well-to-do anglers who expressed great concern about point-source pollution starting in the 1920 s, the river would be even more toxic. These early activists were particularly concerned about municipal sewage effluence and toxic discharges into the river from the pulp and paper mills that lined the Willamette. They worried about the harmful effects of contaminants on commercial fishing, as well as tourist and recreationcentered business, swimming, and fishing. City officials fought against making

\footnotetext{
${ }^{5}$ Point source pollution refers to pollution coming from a single, identifiable source, such as a pipe or smokestack. Non-point source pollution refers to toxins that run into a body of water in a disbursed way, such as via rainfall that moves through the ground and eventually into a river.
} 
improvements, arguing that sewage infrastructure improvements were cost-prohibitive and would place undue burden on taxpayers. Pulp and paper industry representatives contended that eliminating discharges would result in the shuttering of businesses. Early Willamette River boosters - like today's activists - worked outside of established political channels to marshal data in support of their position, including national-scale research conducted with New Deal funds. And like industrial actors of today, growth advocates questioned the veracity of scientific findings that activists used to make their arguments. Nevertheless, these early environmentalists succeeded in establishing the State Sanitary Authority in 1938, which mandated that pulp and paper industries stop dumping waste into the Willamette. And between 1947 and 1952, state-level officials required the City of Portland to clean up its act, resulting in the City spending $\$ 15$ million (the equivalent of nearly $\$ 140$ million in 2017) on a wastewater treatment plant and other infrastructure improvements (Hillegas-Elting, 2009).

These initial river remediation efforts helped land Portland on the map as a leader in the nascent environmental movement. Oregon's Governor Tom McCall eventually tied the economy and environment together in his own vocal advocacy for environmental issues. In a 1962 documentary, Pollution in Paradise, McCall argued that there was "no contradiction between jobs and quality of life in Oregon" (Robbins, 2002). A decade later, when National Geographic highlighted local stewardship of the Willamette in a cover article, Portland landed in the national spotlight (Starbird, 1972). That same year, parts of Oregon's administrative framework informed creation of the federal Clean Water Act (Hillegas-Elting, 2009). The storyline of Portland as a leader in 
the green urbanist movement gained even greater momentum in the 1970s and early 1980s, when Oregon's Land Conservation and Development Commission adopted fourteen goals; one of these goals mandated that local jurisdictions institute urban growth boundaries. Portland's reputation as a sustainability mecca continued to gain energy through the 1990s and 2000s, as the City pursued an explicit policy of encouraging green growth (Goodling, Green, and McClintock, 2015).

But pollution - and its remediation thus far - has had uneven impacts. Finney (2014:56) reminds us that

whether intentional or not, many discussions of the relationship between "man" and the environment, while explicit about the details of that relationship, obscure exactly which "man" controlled and defined this relationship. There is often an unspoken, blanket assumption that the relationship is one without complexity - all humans operate under the same banner.

In other words, discussions about the environmental movement tend to obscure exactly who has carried the burdens of efforts to make whole the relationship between humans and the environment. The Portland Harbor has served as a sink for industry for years, bolstering profits of Fortune 500 companies and local elites alike. These successes were built on the backs of those trying to get by with the help of the river. And yet, cleanup of the river thus far, and the more general greening of Portland, too, have had disparate impacts. Accolades and economic growth in the aggregate that stem from Portland's green initiatives have not translated to improved livability for all: a growing number of 
the city's roughly 600,000 residents lack regular access to sustainability hallmarks, such as fresh and healthy food, safe neighborhoods, convenient transit, and stable housing (Coalition for a Livable Future, 2013; Curry-Stevens et al., 2010; Griffin-Valade, Kahn, and Adams-Wannberg, 2010). Moreover, Portland's sustainability successes come at a direct cost to its less affluent residents - disproportionately residents of color - via displacement from the inner-core neighborhoods most likely to boast green amenities (Goodling, Green, and McClintock, 2015). In an interview with Hern (2017:10), John Washington, a leader at Portland's Black/African American-serving North NorthEast Business Association, remarked, "I knew Black people were fucked as soon as I saw the bike lanes. That's when we knew Black people weren't welcome here anymore.”

\section{A People's History of the Portland Harbor}

The current era of sustainability is only the latest chapter in a long history of slow violence against Native Americans and Black/African Americans, in particular, as well as immigrants and refugees and houseless people of all backgrounds, in relation to the Portland Harbor. Members of these four groups form the core of PHCC's membership. Understanding the rise of PHCC, today, demands that we first understand the historical and present-day relationships of PHCC's members and ancestors to the Portland Harbor.

Today's Portland Harbor has been home to Native Americans for many generations. Prior to the 1800 s, approximately 3,000 Multnomah-Chinook people called this area home. Thousands of members of other tribes also travelled through the Portland Basin for trading, fishing, and wapato-gathering. But starting in the late 1700s, colonial 
explorers brought diseases, including smallpox and malaria, devastating Native populations. Ninety-two percent of Columbia River Valley Native Americans died by the 1830s, and disease reduced the Willamette Valley Native population from 15,000 to fewer than 2,000 people. Then, beginning in the 1850 s, the US government ratified treaties that eliminated access to resources and traditional homelands for Native people. Treaties stipulated that Native Americans would be displaced to reservations around the region (Boyd, 1975, 2013; Ellis, 2013; Spores, 1993; Whaley, 2010).

The forced removal and death-by-disease of Indigenous people opened space for white Euro-Americans to establish the Portland Harbor as a main trading hub for the west; they exported grain, lumber, and other commodities (Lang, 2010). During World War II, Native Americans began moving back to the Portland area, many to work in the shipyards. Several people arrived from nearby reservations, and half of the Turtle Mountain Tribe of North Dakota - 6,000 people - joined the war effort in Portland (Curry-Stevens, Cross-Hemmer, and CCC, 2011). Native Americans again migrated to Portland in large numbers in the 1950s under a series of Termination Acts that were, essentially, "the culmination of over a hundred years of efforts by the federal government to eliminate tribal claims to their lands" (Lewis, Thorsgard, and Williams, 2013:308).

Today, Portland is home to US's ninth largest urban Native American population (Curry-Stevens, Cross-Hemmer, and CCC, 2011). Since the arrival of white Euro-Americans, the relationship between Native Americans and the Portland Harbor has been defined by violent colonization. And yet, Native people have maintained ties to the river and its "life-giving elements", as one PHCC member puts it. Today, thousands of 
Native people from the Portland metropolitan area and Columbia River Basin Tribes consume fish from the Portland Harbor and nearby waterways, eating nearly ten times more fish than non-Native people (Columbia River Inter-Tribal Fish Commission, 1994), and dozens of people use the harbor for canoe journey preparations, water ceremonies, and other cultural activities.

At the same time that white people travelled over the Oregon Trail to seize the land of Illahee from Indigenous people, an 1857 clause in Oregon's constitution excluded people of African descent from entering the state, under threat of the lash. The Oregon Donation Land Act of 1850 "promised free land to White settlers only" (Gibson, 2007:6), codifying efforts to create a "white homeland" up until 1926. Although some Black people migrated to Portland in the late $1800 \mathrm{~s}$ and early $1900 \mathrm{~s}$ despite these discriminatory laws, it was not until World War II that, like urban-bound Native Americans, large numbers of Black people boarded trains destined for Portland to work in the shipyards. Roughly 23,000 Black workers and their families migrated to Portland in the 1940s, and the Portland Harbor became home to the largest shipbreaking operation in the US (ibid.). Over the years, people have been exposed to extremely toxic substances in the shipyards, such as lead and asbestos (Pearson, 1996), as well as diesel emissions from harbor-related and freeway traffic in the nearby neighborhoods to which city statutes segregated African Americans (Multnomah County Health Department, 2014). Black workers were not allowed to join the Boilermakers Union, which meant lower wages and fewer workplace protections for them than for white shipyard workers (Pearson, 1996; Smith and Taylor, 1980). 
Since their arrival, Black Portlanders have endured forced segregation and waves of displacement. Gibson (2007) recounts how people first settled in defense housing developments constructed north of the harbor, in Vanport. But in 1948, shoddy levies built along the Columbia River failed, displacing thousands of residents. The City forbade Black people from re-settling anywhere but the Albina area, just south of Vanport and adjacent to the harbor: the Portland Real Estate Board's Code of Ethics prohibited agents from selling homes to Black residents outside of Albina, and racial covenants excluded them from living in other neighborhoods. Banks refused to loan money for the purchase or renovation of homes inside the "redlined" Albina area, and the City stopped investing in basic services and infrastructure there. This disinvestment set the stage for a policy of Urban Renewal beginning in the 1960s, once again tearing apart Portland's Black community in the name of "blight removal". More recently, Urban Renewal Area policies infused Albina with money for the Interstate MAX Light Rail line and other (often green-themed) projects - without also instituting anti-displacement provisions that would help people afford to stay in the area (Goodling et al., 2015). In short, "a deliberate, methodical effort" (Hern, 2016:7) on the part of City officials has resulted in the involuntary displacement of nearly 10,000 and counting Black Portlanders from Albina. People live further from their jobs, businesses have lost customers and leases, congregants commute long distances for church, and many now live in neighborhoods with reduced public transit service, fewer parks, and less access to other services (Bates, Curry-Stevens, and CCC, 2014; Gibson, 2007). 
And yet, Black Portlanders have long fought against these injustices (Oregon Public Broadcasting, 2015; Pearson, 1996), and today's grassroots leaders are following in the footsteps of activists of years past by fighting for economic opportunities and access to land in the harbor for the Black community. Many people still speak fondly of the Willamette River, recalling weekend outings to fish in the harbor. In recent years, organizations serving Black youth have become keen to take advantage of the green job opportunities that a thorough cleanup of the harbor might provide, as well as the possibilities of producing food and teaching young people about ecology, engineering, and agriculture on community-controlled land near the river.

Over the last few decades, immigrants and refugees from Eastern European, Asian, and Latin American countries have arrived in Portland and surrounding municipalities (Hume and Hardwick, 2005). People travel to the harbor and other nearby waterways to fish, with motivations ranging from addressing food insecurity to continuing cultural traditions. A 2012 study drawing on a telephone survey of licensed anglers reported that about 7,800 people consumed resident fish from the Portland Harbor in the previous year. Licensed anglers with the most people reporting resident fish consumption were Eastern Europeans; 38 percent acknowledged eating resident fish, which are particularly susceptible to contamination. The study did not account for nonlicensed anglers, and it is estimated that about 13.5 percent of those fishing in the Portland Harbor do not have licenses (Sundling and Buck, 2012). Anecdotal reports from Department of Fish and Wildlife officials as well as local social service providers indicate that many unlicensed fishers are likely to be an immigrant or refugee; many are 
unaware of the dangers of consuming resident fish or have few other affordable sources of protein. Like Native and Black Portlanders, Portland's immigrants and refugees also face housing instability, contributing to household food insecurity and compounding challenges for people who have fled conflicts and poverty in other countries (CurryStevens, Cross-Hemmer, and CCC, 2010).

Finally, a fourth group, those experiencing houselessness, have a long history in relation to the Portland Harbor. A late nineteenth century article in the Oregonian (quoted in Blalock, 2012:126) describes the scene at the turn of the century in detail:

Old skeletons of mighty ships - or shallow river crafts - lie white and dry on the embankment. Scant trees, usually shaking in the river breezes, of such deciduous growth as balm or oak, lend grace to an eerie looking shore. There are various river crafts tied up or moored along, or hauled up on the sand, some of which are occupied by families whose cook stove smokes ever curl and blow, and whose red and white garments washed and hung out to dry, ever flap in the breezes. (1890:498)

In 1910, there were approximately 5,000 people living in "scows", old ship skeletons, and other makeshift shelters up and down the Willamette within city limits. Like today, the river's bounty of fish enticed houseless people to call the banks of the river home. Also, like today, police officers frequently evicted people from the waterfront. Around the peak of riverside inhabitance, Joseph Simon, Portland's mayor from 1909 to 1911, ordered scows and their residents removed. Simon's recruits set many shelters on fire, and the mayor directed workers to move others to cheap plots of then-rural land six miles 
east of the river (Blalock, 2012:130). Nevertheless, people continued to seek refuge along the Willamette. Numbers surged in the "Hoovervilles" of the Great Depression (Rose, 2016), and again beginning in the 1980s, with Reagan's rollback of the social safety net and the defunding of mental health services (Bayer, 2014). In 2015, a low estimate of around 3,800 people slept on the streets or in a shelter during a point-in-time count, and an estimated 12,000 people were doubled up or sleeping in unsafe conditions (Multnomah County, 2015). Black and Native people are disproportionately represented in these counts, and their numbers are growing (ibid.). Living along waterways throughout the city, houseless people continue to be much more susceptible to police violence than housed people, as well as to bodily harm due to exposure to the elements and toxic substances buried in the soil.

This very brief "people's history" paints a dire picture of life for PHCC's constituents and their ancestors in relation to the Portland Harbor, touching on the cumulative and intersectional ways that people have suffered in the past and continue to suffer today. People are struggling in profound ways due to historical layers of displacement, violence at the hands of police, exposure to environmental toxins, and more. It is important to emphasize, however, that at the same time that the communities mentioned here have experienced serious hardships, they have collectively endured these challenges, and have summoned vast amounts of perseverance and love to fight for changes over the years. I hope that this comes through loud and clear in the pages that follow, for perseverance and love, as well as creativity, are often important yet undersung ingredients in social change movements. PHCC represents one group of people that 
is channeling energy and imagination toward the task of overcoming the seemingly irresolvable contradictions of city-building.

\section{The Portland Harbor Community Coalition}

It is in this historical context and on behalf of the four groups outlined here that PHCC works. PHCC is at once an ordinary and an extraordinary organization. It is ordinary in that it has yet to accomplish anything so monumental as to garner national and international headlines, as Love Canal activists over four decades ago did when they challenged pollution in Niagara Falls, New York, kicking off the modern environmental justice movement (Gibbs, 1982). Or as the Standing Rock Sioux Tribe has done in more recent times, challenging construction of the North Dakota Access Pipeline (Trahant, 2016).

Nevertheless, PHCC is noteworthy in that, as a loose alliance of grassroots groups, most with fewer than a hundred members, people from disparate corners of the city and beyond have come together to work in solidarity toward a common goal. Native Americans, who are cut off from key traditional food sources and land, have joined PHCC. Black/African Americans, whose families were exposed to air and water toxins while working in the shipyards and fishing in the harbor - and were segregated, redlined, and moved, moved, and moved again - have joined PHCC. Latinos, many living in a neighborhood that is quickly becoming too expensive for long-time residents, and whose families and friends rely on the river for sustenance despite the toxins, have joined PHCC. Eastern Europeans and Asian Americans with myriad lineages, whose families all fill their freezers with toxic fish from the harbor, have joined PHCC. Houseless 
Portlanders of all races and ethnicities, but disproportionately (and increasingly) Black/African American and Native, worried about their brothers and sisters living in highly toxic soil and consuming highly toxic fish, have joined PHCC. Working-class activists of all backgrounds, concerned about the rising property values and waves of displacement that have hit their neighborhoods, have joined PHCC. Labor groups, insisting that cleanup jobs pay a living wage and go to members of impacted communities, have joined PHCC. Environmentalists, concerned primarily about bird and fish habitat in the Portland Harbor, have joined PHCC. College students, members of faith-based organizations, and unaffiliated Portlanders preoccupied with some or all of the above, too, have joined PHCC. In other words, people from all walks of life have convened to fight for a more just cleanup of the Portland Harbor. Beginning in 2012, PHCC has pushed the City of Portland and the EPA to address the myriad social and environmental justice issues touching the harbor. While it remains to be seen what these public agencies will do during the implementation stage of the cleanup in the decades to come, what is certain is that PHCC's constituents have grown immensely in their capacities to work collectively; this is remarkable, and worthy of attention.

\section{Research Questions}

PHCC did not arrive at the 2016 press conference on the sidewalk in front of the Portland Building overnight. This dissertation investigates the previous five years of convening, relationship-building, learning, planning, and engaging with public agencies that laid a foundation for coalition members and supporters to stand together in solidarity, to condemn the Proposed Plan and call for a remediation that would instead explicitly 
prioritize the needs and perspectives of those gathered with Rahsaan that morning. Like numerous groups in cities across North America, PHCC aims to raise the voices of those most impacted by pollution and least likely to benefit from whatever remediation and development comes in its wake. In undertaking this kind of work, it is not only "the city" that changes. Marx (2012 [1867]:73) articulates the dialectical process involved in shaping the city, as we shape ourselves:

Labour is, in the first place, a process in which both man and Nature participate, and in which man of his own accord starts, regulates, and controls the material re-actions between himself and Nature. He opposes himself to Nature as one of her own forces, setting in motion arms and legs, head and hands, the natural forces of his body, in order to appropriate Nature's productions in a form adapted to his own wants. By thus acting on the external world and changing it, he at the same time changes his own nature. (emphasis added)

Far from passively receiving the decisions of the powers-that-be, ordinary people have come together in an effort to shape Portland and other sustainable cities along more progressive lines. At the same time, the labor involved in this effort - the planning, organizing, fighting, laughing, crying, creating, bleeding, healing, feeding, loving, learning - changes those involved.

This dissertation, then, is about the making and remaking of cities and their inhabitants in an era of great consternation over climate change and air and water pollution, as well as housing unaffordability, racialized police brutality and other forms 
of overt and institutionalized racial violence, xenophobia, homophobia, and numerous other interconnected threats to the human spirit and Mother Earth. More specifically, this dissertation is about the challenges and possibilities of grassroots organizing in the green city, including the ways in which learning shapes collective action and vice versa. Engaging with the intersecting fields of critical urban studies and urban geography, and the sub-field of urban political ecology, four research questions guide this project. In the green city...

1. What historical and present-day circumstances give rise to grassroots collective action?

2. What obstacles do grassroots groups organizing for social and environmental justice face?

3. How do grassroots groups organize to ensure that underrepresented residents have a say in the shaping of remediation and redevelopment initiatives, and that they partake in benefits (e.g., jobs, affordable housing, green space, etc.) emerging from urban sustainability initiatives?

4. What role does (historicized) learning play in the politicization and collective action of people working for social and environmental justice?

\section{Inspirations}

I first met PHCC's founder, Cassie Cohen, when I interviewed her for another project in fall 2013. At the time, I was investigating how and why the Community Watershed Stewardship Program (CWSP), housed within the City of Portland's Bureau 
of Environmental Services, came to take an "equity planning" approach (Gooding and Herrington, 2014). As the executive director of Groundwork Portland (GWPDX), an environmental justice-focused non-profit, Cassie had recently successfully applied for two CWSP grants. I asked her questions about the impact those grants had on GWPDX's ability to address social and environmental justice issues. At one point in our interview, Cassie described the layers of historical land use and institutionalized exploitation that have merged to produce disparities along racial lines in Portland. Referencing Portland's historically Black Albina neighborhood, where GWPDX was headquartered, Cassie explained,

[Brownfield lots] have been vacant, sitting there for decades while the Black community was there, and now they're getting flipped and turned into beautiful coffee shops and bars. People can't afford to live here [in inner Northeast Portland] anymore and reap the benefits . . . There's systemic racism and oppression that affect folks here locally, and impact their lived experience... Youth tend to blame themselves. They think about change as "What can I as an individual do to pick up trash?" versus what are the systemic things that need to be fought and organized around? (Quoted in Goodling and Herrington, 2014:197).

Cassie hints at the complex ways that (eco-)gentrification and displacement, environmentalism, race relations, and shifting political consciousness were intersecting and unfolding in Portland in the mid-2000s. These were themes with which I was familiar, having grown up in Portland and witnessed the city's dramatic transformation 
over the last three and a half decades - and particularly as a youth worker and high school teacher since 2002. These are also themes that are central to PHCC's work, and in turn this dissertation.

A few months after interviewing Cassie, I stopped by GWPDX's office to say hello. Cassie asked if I would be willing to help interview applicants for a community organizer position, someone who would mainly work with PHCC. I had spent the previous two years as a graduate student in PSU's National Science Foundation Integrative Graduate Education and Research Traineeship (IGERT) program, designed to steep students and faculty in interdisciplinary approaches to tackling urban environmental issues. I also had a vague sense that people fishing and swimming in the murky Willamette were taking their lives in their own hands from lore I had heard throughout my life. And yet, this was my first time learning that the Portland Harbor was so polluted as to warrant designation as a Superfund site. Cassie conveyed the complexity and urgency of the issue in our ten-minute conversation, and I agreed to help with interviews in December 2013 and January 2014.

Then, around April 2014, I stopped by GWPDX's headquarters again to say hello. As I was leaving, I peeked my head in the door of the room across the hall from Cassie's office. The scene mirrored the one on the sidewalk I describe earlier in this introduction: people who appeared to represent a wide variety of races, ethnicities, genders, ages, and socioeconomic classes were busy moving chairs around, eating takeout pizza, and chatting excitedly. A man who I would later come to know well, 
Ibrahim Mubarak, invited me in. I accepted his invitation and took a seat next to another person for whom I would come to develop great respect, Mike Summers.

From then on, I began attending PHCC functions in earnest. As I learned more about what promised to become one of the largest environmental remediation projects ever undertaken in the city's history, I wondered why so few of my friends and family members, not to mention professors, classmates, and local media outlets, seemed to know about the planning process that had been ongoing for nearly a decade and a half. I also wondered why the veteran activists I knew were not more up in arms about the obvious social and environmental justice concerns related to the harbor. Cleanup of the harbor could entail the entire re-creation of eleven miles of our river-twenty-two miles of shoreline. It was staggering to think about the layers of issues, including labor rights and workforce development, gentrification and displacement, treaty rights, environmental racism, houselessness, and more that were implicated in the harbor's contamination and cleanup. But I was also aware of the long history of white-led environmental groups excluding people of color in the US (Finney, 2014), likely making many people leery of engaging in what was portrayed as a straightforward "environmental" issue in the handful of media reports addressing it around that time. I also fully understood that no-cause evictions, racialized police violence, "sweeps" of houseless camps, and a host of other threats disrupted people's lives and livelihoods in the here-and-now. Any substantial benefit that might accrue from the harbor cleanup was several years off; too many people were not sure if they would make it another day. 
And yet, a few dozen people like Ibrahim and Mike made up PHCC's core membership, and had committed themselves to working for a cleaned-up harbor on behalf of so many others. Except for a few key people (including Cassie and Ibrahim), PHCC participants were largely new to activism and community organizing. The complexity of the cleanup planning process would have challenged even the most seasoned activists. Through meetings I attended during spring and summer 2014, I witnessed PHCC participants struggle to tie all the threads involved together and gain traction with public agencies. In addition to at least a half-dozen public agencies, several Tribes and numerous conservation groups were also involved, and each of these entities released a dizzying number of memos and studies on a regular basis. It was hard to know where to spend limited time and resources.

Recognizing that the Superfund cleanup process in Seattle was about two years ahead of the one in Portland, in summer 2014, PHCC representatives formed an ongoing relationship with their counterparts at the Duwamish River Cleanup Coalition (DRCC) in an effort to learn from their experiences and avoid reinventing the wheel. While DRCC leaders were empathetic to PHCC's requests for information and guidance via email and phone, and met with PHCC leaders in person a few times, they understandably had little time to devote to tasks not directly connected to their own local efforts. PHCC leaders lamented that there was no easy-to-share account of DRCC's work and lessons learned.

In summer 2014, I made a suggestion to PHCC leaders: for my dissertation research, I could help document PHCC's efforts so that grassroots groups working in similar contexts could learn from the coalition's experience. Cassie and other PHCC 
leaders agreed that this would be a worthwhile endeavor. After a discussion at PHCC's monthly meetings, coalition members and I agreed that I would investigate PHCC's struggles and successes working for a more just cleanup of the Portland Harbor Superfund Site. As part of the research project, I would interview members about their motivations for being involved with the coalition, as well as their learning processes. This information would help bolster PHCC's organizing efforts in the short-term. And telling PHCC's story will hopefully help amplify the coalition's work and assist other likeminded groups in the long term. Following several participatory action research projects that I have helped facilitate over the last three years with PHCC, this dissertation is the first major scholarly output of this investigation. In the months and years to come, I plan to work with PHCC representatives to determine how to make the findings here useful to the coalition. One possibility is to produce a comic book detailing a "people's history" of the Portland Harbor.

To be clear, this dissertation is not primarily about Superfund sites, or even mobilization around brownfield cleanups. Given that the Portland Harbor Superfund Site is PHCC's main place of concern, a host of technicalities germane to CERCLA and other local and federal statutes are central to the case of PHCC. But the harbor serves more as a locus where broader themes of power relations and urban socio-environmental change intersect. I have spent nearly my whole adult life facilitating learning. Whether in undergraduate classrooms with students who are preparing for careers in public service, in social service agencies with homeless teens who are striving to find their footing in the world, or in community-based settings with housed and houseless people alike who are 
working together to make cities more equitable, I am constantly amazed at the way that images, stories, and other catalysts draw people in and motivate them to critically examine their surroundings. Occasionally, this process lays a foundation for small and big changes to occur. This dissertation is about how urban residents, like PHCC members, make sense of an incredibly complicated landscape of urban change in order to work collectively toward a more just future.

Without over-romanticizing a process that often entails sacrifices large and small, is fraught with setbacks and dangers, and ends in defeat, I maintain that ordinary people - bus drivers, landscapers, teachers, cashiers, mothers, community health workers, amateur musicians - possess astonishing potential to analyze complex circumstances and shape their surroundings. Writing about gentrification, "the landed expression of displacements and dispossessions from our neighbors, our labor, and our bodies," Hern (2016:19) stresses that "the domination of land enables and ennobles the domination of people, but the reverse is equally true. Undoing our commitments to one means undoing the other." At its heart, this is a story about ordinary people, inspired by a beloved river, who are working to unravel our society's commitment to the interconnected domination of land and people — and who are attempting to build something new, and more just, in its stead. 


\section{Dissertation Overview}

\section{Chapter 2 - Theoretical Engagements}

In the next chapter, I outline three relevant literatures that situate the case of PHCC within broader understandings of socio-ecological change: 1) uneven development in/of the sustainable city; 2) grassroots collective action; and 3) political subject formation and learning.

\section{Chapter 3 - Research Approach}

In Chapter 3, I outline my research approach, including my research design, guiding propositions, and data collection and analysis process. I also elaborate on my positionality within the research process, and provide an explanation of terminology.

Chapter 4 - Little Bugs in the Mud: Origins and Rise of the Portland Harbor Community Coalition

In Chapter 4, I trace the origins and rise of PHCC. Drawing on existing understandings of political subject formation, I show how the case of PHCC complements Curran and Hamilton's theorizing of "just green enough" strategies, in which grassroots groups prioritize social and environmental justice outcomes above environmental stewardship in order to avoid the displacing effects of environmental remediation and green development. I illustrate how a suite of motivations, ranging from personal relationships with other participants to concerns about one or two specific social justice issues, has prompted people from a wide variety of backgrounds to join PHCC, and how, at the heart of nearly all PHCC members' involvement, is a deep feeling of connection to the Willamette River. The river itself has drawn together dozens of people 
to work in solidarity for a robust cleanup that first and foremost benefits members of communities most impacted by pollution.

Chapter 5 - A Public Opinion Poll ... and a Webinar!: Holding Public Agencies Accountable

Chapter 5 builds on this foundation. I first briefly illustrate PHCC's implicitly oppositional community development approach to organizing during the coalition's first few years, emphasizing political education activities from 2012 to early 2015 . I then articulate the tokenizing nature of PHCC's interactions with the City of Portland and the EPA, focusing on late 2015 through summer 2016. In spring 2016, on the eve of the public comment period, PHCC members and leaders realized that public agencies had little intention of engaging with impacted communities in a meaningful way. At this point, the coalition shifted to take a more adversarial stance than before. PHCC members confronted City officials, demanding resources to support authentic inclusion of vulnerable Portlanders in the cleanup planning process, as well as insisting on City support for a series of provisions that would help redress harbor-related disparities. Then, during the public comment period in summer 2016, the coalition submitted a strongly worded letter to the EPA, accusing the agency of disregarding Title VI Civil Rights laws in its handling of the harbor cleanup planning process, at the same time as PHCC helped mobilize more than 5,300 people to submit testimony to the EPA. PHCC's shift toward more confrontational tactics helped re-politicize the planning process, opening space for those left out of formal channels to sway outcomes. 
Chapter 6 - Taking Collective Action: Historicized Learning

Finally, in Chapter 6, I show how historicized learning has played a central role in PHCC's organizing in three interconnected ways. Most elementally, historicized learning has helped PHCC members become engaged in the coalition. Second, it has played a key role in members' individual and collective development of a political analysis about disparate impacts related to the harbor. Finally, PHCC members have collectively produced a narrative about the overlapping histories of four main groups: Native Americans, African Americans, immigrants and refugees, and houseless people. This narrative has formed the backbone of PHCC's communications with the City and EPA, and it ultimately helped push public agencies to acquiesce to many of the coalition's demands. The case of PHCC demonstrates that a historical perspective is an important part of grassroots groups' efforts to re-politicize sustainability discourse and sway outcomes in favor of marginalized groups. These empirical findings open space to engage with recent debates in urban political ecology. I argue that it is imperative for urban political ecology scholars to not just pay attention to the "the deep historical spatial logics" of marginalized spaces (Heynen, 2015:2), but also to understand what learning this history does for those on the front lines of change; learning this history is an important ingredient in grassroots efforts to redress histories of dispossession and displacement, particularly in a context of depoliticized sustainability discourse.

Chapter 7 -Discussion \& Conclusion: Green City Rising

I conclude this dissertation by first synthesizing contributions from the three empirical chapters to my research questions. Then, I articulate two overarching theoretical interventions. The first addresses theorizing on sustainability postpolitics 
(Swyngedouw, 2007, 2009) and sustainability fixes (While, Jonas, and Gibbs, 2004), arguing that the case of PHCC does not illuminate the work of a green growth machine in the Portland Harbor, as we might expect, but rather it sheds light on a status quo growth machine. I then draw on Pulido, Kohl, and Cotton's (2016) work on "EJ failure" and Pieterse's (2008) theorizing on radical incrementalism to propose an updated framework for understanding grassroots-led socio-ecological change in the green city that accounts for the particularities of the case of PHCC. I close by discussing limitations of this research, as well as future research directions that emerge out of this dissertation. 


\section{Theoretical Engagements}

This chapter outlines three relevant literatures that situate the case of PHCC within broader understandings of urban socio-ecological change, providing entry points for analysis: 1) uneven development in/of the sustainable city; 2) grassroots collective action; and 3) political subject formation and learning. I elaborate and link these literatures to the case of the Portland Harbor Community Coalition in the empirical chapters and discussion that follow.

\section{Uneven Development in/of the Sustainable City}

Employing tools such as special permissions and subsidies, and pushing particular forms of public infrastructure to advance their entrepreneurial interests through the real estate sector, those most interested in increasing the exchange value of cities belong to an urban growth machine coalition (Logan and Molotch, 2007). Smith (1982:151) describes the process by which growth machine actors are perpetually in pursuit of profit through a "spatial fix":

The development of one area creates barriers to further development, thus leading to underdevelopment, and ... the underdevelopment of that area creates opportunities for a new phase of development . . . Capital jumps from one place to another, then back again, both creating and destroying its own opportunities for development. 
In other words, the lucrativeness of a previously devalued space is only temporary; as the value-generating potential of fixed capital diminishes over time in a given place, new spaces of development are required. The cycle repeats in an ever-expanding and unevenly developed landscape (Hackworth, 2007; Harvey, 1989, 2007; Smith, 2008).

Today, boosters of many North American cities are thinking not only about how to generate profit through the built environment, but they are also preoccupied with how to clean up industrial pollution in urban waterways, mitigate and adapt to climate change, reduce air and water pollution, and address other environmental challenges, at least superficially. Municipalities and private firms alike (and often in partnership) seek to leverage environmental concerns into profit, often through what While, Jonas, and Gibbs (2004) dub a "sustainability fix". By developing green features such as eco-roofs, electric car charging stations, bio-swales, and bike infrastructure, as well as remaking entire neighborhoods as "eco-villages" and undertaking other small and large sustainabilitythemed initiatives, green growth regimes "fix" capital in the built environment at the same time as they appeal to the green aesthetic desired by the creative class. North American waterfronts are particularly attractive as sites for green growth regime actors to undertake redevelopment projects under a banner of urban sustainability (Bunce and Desfor, 2007; Hagerman, 2007). For much of the last two centuries, urban waterfronts in North America were centers of industry and manufacturing and served as gateways for the import and export of goods. No longer the hubs of commerce they once were, many urban ports now contain a material legacy of pollution. Municipal leaders and developers looking to capitalize on the recent in-migration of people and capital to inner cities invest 
in waterfront redevelopment projects that involve "cleaning up" these former sites of industry. Logan and Molotch (2007:xx) refer to the factions promoting such urban greening trends along waterfronts and in other industrial areas, as well as in previously devalued neighborhoods, as part of "the same old growth machine but with a decorative skin."

But not all urban residents benefit equally from green-themed development. One hallmark of the sustainable city, as with cities that are more generally "perceived to be success stories" (Hern, 2016:11), is racialized displacement (Gould and Lewis, 2016). Checker (2011:212) defines "eco-gentrification" as "the convergence of urban redevelopment, ecologically-minded initiatives and environmental justice activism in an era of advanced capitalism." Foreshadowing and coinciding with the "see-sawing" of capital investments in the built environment is the movement of bodies in and out of neighborhoods, mostly black and brown in one direction, mostly white in the other. Without provisions to stabilize rents, as public and private capital moves into previously devalued neighborhoods, many lower-income households - disproportionately households of color - are priced out. The reshaping of "blighted" working-class and industrial areas - including those listed as Superfund sites - into urban neighborhoods centered on expensive condominium development, boutique restaurant strips, and manicured parkways has displaced whole communities as well as living wage jobs (Bunce and Desfor, 2007; Davidson and Lees, 2010). Cleanups of Superfund sites have rendered residents in nearby neighborhoods particularly vulnerable to displacement: housing values within one kilometer of sites appreciated 24.4 percent in the lowest $10^{\text {th }}$ 
percentile and 18.7 percent in the $90^{\text {th }}$ percentile for sites removed from listing by 2000 (Gamper-Rabindran and Timmins, 2013), and the removal of Superfund sites from federal listing has correlated with a 26 percent increase in mean household income and a 31 percent increase in college graduates living nearby (Gamper-Rabindran and Timmins, 2011).

Those who are displaced and excluded from the neighborhoods that now boast green amenities are often the same residents who suffered from years of exposure to toxic pollution (Banzhaf and McCormick, 2012). In fact, it is the original toxic facility siting and presence of other "locally unwanted land uses", as well as municipal and private disinvestment in the existing built environment, that, when later coupled with public subsidies to "clean up" and "revitalize" previously disinvested neighborhoods, paves the way for these areas to become profitable for (green) developers (Checker, 2011; Dillon, 2014; Smith, 1982). The federal government's National Environmental Justice Advisory Council (NEJAC, 2006:2) acknowledged this reality over a decade ago, placing the current wave of displacement in historical context:

Gentrification has placed populations in urban areas in direct competition for inner city space with relatively powerful and privileged groups. Environmental cleanup of these formerly industrialized, now residential, communities can be a powerfully displacing force ... Citizens living in urban, poor, and people-of-color communities are currently threatened by gentrification, displacement and equity loss on a scale unprecedented since the Urban renewal movement of the 1960s. 
In a study of the Hunters Points Shipyard in southeast San Francisco, Dillon (2014:1207) explains how brownfield redevelopment, for instance, "rather than representing a clean break with an industrial past, often reproduces the social relations of an older, industrial economy", especially with regard to racialized health-related injustices. Environmental racism, in other words, lays the groundwork for another form of institutionalized racism to take hold, this time in the form of wholesale evictions of communities of color to make way for wealthier, whiter consumers of sustainable development.

In Portland, investment in green-themed initiatives in the urban core without accompanying provisions to address housing affordability has contributed to the dispersal and re-concentration of racialized poverty in neighborhoods on the outskirts of the city over the last few decades (Bates, 2013; Gibson, 2007; Goodling et al., 2015). Here, there is disproportionately less access to basic services and hallmarks of the sustainable city, such as public transportation, walkable sidewalks, and green space (Coalition for a Livable Future, 2013). Displacement that is part and parcel of (eco-)gentrification has disrupted the lives of thousands of residents in urban areas across North America as well, including Austin (Tretter, 2013), New York (Checker, 2011; Curran and Hamilton, 2012; Gould and Lewis, 2016; Miller, 2015; Pearsall, 2013), the San Francisco Bay Area (Causa Justa/Just Cause, 2014; Dillon, 2014), Seattle (Dooling, 2009), Toronto (Bunce, 2009), Vancouver (Quastel, 2009) and other cities (Bunce, forthcoming).

Scholars studying the green growth machine and its implications for residents who it pushes to the margins frequently draw on Swyngedouw's $(2007,2009)$ argument that the depoliticized - "postpolitical" - discourse surrounding the urban sustainability 
movement serves to dampen oppositional voices (e.g., Anguelovski, 2016; Checker, 2011). Davidson and Iveson (2014:2, citing MacLeod (2011:2632)) draw on Swyngedouw and other critical scholars to define the "postpolitical city" as one that is governed "“through a stage-managed consensus' ... whereby certain ends become 'common sense' and disagreement from these ends is depoliticized (i.e. rendered as deviant rather than political)." Sustainability boosters indicate that pollution threatens a “perceived state of ecological balance", endangering all (ibid.:3). They often invoke an Armageddon-like narrative, that all city residents will suffer without environmental improvements and green development, putting sustainability agendas "beyond contestation" (ibid.). Cities need immediate action to remediate pollution - not political debating - city leaders say (ibid.). Technological solutions emerge as the apolitical answer to ecological challenges, opening space for green-themed initiatives to (temporarily) generate new rounds of capital accumulation with few obstacles (Swyngedouw 2007, 2009).

Postpolitical discourse that renders disagreement with green planning and policy as deviant, Swyngedouw (2007, 2009) argues, forecloses space for alternative perspectives and solutions to surface-especially ones that involve a redistribution of resources and power. To this end, Checker (2011) argues that sustainability discourse that appealed to eco-conscious residents and implied a "technocratic, politically neutral approach to solving environmental problems" shut longtime lower-income residents of color in Harlem out of the planning process for a new park. While stifling dissent is not unique to the green city (Logan and Molotch, 2007), Gunder (2006) argues that the 
conceptual "fuzziness" of sustainability discourse imbues it with a particularly powerful tendency, even as it remains an "empty signifier" (Davidson, 2010). In essence, Swyngedouw, Gunder, Davidson, and others contend, the slipperiness of the concept allows decision makers to appeal to a wide variety of people, without actually making any real commitments.

There is some disagreement amongst scholars, however, around the distinctiveness of postpolitical discourse to the sustainability era, as well as to the utility of employing a postpolitical lens in critically analyzing green-themed uneven development. As McCarthy (2013) argues, postpolitical discourse is not unique to the green city, and Davidson and Iveson (2014) point out that contemporary governance regimes using postpolitical discourse to promote sustainable cities employ similar (and oftentimes overlapping) tactics as those perennially employing similar framing devices to foster cities that are competitive, global, and/or secure. And despite depoliticized planning processes, there is still plenty of antagonism and activism occurring in sustainable cities (Davidson and Iveson, 2014; McCarthy, 2013), as we see in the case of PHCC.

Instead of fixating on the postpolitical tendency of sustainability discourse, McCarthy (2013:22) suggests, "Perhaps we ought to ask broader, more structural questions about the recurring ways in which capitalist modernity consistently creates and frames environmental 'problems' and 'solutions'." I propose that, in so doing, we might better understand the ever-evolving relationship between depoliticized discourse (sustainability-themed or otherwise) and the pursuit of profit via urbanization processes. 
And even more importantly, we might open space to see where growth regimes working in green cities are susceptible to progressive challenges. After all, as a "fix", sustainable development is temporary, susceptible to splintering when profit margins shrink-or when communities rise up (Hackworth, 2007; Harvey, 1989; While et al., 2004; see also Long, 2014; Temenos and McCann, 2012; Walker, 2015). By addressing the challenges that PHCC has faced, I interrogate the growth machine operating in the Portland Harbor from the vantage of those fighting for a more just cleanup. I question the extent to which a green growth machine and sustainability postpolitics are present in this case, opening space to nuance theorizations of socio-ecological change in the green city.

\section{Grassroots Collective Action}

\section{Just Green Enough?}

But it is not enough to simply critique sustainability discourse and its attendant political economy (Cook and Swyngedouw, 2012; Davidson and Iveson, 2014; Schafran, 2014). Grassroots groups and progressive planners and policymakers are not standing idly by in the sustainability era (Agyeman, 2005, 2013), and critical scholars have an important role to play in "identifying those times and spaces where equality declarations might be manifest and made into political practice" (Davidson and Iveson, 2014:8). Addressing the contradictory, conflicting, messy relationship between the dialectical poles of what is going on and what people are doing to address the problem is crucial to developing a full picture of how change happens. Merrifield (2002:137) succinctly summarizes this sentiment: "how things hang together is the crux." 
Since 2012, scholars studying social and environmental justice implications of the green growth machine have widely described communities fighting against displacement, environmental racism, and other forms of exclusion and oppression in the green city context as taking an approach that is "just green enough" (JGE). Curran and Hamilton (2012) first coined the phrase in a case study of Brooklyn's Greenpoint neighborhood, where residents faced displacement following the remediation of the Newtown Creek Superfund Site—what Checker (2011:211) calls a "pernicious paradox". She asks, "Must [residents] reject environmental amenities in their neighborhoods in order to resist the gentrification that tends to follow such amenities?" (ibid.). Curran and Hamilton argue that a JGE strategy, which entails environmental remediation that "does not automatically or exclusively lead to the 'parks, cafes, and a riverwalk' model of a green city" emerged in Greenpoint in order to make room for "continued industrial use and blue-collar work" (2012:1028). The authors simultaneously use the JGE frame to describe what is happening in Greenpoint, as well as to normatively argue what should happen there and in neighborhoods undergoing similar transformations. Environmental cleanup, they conclude, ought to be "just green enough" for it to improve the "health and quality of life for existing residents, but not so literally green as to attract upscale 'sustainable' LEED-certified residential developments that drive out working class residents and industrial businesses" (ibid.). In other words, a JGE strategy entails finding a balance between making environmental improvements and keeping housing prices relatively affordable. Another way of putting it is that residents desire some degree of 
actual or perceived environmental dis-amenities, which may provide for industrial jobs as well as serve as bulwarks against gentrification and displacement.

Curran and Hamilton's Local Environment paper has been cited over 60 times in urban studies and geography journals. Researchers undertaking later case studies by and large echo Curran and Hamilton's original findings. Pearsall (2013), for example, describes how the entry of Brooklyn's Gowanus Canal on the federal Superfund register ultimately rendered nearby neighborhoods less attractive to developers and newcomers, due to the length of time it would likely take to complete the cleanup. She argues that Superfund listing therefore served as a desired and "effective tool" that residents wielded against displacement—particularly for "middle-class professionals working with their lower-income neighbours to resist developer-led redevelopment" (16). In a later study of the same area, Miller (2015) explains that newcomers to the neighborhood ultimately rallied around a strong cleanup of the canal. Longtime residents, however, undertook what Miller calls a "pollution protection" strategy, which deemed a certain level of hazard acceptable in order to guard against gentrification. Similarly, in a Boston case study, Anguelovski (2016) argues that eco-friendly supermarkets, green spaces, and other environmental amenities can be understood as new "locally unwanted land uses" because of the displacement they trigger or accelerate. In all of these cases, those who cannot afford a rent hike encounter a paradox: the development of green amenities accelerates the evictions of lower-income residents. To guard against displacement while still addressing environmental health issues such as air and water pollution, lower-income communities shore themselves up by pursuing some environmental improvements-but 
not so many as to make their neighborhoods attractive to developers and wealthier residents.

The concept of JGE has gained traction not only in urban studies and geography scholarly conversations, but also in more practitioner-oriented landscape ecology and urban planning circles, as well as in the popular media. In 2014, Wolch, Byrne and Newell published "Urban Green Space, Public Health, and Environmental Justice: The Challenge of Making Cities 'Just Green Enough"' in Landscape and Urban Planning. This paper has in turn been cited over 330 times, in journals such as Ecosystem Services, Building and Environment, and Urban Forestry and Urban Greening. The authors offer policy prescriptions similar to the recommendations that Curran and Hamilton put forth, concluding that environmental planners and others "need to focus on urban green space strategies that are "just green enough"” in order to help residents avoid the displacing effects of urban greening. Journalists and bloggers dedicated to urban questions likewise take cues from Curran and Hamilton. The byline of a 2015 article in The Guardian drives home the perennial predicament of how to foster development without displacement, referencing the redevelopment of an old elevated rail line into a mile-and-a-half-long parkway: "With upwards of 5 million visitors each year, the popularity of New York's High Line has created difficulties for local residents and small businesses. So is there a better way of introducing nature into our cities?" The title of the article puts this provocative question even more bluntly: "The dangers of eco-gentrification: What's the best way to make a city greener?" The article goes on to cite Curran and Hamilton's JGEfocused research, and suggests a handful of interventions presumably inspired by their 
work, including "explicitly rejecting elements that tend to lead to gentrification, such as fancy waterfronts," as well as "including neighbourhood residents in the planning process" and "implementing changes gradually" (Haffner, 2015).

From scholars and students in multiple disciplines to ordinary people reading the news, Curran and Hamilton's JGE strategy has gained a wide audience. Theorizing around JGE has perhaps encouraged scholars and practitioners to think more sensitively about the equity implications of urban greening initiatives, and to consider the need for anti-displacement provisions such as rent stabilization programs and shared equity housing projects (i.e., Wolch, Byrne and Newell, 2014). And yet, in these conversations, a JGE approach is often portrayed as the main bottom-up way that vulnerable communities can resist displacement in the green city, as well as a prescriptive, an ideal approach that other communities and policymakers should adopt. While cases featuring a JGE approach may well reflect some grassroots groups' efforts to overcome (green) development-displacement tensions, they do not account for the approach taken in all communities, including those that take a more radical approach focused on communitycontrolled cleanup and redevelopment and/or that put pressure on local jurisdictions to implement robust anti-displacement policy provisions. Nor is a JGE model the only one available to policymakers seeking to prevent and mitigate displacement, who might also consider a suite of tools, including rent control, inclusionary housing, community benefits agreements, and more (see Bates, 2013).

That is not to say that one approach is inherently better than another; rather, it is important to recognize that different approaches arise in different contexts, with different 
possible outcomes. Writing of gentrification and dispossession, Hern (2016:44) argues, "The first step is to admit you have a problem, etc., but I'll suggest that collectively we've got to be more imaginative to think over, through, and beyond gentrified aporias." I contend that without bringing attention to other "more imaginative" approaches, scholars and journalists risk reifying the notion that it is impossible for neighborhoods to fight for robust environmental improvements while also remaining affordable to poor and working-class residents. There is therefore space to account for the work of groups - like the Portland Harbor Community Coalition (PHCC) - that are simultaneously attempting to both prioritize the ecological integrity of surrounding land, water, and air in the interests of vulnerable communities and guard against displacement and other forms of exclusion and oppression. Curran and Hamilton (2012:1027) note, "Many visions of the green city seem to have room only for park space, waterfront cafes, and luxury LEEDcertified buildings, prompting concern that there is no place in the 'sustainable' city for industrial uses and the working class". Do only middle and upper-class residents desire parks, a place to sip a coffee next to an urban river, and housing that is free of toxins and built in a way that does not contribute to climate change? In this dissertation, I argue that it is not environmental improvements that groups like PHCC eschew, but rather environmental improvements that are pursued independent of community-controlled remediation and development schemes and robust anti-displacement policies. In fact, PHCC turns this line of thinking around, demanding a robust cleanup in the same breath as the coalition advocates for living wage cleanup jobs, access to affordable housing near 
the river, anti-displacement provisions, access to sites for community-led cleanup, and more.

\section{Environmental Justice: Second Generation Scholarship}

To address the intersection of issues that emerge in cases such as PHCC, and to better account for a wider spectrum of approaches to improving environmental health through community development and organizing practices in the green city, it is necessary to establish an understanding of the environmental justice movement and how it has evolved over the last few decades. Pellow (2016) articulates two phases of scholarship around environmental justice. Using a lens of race and class, "first generation" scholars addressed questions of distribution and documented struggles over environmental inequality, focusing especially on spatial distribution of burdens. Key cases include a handful of campaigns fought in the 1970s and early 1980s around toxic facility siting and disproportionate exposure of communities of color to contamination (Taylor, 2014). More recently, "second generation" environmental justice scholars have begun to address gaps in first generation scholarship procedural and representational (in)justice (e.g., Pierce and Pearsall, 2017; Walker, 2009) and "incorporate a deeper consideration of theory and the ways that gender, sexuality, and other categories of difference shape EJ struggles" (Pellow, 2016). Dillon and Sze (2016) draw on critical race studies to examine environmental racism around "insecure breathing spaces", connecting racialized exposure to industrial toxins that results in disproportionate asthma rates to anti-Black police violence that literally denies breath. Their argument that the phrase "I can't breathe" is both a reflection of "uneven environmental conditions" as well 
as "an assertion of the humanity of a population for whom human-ness, and life, has been historically denied" (1) points to the cumulative and intersectional ways in which environmental racism impacts people's lives and inspires the contemporary Black Lives Matter movement.

Reflecting on what a more mature version of second generation environmental justice scholarship might further account for, Pellow (2016:223) suggests that scholars should investigate questions of intersectionality (in terms of race, class, gender, sexuality, etc.); more readily undertake multi-scalar analyses of the "causes, consequences, and possible resolutions of EJ struggles"; examine the degree to which inequality and power relations, "including state power", are perceived as being entrenched; and better account for the ways in which human and non-human populations experiencing violence are deemed "expendable". Carter's (2016) case study of Latino organizing in Los Angeles begins to address some of these second-generation environmental justice frames. $\mathrm{He}$ examines the recent shift in environmental justice politics such that grassroots groups (like PHCC) are now not only preoccupied with urban environmental "bads" but are also concerned with "the production of nature in the city." At the same time that communities take issue with pollution and its impacts on human health, he illustrates, they also are taking a proactive approach to ensuring access to "environmental 'goods", such as parks, bike paths, community gardens, as well as job opportunities, funding for community programs, and "investment options that revolve around the new green economy" (ibid.:56). This shift is indicative, Carter argues, of new "green economy" development models. Relevant for my study, in which activists are as concerned with environmental 
remediation as they are social and environmental justice issues around exposure to toxins, access to jobs, and displacement, many of the leaders who Carter interviewed eschewed an "EJ" label as the main way to describe their work, situating their work in "relation to both (mainstream) 'environmentalism' and 'EJ'” (ibid.:5). More generally, Faber and Kimelberg (2014) re-focus thinking around cleanup of hazardous sites to also emphasize "building healthy urban spaces." The key issue is not, they argue, whether such undertakings are positive or negative on the whole, but rather "the extent to which the decisions undertaken to accomplish those efforts, and the consequences that stem from them, are fair and equitable" (84). This frame echoes Agyeman's $(2005,2013)$ "just sustainability paradigm", which he defines as a convergence of the environmental justice and conservation movements in order to emphasize "a better quality of life for all, now and into the future, in a just and equitable manner, while living within the limits of supporting ecosystems" (Agyeman, 2005:79).

With this investigation, I attempt to take cues from Pellow (2016) and others undertaking second generation environmental justice research, particularly with regard to undertaking multi-scalar analysis in the case of PHCC and considering the inter-related ways in which local and federal agencies intervene (or refrain from intervening) between polluters and polluted communities. In this way, I move away from a purely spatial justice analysis, pivoting to also consider procedural and representational justice.

Environmental justice scholars have also recently taken stock of the relationship between the EJ activists and the state, with important implications for the case of PHCC. The environmental justice movement, Pulido, Kohl, and Cotton (2016) contend, relies far 
too heavily on state regulation to achieve its goals of racial equity. In theory, Environmental Protection Agency (EPA) involvement in Superfund cleanup projects protects communities of color and low-income neighborhoods from disparate impacts of pollution. Signed by President Clinton in 1994, Executive Order (EO) 12898 mandates that all federally funded projects overtly address environmental justice issues (The United States Commission on Civil Rights, 2003). In reality, however, federal-level legislation offers only a façade of protection for environmental justice communities (Pulido et al., 2016). ${ }^{6}$ As of January 2014, out of 298 Title VI Complaints filed against the EPA grievances registered "in response to perceived discrimination by a public agency using Federal funds" - all but one have been dismissed (Pulido et al., 2016:4). In other words, while the EPA may have expanded administrative infrastructure to allow for greater public involvement of marginalized communities over the last few decades, EO 12989 has done little to actually improve the environments of vulnerable groups (The United States Commission on Civil Rights, 2003). Pulido et al. (as well as Mank (2008)) deem that a lack of political will - "a lack of regulatory action and effective enforcement" - at the federal level accounts for the EPA's dismal record. And what accounts for this lack of political will? Racial capitalism requires pollution "sinks", vulnerable communities serve

${ }^{6}$ Defining "environmental justice communities" remains a contested, context-dependent undertaking. Grassroots groups operating under this umbrella commonly adopt a broad definition, refraining from limiting the kinds of issues encompassed under the termgiving the term its "rhetorical power" (Holifield, 2007). Pellow (2016:222) offers a simple definition: environmental justice communities are those facing a "disproportionate burden of environmental harm". 
this function, and states are beholden to the companies that rely on this arrangement, Pulido and colleagues argue.

Given that the primary levers meant to help marginalized groups do so little on their behalf, in reality, and given that the process of invoking these tools requires so much time and energy, Pulido et al. contend that environmental justice groups' continued faith in the state to check the power of polluters actually inhibits achievement of more equitable outcomes: engaging with state regulators distracts impacted communities from taking more effective actions that fall outside of the environmental justice movement's historically liberal lens, including directly challenging the state. ${ }^{7}$ The state's "lip-service to EJ" (ibid.:16) placates impacted communities into thinking that regulators have their best interests in mind. And yet, the state actually has no intention of eradicating the "necessary 'sinks"” (16) that communities of color provide for the economy's toxic biproducts. Given this state of affairs, the authors argue for environmental justice leaders to fundamentally rethink their perspective of the state as partner, and instead refuse to "participate in [its] regulatory charades" and think of it as an adversary in need of direct confrontation. Echoing what Piven (2006) and Piven and Cloward (1977) have articulated since the 1970s, Pulido et al. (2016:16) suggest that environmental justice groups take cues from the Black Lives Matter movement: "It's not about being respectable,

\footnotetext{
${ }^{7}$ Pulido et al. (2016) do not list specific alternative actions, but presumably they have tactics ranging from letters of opposition and mass petitions to sit-ins and boycotts and beyond in mind.
} 
acknowledged, and included. It's about raising hell for both polluters and the agencies that protect them."8

Pulido et al. convey three important messages for scholars examining contestation in Superfund site cases and in sustainable city change processes more broadly: 1) that meaningful participation in sustainability initiatives - in city land use decision-making, in intersecting EPA Superfund cleanup planning processes - is not equally available to all; 2) that it is necessary to operate outside of established political channels to enact changes; and 3) that it is possible to hold regulators (and polluters) accountable while pursuing more radically just visions of urban life. The case of PHCC provides an opportunity to examine a group that is grappling with issues the authors raise, especially with regard to how to effectively engage (or disengage with) the state. While PHCC has not entirely given up on the EPA (as well as local and state agencies) to act on its behalf, as I show in this dissertation, the coalition has also begun to operate in a more confrontational, or oppositional, way in its engagements with public agencies.

\section{Oppositional Community Development}

Community development scholars describe an "oppositional community development" (OCD) approach (DeFilippis, 2004; DeFilippis, Fisher, and Shragge,

\footnotetext{
${ }^{8}$ While not exactly following Pulido et al.'s call for direct action, environmental justice activists in Los Angeles have begun to heed the reality that regulatory agencies are often of little help for impacted communities, and have begun to rely on public-private partnerships enacted through a network of foundations, non-profits, and environmental NGOs to address disproportionate exposure to contamination and lack of access to environmental amenities (Carter, 2016).
} 
2010), providing a useful framework for investigating the work of groups like PHCC and others who are open to operating outside of established regulatory frameworks and participatory channels in order to bring about a more just urban sustainability. True to its name, OCD work often involves confrontational engagement - rather than passive participation - with public agencies. To shift the balance of power and ensure that a wider array of concerns gains traction, groups taking an OCD approach frequently work outside of established participation channels. As a leader in the Bay Area's antidisplacement movement over the last two decades, for example, Tracy (2014:6)) describes himself as "extremely leery of complete reliance" on either the market or the state to solve today's housing crisis. Groups like those with whom Tracy works both implicitly take an OCD approach, as well as borrow from Saul Alinsky's (1971) Rules for Radicals, using a range of tactics and strategies that entail taking "direct action" to challenge established hierarchies of power. ${ }^{9}$ Tracy (2014:127) defines direct action as "any political tactic operating outside the dominant formal electoral-legislative decisionmaking structures in a given society." Tracy illustrates the multi-pronged approach taken by Bay Area housing activists, including picketing landlord's homes and businesses, staging sit-ins to prevent evictions, and blocking buses carrying wealthy tech-workers to Silicon Valley jobs south of San Francisco. As my research shows, PHCC also takes an

${ }^{9}$ Tracy (2014) also summarizes critiques of Alinsky's work, most notably that the Alinsky model does little to directly address racialized oppression and that it depends on "winning the favor of established institutions like churches and unions" (14) - many of which are "contaminated with racism" (15). Nevertheless, Alinsky continues to inspire generations of activists to confront power using direct action tactics. 
oppositional stance in pushing a social and environmental justice agenda in the Portland Harbor when it becomes clear that government agencies will not be moved through more conventional channels.

In addition to embracing confrontation when necessary, OCD-oriented groups recognize that there is a dialectical relationship between place-based community organizing and broader social change movements; each relies on the other (DeFilippis et al., 2010). The anti-poverty Association of Community Organizations for Reform Now (ACORN) exemplifies an organization that takes multi-scalar organizing seriously (ibid.). Between its inception in Little Rock, Arkansas in 1970 and 2010, ACORN grew to include chapters in more than 150 US cities (Atlas, 2010). DeFilippis et al. contend that ACORN and other organizations like it have persisted precisely due to the "devolution of responsibility from the public sector to the "voluntary' and nonprofit sector" (154). ${ }^{10}$ At the same time, it is through a commitment to driving broader social movements, like the recent nationwide campaign for a living wage, that organizations like ACORN and others help foment change beyond local communities. In her study of four neighborhoodspecific environmental justice struggles in New York City, Sze (2007) argues that local campaigns must be examined within a context of larger movements for environmental justice in order to understand why they emerged when and where they did. ACORN and

${ }^{10}$ The Industrial Areas Foundation (IAF), People Improving Communities Through Organizing (PICO), Direct Action and Research Training Center (DARTC), and Center for Third World Organizing (CTWO) are other examples of national and regional community organizing networks, which, although they differ in many other respects, share in common a commitment to linking local or community-based issues across cities and states to statewide, regional or national campaigns (DeFilippis et al., 2010). 
others like it are substantially larger in scope than the neighborhood groups in Sze's investigation, as well as much larger and well-connected than PHCC. And yet, as we will see in the chapters to come, PHCC has begun to connect with other likeminded groups locally and beyond, and it is within a broader context of the urban sustainability era that PHCC and these groups operate. It remains to be seen the extent to which PHCC's focus will extend geographically beyond the Portland Harbor, but what is certain is that the coalition is grappling with similarly complex scalar challenges as grassroots groups operating in many other green cities. ${ }^{11}$

Finally, OCD-oriented groups have a strong commitment to political education in order to help those most impacted by exploitative and oppressive systems develop a critical analysis (DeFilippis et al., 2010). Pedagogical activities in OCD work commonly revolve around a historical, multi-scalar perspective rooted in people's own experience and that considers the place of community within analysis of broader political economic systems (ibid.). The Industrial Areas Foundation, for example, grounds popular education activities in the faiths of constituents, emphasizing relationship building in order for people to determine collectively which issues are most important to address. Organizers understand that participants' own lives and histories provide powerful entry points into

\footnotetext{
${ }^{11}$ Notably, PHCC members do not all live in Portland. Native Americans belonging to many Northwest tribes consider the Portland Basin an important place; a handful of tribal members belong to PHCC but live several hours away. In addition, many people particularly Black/African Americans - used to live in inner-city, close to the Portland Harbor, but now live on the outskirts of the city as housing prices continue to rise. As we will see in Chapter 5, what to make of these socio-geographic complexities has eluded the Environmental Protection Agency.
} 
political activity and social change work, and prioritize developing leaders with this in mind (Warren, 2001). I address the role of political education activities in greater detail in the next sub-section, discussing how the consciousness-raising that can arise through workshops, film screenings, direct action undertakings, and other activities organized by OCD groups is a key mechanism that can infuse this work with transformative - rather than solely palliative - potential (Choudry, 2015; DeFilippis et al., 2010).

As we will see in the chapters that follow, PHCC emerged out of a recognition by local leaders that local and federal agencies were doing little to center the perspectives of those who have suffered the effects of pollution in the past and who, absent substantial interventions, are unlikely to benefit from harbor cleanup moving forward. An OCD framework, with its embrace of the potential for conflict-oriented tactics to enact change when established participatory channels are not working, its attention to the relationship between local-scale action and broader social movements and political-economic contexts, and its emphasis on political (popular) education, provides a baseline for investigating the work of PHCC and grassroots organizing, more broadly, in the green city.

\section{Political Subject Formation, Learning}

Working towards more just urban sustainabilities via an OCD approach entails operating at least partially outside of conventional public participation channels - and therefore an accompanying politicization of those on the front lines. Although scholars studying social movements and community organizing more broadly have long 
considered the interrelated roles of political subject formation (PSF) and learning in processes of grassroots collective action, urban geographers (and, I submit, urban political ecologists, more specifically) are only beginning to grapple with this key dimension of socio-environmental change (Rutland, 2013). Rutland draws on French sociologist Francois Dubet $(1994,2004)$ to describe three main reasons people initially engage in social change work: an ongoing or previously unmet tangible metabolic need (e.g., food, shelter, safety, etc.); a desire for connection/community that comes with being part of a larger group; and/or concern over a particular social/environmental justice issue. Rutland notes, however, that it is nearly impossible to speak of a fully formed or internally homogenous political subject. One's resources and objective interests, social circles, and core dispositions are always in flux, independently and in relation to one another. Political subjects are "made and remade," ever changing, always evolving, and they must "manage several discordant, even contradictory, logics of action ... the subject [can be understood, therefore, as] a work on oneself" (Rutland, 2013, citing Dubet, 1994:22). Central to the making and remaking of political subjects - and therefore more than just "background noise" in urban politics (McFarlane, 2011:1) - are formal and informal processes of learning. Hern (2016:110) contends that learning is a "grossly inadequate word" to capture the myriad ways that "people acquire new skills, ideas, insights, and capacities." I agree with Hern, but nevertheless use the word for lack of a better one, and hope that readers of this dissertation will adopt a generous definition that embraces the broad capacity of humans to reflect, expand, and grow, adjusting in big and subtle ways to the circumstances they encounter. 
Activist-scholars in the field of adult education unite on-the-ground activism with academic undertakings, working to understand learning in the context of grassroots activist endeavors. Choudry (2015:34) describes the praxis - the dialectical relationship between learning and doing - involved in grassroots activism: "Human activity and thought are mutually constitutive; they are shaped by each other." Just as in other changemaking contexts, it is necessary for those working toward a more just sustainability to undertake a host of tasks that entail learning in one form or another. There are city ordinances to understand, statistics on health disparities to analyze, dominant discourses to critique, relationships with other like-minded groups to develop, intersecting issues to articulate, depoliticized processes to re-politicize, and many other nexuses where learning, politicization, and action converge. For Foley (1999:2), tacit knowledge develops both individually and collectively in the course of day-to-day "struggle to make sense of what is happening....and to work out ways of doing something about it." Choudry (2015:9) further explains the significance of such informal learning: "Incremental, below-the-radar learning and knowledge production in the course of organizing and action is so important ... Often, 'learning by doing' leaves the deepest footprints.”

While informal learning may make valuable contributions in the day-to-day, however, it can be ephemeral and hard to grasp over the long term, and is often hard to recognize, document, and theorize. More formal learning often supplements the important growth that happens via casual channels. Grassroots movements build power by making time and space for "collective reflection, by bringing people together to build 
understandings and analyses that start with their lives, experiences, and actions" (Choudry, 2015:34). As DeFilippis et al. (2010:180) assert, "Political education is the basis for unmasking the central issues of power and inequality ... and building a longerterm vision and political culture.” Freire's depiction of popular education-style learning offers a useful framework to guide investigation of the role of learning in community organizing work.

In Freire's framework, learners first reflect on and activate the knowledge they already possess, which has been acquired through a lifetime of formal and informal experiences. For instance, in a setting in which facilitators are explicitly following Freire's model, they might invite participants to collectively list or draw all that they know about a given topic, regardless of whether that knowledge came via work experience, observation, interactions with family members, formal classroom instruction, etc. Facilitators might then invite participants to build on this prior knowledge to ask questions about the topic at hand, pursuing additional investigation and learning in realworld contexts to deepen understanding. This refined understanding, in turn, can then contribute to a course of action, and to new cycles of learning embedded in real life (Freire, 1970; Horton and Freire, 1990). In reality, learning in pursuit of social change is messier than this model suggests, with overlapping cycles occurring simultaneously, in a "process of continuous unfolding and deepening" (Choudry, 2015:36). Foley (1999) points out that micro-processes occurring along the way, such as interpersonal conflicts amongst those involved, gender dynamics, and racial tensions, can have immense sway in 
if and how social change processes unfold. And engagement in cycles of popular education-style learning often happens organically, without being identified as such.

To investigate and document learning in social change work, scholars assert that participation in movements by scholars, themselves, is necessary. Choudry (2015) explains that it is nearly impossible to pick up on the nuances of a given movement without being on the ground, in the moment, given the immense amount of "intellectual work within - and fundamental to - everyday activism" (58). She draws on examples of scholars who, without day-to-day experience on the ground alongside activists, overlook the ways that activists create political opportunities for themselves as opposed to simply theorizing about given opportunities for change and acting accordingly. Lafazani (2012:192) echoes Choudry: "Being involved in [social change] struggles is the only way to understand the deeper relations, the dynamics of the different groups, the real people involved and how they themselves understand their position and action." Lines of inquiry with potential for such research to actually be useful for movements themselves include questions around the issues that concern participants and the ideas and theories that activists themselves are producing (Choudry, 2015:61, drawing on Bevington and Dixon (2005)).

Popular (political) education has played a key role in short- and long-term progressive change in countless instances. Corburn's (2005) analysis of "street science" in Brooklyn's Greenpoint/Williamsburg neighborhood is particularly relevant for this dissertation. Street science refers to "co-produced" investigations in which communities "engage in science, inject their own knowledge, and reorient investigations, outcomes, 
and actions" (35), combining "local insights with professional techniques" (3) in order to bring about environmental health justice. In Greenpoint/Williamsburg, the EPA planned to pilot a cumulative-exposure study project. EPA officials had no idea, however, that many residents regularly consumed fish from the East River; community members alerted the agency to this reality, and one group worked with the EPA to survey and interview anglers, resulting in the incorporation of local knowledge in what had previously been a top-down investigation. This case provides an example of how the incorporation of local knowledge into research and decision-making processes has the potential to contribute to better outcomes for marginalized communities.

It is important to note, however, that developing consciousness - becoming "woke", as many call it - is, in itself, not necessarily a sufficient condition for effective action and progressive change. Conversely, Foley (1999) points out that material conditions alone are not sufficient for action to materialize. For scholars of social change processes like Shragge (2013), community organizing is the key to moving from individual consciousness to collective action, and in turn participating in collective action often helps to politicize participants, build solidarity with others, and open space to make further progressive changes. Residents might feel emboldened to band together to challenge their landlord, for example, upon reading a news story about tenants in another city that collectively pushed a landlord to make more repairs. In the opposite direction, participants might join their neighbors in a campaign around housing because they are at risk of losing their homes, and in the process, learn about wealth and power structures, become familiar with alternative housing arrangements such as community land trusts 
and cooperatives, demand that more public funds be allocated toward housing, and analyze the problems of a market-based housing system (ibid.). In both of these examples, there is a catalyst at work: a personal experience compels one to learn and take action with others, and in the course of taking action participants gain valuable knowledge and experience. Sometimes, people with no formal organizing experience find their way together. Other times, Shragge notes, someone with community organizing experience, from within or outside of a given community, helps facilitate the process of organizing people to act. In the latter case, if an organizer does their job effectively, they will work themselves out of a job, actively shifting power and control to members as they develop new skills and dispositions.

Even with an experienced community organizer helping to facilitate the shift from consciousness to action and vice versa, however, other factors, can intervene, such as limited access to time and resources (Derickson and MacKinnon, 2015), responsibilities to work long hours or care for children and elders (Shragge, 2013), the perception that neighborhood-based organizing is the sole domain of women (ibid.), or an understandable aversion to the violence that may be inflicted in the course of action (Scott, 1990). It is also important to note that local grassroots mobilization, as well as the learning and consciousness-raising that contributes to organizing, take place in a much broader context of political parties (and, at times, vanguard movements). Piven (2006:1) argues that it is only when ordinary people "defy the rules that ordinarily govern their daily lives" and "disrupt the workings of the institutions in which they are enmeshed" that new issues come to the fore, forcing mainstream political parties to adjust and move 
to the left or right. It is also important to note that there is nothing inherently progressive about grassroots movements, as we have recently seen with the Tea Party and the "altright"; consciousness-raising can occur on both ends of the political spectrum, compelling people to action toward vastly different ends.

Yet, as we will see in the chapters that follow, learning remains a key ingredient in the work of those actively striving to make urban sustainable development processes more equitable. While it may not be sufficient, on its own, to enact change, learning is nevertheless suffused through the whole process, from engagement to problem framing to action to reflection. Historicized learning, more specifically, is a key part of antioppression organizing in the green city (Choudry, 2015). Freire's framework stresses how inquiry via popular education-style learning is rooted in community-defined problems, situated within a particular geo-historical context, as experienced and defined by participants themselves. Engaging with history - learning about the past, evoking memories, reflecting, sewing a thread through decades and centuries of change (or stasis) - plays a crucial role, "including providing a collective memory of prior struggles, strategies, victories, and defeats," and offering an "instant comparative perspective with the present" (DeFilippis et al., 2010:181).

For Finney (2014), historicized learning through telling stories plays a particularly important role in collective imagination of future environments, particularly for Black/African Americans, who have a particularly complex relationship with "the environment" and environmental movements. She recounts an interview with Carla Cowles, an African-American park ranger, who talks about how enslaved people - her 
ancestors - once lived on land in Louisiana that is now owned by the National Park Service (NPS). In an effort to "preserve her family's stories" and teach visitors on park tours about the land where the park now stands, a former plantation, Cowles frequently referenced local histories of slavery. But NPS officials deemed this an inappropriate storyline. Cowles explains the impact of omitting histories like hers: "Without all the stories, you can't understand how America was created ... It becomes Swiss cheese and you can't get a good bite out of that" (51). Finney explains the importance of invoking histories for African Americans, in particular: "Focusing on preserving a piece of the past [through stories] is a way to say, 'We were there' and indirectly allows for more control and power in deciding (collectively?) who we were and who we are. Consequently, memory, as a way of evoking the past, becomes an important vehicle for involving the community in environmental preservation, conservation, and participation" (66).

In this dissertation, I show how historicized learning has helped PHCC members build a collective political consciousness, taking a "good bite" out of how the harbor came to be, in relation to the impacts that pollution and cleanup have on different groups. I address some of the ways in which (historicized) learning articulates with an OCDoriented approach, as well as ultimately how grassroots groups influence processes of socio-ecological change in the green city, and vice-versa. By examining how those on the front lines come to understand the historical context in which they are working - and by paying particular attention to how they employ this history in fighting for a more just future - the case of PHCC contributes to crucial conversations emerging in urban 
political ecology (UPE). Pulido (2015:815) argues that in "this era of global environmental crises" it is imperative that we "identify culprits and name names, so that the global community will understand who the guilty parties are and how we should respond to them" (ibid). For both Pulido and Heynen, being more attuned to "the deep historical spatial logics" of marginalized spaces such as "the 'ghetto', the 'plantation', the 'colony', and the 'reservation"' (Heynen, 2015:2) is imperative for scholarly research to have an impact. Following Choudry (2015:73), who emphasizes the importance of "democratizing the production of critical histories" in order for them to become useful tools for analysis and change, my engaged work with PHCC allows me to pay attention to what history does for those on the front lines of change- those, like PHCC members, who are fighting to undo the effects of colonialist, racist, capitalist city-building processes and build something new and more just instead. 


\section{RESEARCH APPROACH}

\section{Research Design: Extended Case Method}

Investigation of grassroots groups working to improve life for marginalized communities requires a research design that allows for a multi-scalar analysis across time and space, as well as levels of governance. It also begs an approach that embraces, rather than attempts to limit, the (inevitable) interventions of the researcher; one that is flexible and allows for emergent developments to become incorporated into research questions and analysis; and one that recognizes the contingencies of particular places and times. The extended case method (ECM) provides one such framework, demanding that context be incorporated into analysis and theorizing as opposed to sidelined as background noise (Burawoy, 2009).

Four "extensions" define the ECM. That is, the ECM involves the development of four particular relationships through the research process itself, which enable the researcher to investigate and interpret empirical phenomena. Each of the ECM's extensions guide this dissertation research in particular ways. The first extension is between the observer and participants. Each comes into contact with the other, reciprocally influencing one another in subtle or dramatic ways that must be accounted for in interpretation of data. My own presence as participant-observer in the setting of participants inevitably entails both proximity to and distortion of the world under study. Proximity means that I am exposed to people and processes in a far more intimate way 
than would be possible solely through interviews and surveys. When combined with an activist-scholar disposition, this means that I am indeed influencing things in subtle - and at times dramatic - ways. This inevitable distortion means that a reflexive approach is imperative; close attention to the context within which the research takes place (including my own position within it) becomes fundamental to interpretation of data.

The second extension entails observations over time and space. For Burawoy, as well as Pierson (2004:15-16), key drivers of social processes are often "temporally removed from their continuing effects." It is therefore imperative that investigation of political processes be grounded in a historical context that shows how such processes develop over substantial time periods. Moreover, social causes and outcomes are often slow moving, and the way that social change happens, itself, constantly changes (ibid.). The contours of this study reflect a commitment to the ECM's extension of observation over time, space, and scales (see Figure 4). I start with a broad-brush account of multiscalar political economic processes, focusing on the Portland Harbor's role in the cityregion's political economy and associated social and environmental injustices throughout the twentieth century. While the Portland Harbor remains the geographical focus of this research, I consider the Harbor not as a closed container but rather as a permeable space situated within the broader context of the city, region, and beyond. This historicalgeographic background provides context to then use ethnographic tools that more readily address the everyday work of contemporary grassroots groups and their members. 


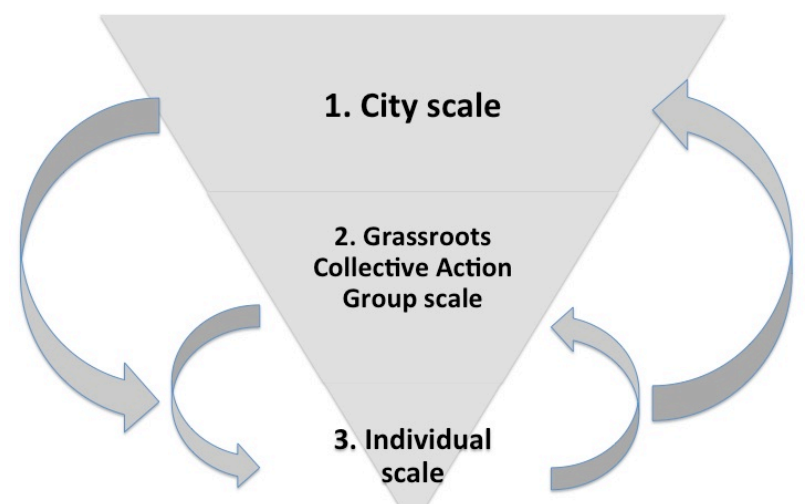

Figure 4. Three scales of analysis address different but overlapping scales and corresponding sets of theoretical concerns and empirical questions. While investigation of each scale could stand alone, the ECM holds them together in one coherent research project.

The third extension involves a dialogue between local processes and macro structures, in which the researcher seeks to understand inter-scalar linkages. Relationships between forces operating at multiple scales may be causal in nature, or they may be reciprocal or dialectical. I also pay particular attention to the relationship between micro-processes and macro-forces, emphasizing how these re-produce each other. This research thus takes a relational approach: I am interested in the relationship between grassroots activist groups and the individuals who participate in them, and, in turn, the ways in which urban (green) development processes shape and are shaped by grassroots groups and their members.

Finally, Burawoy emphasizes that researchers enter into the field armed with existing theories that do not need to be confirmed, but rather refined (or even refuted). The fourth extension involves the extension of theory through revision, improvement, and reconstruction of existing understandings. I seek to extend theoretical 
understandings of interest to urban scholars, activists, and progressive planners and policymakers. I enter the field with a solid understanding of established theoretical frameworks, and examine and extend these through empirical analysis. I undertake empirical research to revise, augment, or refute existing understandings through the case of PHCC. This case, within the context of a city at the forefront of green development, is a revelatory case (Yin, 2009:42): it presents the opportunity to understand phenomena that have previously not been thoroughly investigated, even though similar circumstances are increasingly prevalent across North American cities. This condition means that a single (extended) case study indeed has the capacity to extend prevailing theory and contribute to broader understanding.

\section{Propositions}

Although I did not begin this investigation with formal hypotheses per se, I did develop a number of "propositions" in the early stages of research that steered my inquiry. These propositions were based on a review of relevant literature, as well as extensive pilot research and my own tacit knowledge developed through nearly a lifetime living in the Portland area and working in various community development/organizing capacities since 2001. The following propositions (P), addressing each of the three individual scales as well as relationships between the scales depicted in the inverted triangle above, guided this investigation: 


\section{City scale}

P1a. Conflicts between the use value and the exchange value of a place set the stage for groups to take an oppositional community development (OCD)-oriented approach (following DeFilippis, 2004; DeFilippis et al., 2010).

P1b. Postpolitical discourse permeates planning and policymaking in sustainable cities, which further compels OCD-oriented approaches: the foreclosure of political dissensus means that social and environmental justice activist groups must look outside of established political channels to effect change (following Davidson and Iveson, 2014; Swyngedouw, 2007, 2009).

\section{Grassroots collective action group scale}

P2a. OCD entails the following (following DeFilippis et al., 2010):

- Community development groups understand the potential - and limits for communities to enact systemic change. The potential lies in a dialectical relationship between place-based community organizing and broader social movements; each relies on the other. Limits result from the scalar challenges of addressing oppressive systems that transcend the bounds of a given community, as well as from uneven power relations and oppression that occurs within communities themselves.

- Community development work becomes oppositional CD - and therefore imbued with political potential - when groups emphasize working "within a place" rather than solely "about a place" (ibid.:169). This requires 
analysis of the broader historical and political economic context within which the group works.

- For an OCD approach to emerge, the group must be willing to adopt a conflict-oriented approach when necessary. This entails defining the opposition and stating who benefits from status quo power relations. Conflict might mean engaging directly in tension-filled interactions with those in power, or it might mean building alternative practices that oppose dominant ones.

- Finally, political education is a central component to OCD, providing the basis upon which groups make decisions to act in particular ways.

P2b. Some of the actions of an OCD group may appear to run counter to a systemic change agenda on the surface; however, basic metabolic needs must first be addressed (often incrementally) in order for the group to continue working toward longer-term systemic change (following Pieterse, 2008).

P2c. A process of consciousness-raising and learning for the group (and its members) occurs, both formally and informally, resulting ultimately in the understandings outlined above and the group's (implicit or explicit) decision to take an OCD approach to effect change in radical - albeit incremental - fashion.

\section{Individual scale}

$\mathrm{P} 3 \mathrm{a}$. The motivations to become involved in a social/environmental justice activist group at the outset loosely align with the presence of one or more factors suggested in non-urban social movement literature: a) a tangible metabolic need 
(e.g., for food, shelter, safety, etc.) that is ongoing or that previously went unmet; b) a desire for or initial experience of connection/community that comes with being part of a group; and/or c) a concern about social/environmental injustice that revolves around one particular social/environmental justice issue (following Rutland, 2013, citing Dubet, 1994, 2004).

P3b. A growing understanding of the complexity of the interrelated social/environmental justice issues at hand influences individuals to stay involved (i.e., attend more than two meetings/events); the process of learning is itself a factor that sustains individuals' engagements beyond initial participation.

\section{Relationship between individual and group scales}

P4a. The individuals who are part of grassroots collective action groups influence the group to take an OCD approach as they come to understand (through participation in the group's formal and informal educational opportunities) the unlikelihood of effecting systemic change through established channels in the postpolitical sustainable city.

P4b. Systemic change does not happen overnight. In the interim, individuals who are a part of OCD groups have immediate survival and livelihood needs they must meet (e.g., food, shelter, employment); OCD groups help attend to these needs, to varying degrees.

\section{Relationship between group and city scales}

P4c. OCD-oriented groups work in radically incremental fashion: through the act of ensuring that short-term needs of their group members are met while 
simultaneously working across scales and in solidarity with other like-minded groups, they seek to shift whose knowledge contributes to city-making, thereby re-coding city governance practices and procedures to result in a more equitable city in the long term.

\section{Data Collection}

These propositions informed my decision to collect and analyze data via the methods and procedures outlined here. In conducting this investigation, I combined elements of: ethnography; participant observation (including informal interviews); participatory action research; semi-structured interviews; and document and archival review.

\section{Ethnography, Participant Observation, Participatory Action Research}

From April 2014 through January 2017, I attended between four and ten face-toface PHCC-related functions almost every week, including nearly every public meeting and event organized through PHCC; hundreds of behind-the-scenes coalition planning meetings; several public Environmental Protection Agency, Port of Portland, and City of Portland meetings and events; a handful of Portland Harbor Community Advisory Group meetings; and other functions related to the harbor and more broadly social and environmental justice work in Portland. I also attended nearly every bi-monthly meeting organized by Right 2 Survive, one of PHCC's core member groups, from May 2014 through August 2016, and participated in bi-weekly meetings with Anti-Displacement PDX, a citywide coalition that PHCC joined, from January through September 2015. I 
also racked up approximately 3,000 relevant email threads during this time, and participated in over a thousand conversations via phone and text message. Finally, I worked on a number of smaller-scale implicit "participatory action research" projects with PHCC members, including the production of a short film called A People's View of the Portland Harbor (PHCC, 2015), creation of a Safe Camping Guide (see Appendix A), and development of a Testimony Guide for use during the Environmental Protection Agency's 2016 public comment period. Through all of these activities, I conducted over a hundred informal interviews with dozens of people connected to PHCC and the Superfund site cleanup planning process more generally.

At PHCC-related functions, I nearly always introduced myself as a PSU graduate student who was working with the coalition to document the coalition's undertakings. In non-PHCC organized events that pertained to the coalition's work, I identified myself as a representative of PHCC and/or Groundwork Portland, the organization that founded and stewarded PHCC through fall 2016.

For the first several months of attending PHCC meetings, I mainly listened. PHCC organizers also occasionally asked me to take on a discrete task, such as reading through a Health Impact Assessment conducted on behalf of the Duwamish River Cleanup Coalition and summarizing the fifty-plus-page document for PHCC members. As time went on, and as I became a familiar face within the coalition, I occasionally helped facilitate meetings, frequently took meeting notes that organizers then shared with coalition members, and eventually began working closely with organizers on behind-thescenes preparations, strategizing sessions, communications with public agencies, and 
more. In large part, my role evolved to engage in a "politics of resourcefulness" (Derickson and MacKinnon, 2015) because there were never enough hands available to complete all the necessary tasks. I strived to strike a balance between contributing as much as was needed, but never fully taking the reins on a given project or aspect of organizing. I prioritized frequent check-ins with other coalition leaders and members, and I frequently looked for opportunities to work alongside others so that we could learn from each other.

I filled eleven notebooks with field notes detailing these activities, generated over fifty Word documents containing meeting notes, and produced countless drafts of grant applications, letters, and other coalition-related communications. At meetings where other participants had paper and pens out and were taking notes, I also took notes. These tended to be very detailed, and often included direct quotations. At events where it would be conspicuous to have a pad of paper out, I occasionally write down words and phrases - "jottings" (Emerson and Fretz, 2011) - to help me recall key conversations or observations, and immediately after the event I wrote down as much as I could remember. Many of my notes were "observational" (ibid.) in nature (e.g., "the music began at 4:00 and so-and-so stated 'that was a successful event"'). I also inserted "asides" and "commentaries" (ibid.) with my own impressions, ongoing analysis, confusions, emotions, etc. which I marked with brackets (i.e., ["I wonder why John said that? Maybe he... This seems plausible because...’]). To process field notes, I re-read them monthly and engaged in "focused coding" (ibid.). I also periodically wrote "integrative memos" (ibid.) to conceptually link data to theoretical propositions. I engaged in this iterative 
reading, coding, and drafting process throughout fieldwork to make sense of what I witnessed, vis-à-vis the theoretical propositions laid out above. For example, I paid particular attention to coalition members' articulation of concerns and the evolving discussion of how to effectively articulate these to the EPA, the City of Portland, and other government agencies. I also paid particular attention to evidence of learning, and to the coalition's collective approach to community development/organizing and rationale for various decisions along the way.

\section{Interviews}

To supplement data collected via participant observation and informal interviews, I formally conducted semi-structured, 60 to 90-minute interviews with twenty-four people. All told, I interviewed people associated with seven PHCC member organizations (i.e., East European Coalition, GWPDX, Iraqi Society of Oregon, Líderes Verdes, Right 2 Survive/Right 2 Dream Too, Wiconi International), one supporting organization (i.e., Sierra Club of Oregon), one environmental justice group that prefigured PHCC (i.e., Environmental Justice Action Group); and three government agencies. I formally interviewed a handful of key PHCC leaders more than once. Most of these interviews took place in summer 2015, a few in summer 2016, and a few in winter 2017. I recruited most participants at monthly PHCC meetings, making it clear that participation was voluntary. For others, I emailed or called to invite them to participate. I met most participants for interviews at local coffee shops of their choosing, and provided most participants with a coffee or tea, a $\$ 25$ gift card to a local grocery store, and a TriMet Transit day pass. I recorded most interviews with a digital recorder, and paid a 
transcriber to translate most audio files to written Word documents. (See Appendix B for a list of interview participants and interview dates.)

Semi-structured interviews allowed me to ask about a coherent set of topics across all participants, but also to tailor each individual interview to the experience of the participant. Interviews with people who took on leadership roles within the coalition, and/or who were involved from the coalition's inception, focused on the following themes: origins and development of the coalition (i.e., who founded the coalition, under what circumstances, and with what objectives); key concerns of coalition members and member groups; who decided to join and why; main Portland Harbor-related challenges and undertakings to date; and future PHCC plans. I also asked questions about the coalition's approach vis-à-vis the established political processes of Superfund site cleanup and city land use decision-making, and followed up with questions about the process by which a particular decision or stance came about. For PHCC leaders, as well as PHCC members, I asked how and why they became involved in the coalition and how (if at all) they have been transformed by PHCC-related endeavors. Finally, I asked questions about the individual and collective learning they have engaged in as a member of the coalition. Most of the direct quotes in this dissertation come from these interviews, although some quotes come from meetings and other public forums in which I wrote down the exact words that someone said.

\section{Document, Archival Review}

From spring 2014 through winter 2017, I tracked and saved publicly available communications disseminated by the City and the EPA related to the Superfund cleanup. 
I also tracked correspondence between PHCC representatives and public agencies. An undergraduate research assistant also downloaded nearly all local media stories pertaining to the Superfund site from the mid-1990s through fall 2015, including stories in The Oregonian, The Skanner, Portland Mercury, Willamette Week, and Portland Business Journal, using "Superfund site" as her main search term.

Finally, to understand the origins of contemporary tensions related to the Portland Harbor and the conditions at the scale of the city, generally, and the Portland Harbor, specifically, that have given rise to PHCC's approach, I consulted primary and secondary sources about the Portland Harbor (e.g., Abbott, 1983; Hillegas-Elting, 2009; Lang, 2010), the Portland State University Library Special Collection archive (including the Ernie Bonner Papers and Oral History Collection), and local media archives. I also consulted the Willamette Speaks Oral History Project and a handful of oral histories from the Wake of Vanport Multimedia Project, which informed secondary source research with textured accounts from those living and working in the Portland Harbor vicinity throughout the twentieth century.

\section{Data Analysis}

I used MAXQDA software to manage the organization and coding of field notes and interview transcriptions. I first developed a set of codes that corresponded with my overarching research questions; I used one set of codes for data that was relevant to "city scale" analysis, another for "grassroots coalition scale" analysis, and a third for "individual scale" analysis. While there is substantial overlap between these scales and, 
as I mention above, important interactions occurring across scales, this approach nevertheless served as a useful starting point. Data analysis then proceeded in an ongoing, iterative fashion from spring through fall 2016. Following Emerson and Fretz (2011), I reviewed data sources, refined codes, wrote memos and drafts, talked with key PHCC participants and other researchers, and further refined codes and analysis.

I first read through all transcriptions and engaged in "open coding", which entailed highlighting words, phrases, and longer passages and assigning codes to these. Many of these codes emerged a priori based on my questions and propositions, while others emerged as I read transcriptions. I then re-read through all interview transcripts, refining, adding, and collapsing codes as I went. This stage enabled me to begin formulating arguments in relation to my research questions, and gave clues about where to look in my field notes for additional details.

I then returned to my field notes. Instead of reading through all twelve notebooks, I used my draft arguments, based on interview transcriptions, memos, and my own memories of events, to give clues about what kinds of evidence I would need to marshal in order to develop and refine my claims. This allowed me to consult particular passages from my field notes, based on the kinds of activities that were happening at a given time.

\section{Validity, Reliability, Positionality}

Participant observation, interviews, and document review helped produce a holistic picture of PHCC and the context in which the coalition works, increasing the 
validity and reliability of claims made in this investigation. Moreover, a wide variety of data sources allowed me to triangulate information. For example, I compared my own field notes with memories of interview participants, and I also compared the reports of interview participants with each other to search for commonalities and tensions. I have had numerous conversations with coalition leaders throughout the writing process, including discussions about my claims, framing, tone, and other editorial decisions. I have also solicited feedback on some chapter drafts from PHCC representatives, and will receive feedback on the entire dissertation prior to the defense from one or two PHCC leaders.

Beyond these mechanics, however, is the question of my own influence on the circumstances under investigation. Burawoy (2009:4) explains that because ethnographers produce theories, concepts, and facts that "destabilize the world" that social scientists seek to comprehend, a methodology keeping the research grounded is necessary. One way to address the ever-shifting world under study is to attempt to minimize the researcher's involvement in the field site. Impartiality, however, is nearly impossible in participant observation research. At the other extreme, interpretivist researchers attempt to address such challenges by avoiding generalization, placing everything (including the researcher) in the context of the specific case at hand. The extended case method takes a middle ground, enabling the "exploration of broad historical patterns and macrostructures without relinquishing either ethnography or science" (ibid.:6). This reflexive approach embraces engagement as opposed to detachment, and demands that context be incorporated into analysis and theorizing. 
An important part of the context in this investigation into the case of PHCC is my own participation with the group, in addition to my overlapping role as a researcher. As I detail in the introduction to this dissertation, I began participating in PHCC's monthly meetings in spring 2014 as an interested community member. I then attended nearly every meeting and event through September, 2016. The extent to which I am much closer to the "participant" as opposed to the "observer" end of the spectrum requires an extra layer of reflexivity around the way I may be influencing (or not influencing) PHCC's process. A central piece of this sensitivity is being aware of my own background, including my racial/ethnic identity and class position, and how these affect my own particular lens as well as the ways that others might perceive me.

My personal connection to the Portland Harbor begins with my white, Irish Catholic (maternal) great-grandfather, Paul Nester. Paul was born in 1900, right off of Mississippi Avenue, adjacent to the present-day Swan Island industrial area of the Portland Harbor. His family migrated to Portland from Ohio via the Oregon Trail in the early 1800 s. As a boy, he wandered the streets of Albina in the days before the city segregated African-American residents to the area, and he canoed and fished the Mock's Bottom swamplands in the days before the military sent warships to the Willamette's docks. Paul learned to write stories in a class at the Beaverton Library when he was in his eighties. He recollects Portland Harbor adventures from his childhood in a memoir, First Half of My Life (1983:12):

Guy [Paul's cousin] and I went through Overlook, entered the woods and followed the trail down the canyon. We passed the shacks of the hobo 
jungle and crossed the railroad tracks. To get across the slough at the south end of Mock's Bottom, there was a narrow walkway on pilings, which led across to Sandy Bottom. Here was a beautiful beach - a regular paradise of the river just north of the Portland Flour Mill. The kids from Lower Albina took the route across the railroad yards then through the Flour Mill property ... Catfish and carp were plentiful. All one needed was a hook, line, and a bit of bait. If you were lucky, you'd have enough catfish for a fish-fry on the beach. What could be better after a good swim?

Like my great-grandfather, I grew up playing in the waterways of Portland. I remember throwing rocks at frogs peeking their eyes up through green algae, particularly in the Columbia Slough (a tributary of the Willamette) behind the Portland Airport, on warm summer afternoons. The Slough cut through the land loaned to my (paternal) grandfather by the owners of the golf course where he worked for over fifty years, and where we grew a garden every summer. We grew so many tasty fruits and vegetables, produce that has put the Willamette Valley on the agricultural map. I remember spreading blackberry jam on toast, gobbling up spaghetti made with homemade tomato sauce, and stealing hunks of ripe, bright, maroon-colored fruit while my grandma made plum cake as a child. My father and grandfather used water from the Columbia Slough to grow our produce. While I have not developed any health concerns linked to this sustenance, it is very possible that the illnesses that have taken the lives of others in my family can at least in 
part be traced to this garden. Admittedly, I never thought about this personal connection until after participating in PHCC's activities for several months.

Through my involvement with the coalition, I have heard both joyful and painful histories linked to the harbor. As I recount in this dissertation, in addition to hearing happy memories of families playing and fishing in the Willamette, I have borne witness to stories of stripped ancestral fishing grounds; asthma and other health problems caused by exposure to industrial emissions; segregation to the nearby Albina area, only to have entire blocks bulldozed for the Memorial Coliseum, Emmanuel Hospital, and yoga studios; makeshift riverfront shelters torn down by the Port of Portland police; children subsisting on fish with PCB levels 100 times what is deemed safe. My uncle (Paul's grandson) worked in the port for years. He has shared in great detail stories of friends going through treatments for a host of cancers and other ailments, likely due to stripping lead paint off of boats and exposure to other toxic substances in the river over the years.

The tellers of these tales are overwhelmingly working-class, disproportionately people of color. Race, ethnicity, and class (as well as gender) are too often predictors of one's life chances in our society. While my own body has not been directly impacted by contamination in the Portland Harbor, I have seen its harsh impacts on many others via participation in PHCC and communication with extended family members. I have also witnessed the commitments made by PHCC leaders and members to redressing past and present injustices, and my involvement with PHCC (including aspects of this dissertation research) entails contributing my own head, hands, and heart to the coalition and its mission. 
Growing up, I came to understand what it is like to not quite know how one paycheck will stretch to the next. This experience fueled my initial involvement in social and environmental justice work in my early twenties. Yet, my family did not have our land taken from beneath our feet, and we have not been excluded from traditional wealthbuilding institutions on the basis of our (white) skin. I do not know personally what it is like to sleep on the banks of a river for any reason other than pure adventure and fresh air. Through this research, I have therefore kept the extent to which my family has benefited from the exploitative systems that have oppressed so many others in the front of my mind. This entails working hard to listen to those who have suffered from injustices, and following their lead, as opposed to the other way around. I have also maintained an awareness that others may perceive me as being part of the oppressive systems they seek to dismantle - especially as someone affiliated with a university.

Whereas my sister joined the army to pay for college, I was lucky to receive a scholarship to attend a private high school for three years, another to attend college, another to become a teacher, and yet another to attend graduate school as an (activist)scholar-in-training. Through much of this, I have been involved in social and environmental justice activism. As Lafazani (2012:191) describes, in some ways I am therefore possibly "too political for the academy and probably, at the same time, too academic for politics." While the necessity of living a "life of reflection" when one occupies these two worlds cannot be overstated - including through every step of a research project (Pulido, 2008) - active involvement in actual struggles forces activistscholars not only to think much harder about the contradictions and conflicts involved in 
social change, but, crucially, how to overcome them. Lived experience in this regard can help scholars avoid two common pitfalls of academia: "romanticization of the agents," and never moving beyond critique to provide useful "ways out" (Lafazani, 2012:192). Lafazani explains, "Being involved in such struggles is the only way to understand the deeper relations, the dynamics of the different groups, the real people involved and how they themselves understand their position and action" (ibid.).

To conduct the style of engaged scholarship that has culminated in this dissertation, I draw inspiration from Flyvbjerg's phronetic social science approach. Building on Aristotle's concept of phronesis ("practical wisdom"), Flyvbjerg (2001:162) outlines a type of social science rooted in a commitment to reflexive involvement in rather than passive (ostensibly objective) research of - a given social phenomenon or process. Four questions guide phronetic social science-style research: Where are we going? Who gains, who loses, and by what mechanisms? Is this desirable? What should be done? And, drawing on Pieterse (2008:5), I add an important fifth question: In what ways are the "dynamic, capillary and decentered nature of circuits of power...unstable and vulnerable to resistance and transformation"? While this study does not directly map to these five questions, they implicitly guide this research project. They provide touchstones for an investigation that does not merely seek to produce knowledge that challenges power in theory, but rather one that has the potential to steer "real efforts to produce change" (Flyvbjerg, Landman, and Schram, 2012:20), collectively, with PHCC. 


\section{A Note on Terminology}

It is important to briefly mention that, throughout this dissertation, I use several terms in relation to the people associated with PHCC. When mentioning "leaders" working on behalf of the coalition, I am referring to individuals who are working in a given moment to organize behind the scenes and keep the coalition going. A few people are nearly always operating in a leadership position throughout the course of this investigation. Others come and go, depending on the task at hand and their own life circumstances at the time. I am also often, though not always, working in a leadership position, given the regularity with which I helped facilitate meetings, apply for funding, communicate with members, and talk through strategic decisions. When mentioning "members", I loosely refer to those who attend PHCC meetings and events with any frequency, or who are in touch with leaders from afar on a regular or occasional basis in order to weigh in on decisions (a few people live too far away to regularly travel to meetings). Most, but not all, members are associated with one of PHCC's core member organizations. Many members take on leadership roles frequently or from time to time.

On occasion, I use the terms "participants", "attendees", and "supporters" to denote categories that are even more relaxed than the previous two. I tend to use the terms participants and attendees to refer to multiple people at once, some of whom are PHCC members and some of whom may or may not be members of impacted communities, but who are involved in a particular PHCC-led activity (and who do not work for a government agency or are affiliated with a PRP). Supporters refers to people who show up to PHCC events in a supportive way, but who are not affiliated with an 
impacted community; these people include members of local environmental organizations and the EPA-designated Community Advisory Group, as well as a handful of lawyers and other "experts" who weigh in when PHCC leaders solicit their input.

Finally, on occasion I use the term "the coalition" or "PHCC" as though the entire group of people is acting as one. I try to employ this tactic only sparingly in order to avoid speaking about the coalition as an actor. These terms make sense on some occasions, however, such as during the EPA's public comment period when several dozen PHCC members and supporters signed on to and submitted "the coalition's" letter. While the slipperiness of these terms poses some analytical challenges, more than anything, they are a reflection of PHCC's relatively loose structure and the permeability of the coalition itself. 


\section{4. 'Little Bugs in the Mud': ORigins and Rise of the Portland Harbor Community Coalition}

"Don't think of them as chemicals; think of them as little bugs in the mud.",12

In late 2011 and early 2012, representatives of companies likely on the hook to pay for cleanup of the Portland Harbor Superfund Site hosted a series of events for communities of color to learn about the cleanup. But the information presented was misleading. One presentation in particular led the mostly Latino audience to believe that toxic substances, such as PCBs, heavy metals, and perchlorate - the main ingredient in rocket fuel - had become harmlessly integrated into the ecosystem, akin to the benthic organisms living in the river's sediment. A few key figures in Portland's grassroots activism community decided to launch an outreach campaign of their own, to counter this narrative and ensure that communities with roots in the harbor had a say in the planning process. Representatives from a dozen grassroots groups ultimately came together to form the Portland Harbor Community Coalition (PHCC), adopting what would become an implicitly oppositional community development approach to organizing in an effort to ensure that communities of color and lower-income Portlanders would influence and

\footnotetext{
12 Jeri Jiménez recalls this quote from a presentation to Portland's Latino community by contractors working for the Portland Harbor Partnership, a group of potentially responsible parties to the Portland Harbor Superfund Site, in early 2012.
} 
benefit from the cleanup. This chapter addresses my second overarching research question: How do grassroots groups mobilize to ensure that underrepresented groups have a say in the shaping of green cities, and that they partake in benefits (e.g., jobs, affordable housing, green space, etc.) emerging from urban sustainability initiatives?

I first give a chronological account of the origins and early years of PHCC, answering a suite of empirical questions: how and why did PHCC originate? Who joined PHCC, and why? Then, in the third and final section, I draw on these empirics to argue that PHCC is a grassroots group fighting for social and environmental justice - and that an uncompromised cleanup of the Portland Harbor is central part of the coalition's vision. Articulating overarching concerns about past and ongoing displacement of the coalition's constituents, the health of subsistence fishers and their families, and ecological integrity, PHCC members rarely categorize their concerns along the kinds of binary lines that permeate mainstream sustainability discourse; for $\mathrm{PHCC}$, social and environmental justice and conservation issues are inextricably linked. The case of PHCC therefore reveals a different orientation than groups taking a "just green enough" approach (Curran and Hamilton, 2012).

\section{Polluter Pays...for Outreach: Antecedents to PHCC}

Leaders of the groups that would become PHCC's core membership base first convened in early 2012. To understand why they came together, however, it is first necessary to look back to 2000, when the Environmental Protection Agency (EPA) initially designated the Portland Harbor as a Superfund site and assembled the Portland 
Harbor Community Advisory Group (PHCAG). This early history foreshadows the tokenizing treatment that impacted communities would experience time and again over the next decade and a half as they engaged with public agencies.

\section{Polluters at the table, "running everything"}

Prior to joining the City of Portland's Office of Neighborhood Involvement as a program coordinator in 2006, Jeri Jiménez had become familiar with the complexity of the cleanup planning process from her earlier work with the Workers' Organizing Committee and then as director of the Environmental Justice Action Group (EJAG). Jeri understood the environmental justice implications of the cleanup, and worried that those who were affected by pollution were not being given adequate attention:

[In the late 1990s], I was approached by the State and the County at times going, "Can you help us get this word out to these people who don't speak English? Because we're putting fish advisories out." ... The state paid to have fish advisories put out, but none of them are saying anything about the effects. They're not saying, "Oh, as a pregnant woman you should only have one ounce a month." They're not saying any of this. They're just saying, "We're saying it in Spanish, in English, in Russian, and Chinese; help us put those out." And we're saying, "Well, what is the effect?" [We saw] a report that showed ... [one in] a thousand recreational fishers would contract cancer, but [one in] a hundred native fishers - because they were subsistence fishers - would contract cancer from the fish. 
For Jeri and other local environmental justice leaders, it was clear that people with lower incomes and people of color - particularly Native people and others relying on fish in the Portland Harbor for subsistence - were at much greater risk of getting sick from pollution than the general population. This was an overt environmental justice issue. They agreed to help public agencies get the word out about the fish advisories. Jeri and other EJAG representatives, however, remained concerned about health impacts. Drawing comparisons to the air pollution campaign they were also running against Oregon Steel Mill (now Evraz) at the time, EJAG leaders asked what good advisories did if people still breathed contaminated air because of where they lived or worked ${ }^{13}$ Similarly, what good were warning signs if people continued to eat contaminated fish for subsistence and cultural reasons? Physiological damage would be - and had already been - done, regardless of fish advisories posted in multiple languages along the riverbanks. They felt strongly that something more needed to be done about the environmental risks associated with pollution in the Portland Harbor.

State and County staff were not the only public agency representatives contacting Jeri and EJAG in the mid-2000s. Familiar with the grassroots group's work on community-led brownfield cleanups with the City of Portland, the Environmental

\footnotetext{
${ }^{13}$ In 2001, EJAG joined a lawsuit led by the United Steelworkers of America against Oregon Steel Mills (now part of Evraz, a Russian-owned Portland Harbor PRP) (Strom, 2003). EJAG was concerned about work conditions at Oregon Steel, as well as air pollution emitted by the company's steel smelting operations that impacted communities of color (especially Black residents) living in North Portland. In 2003, Oregon Steel settled the lawsuit by agreeing to pay for air quality monitoring - a win for EJAG, according to Jeri.
} 
Protection Agency (EPA) also came knocking. Jeri recalls federal officials' request for assistance: “We [know you] already know how to build great community advisory groups, so help us'." Specifically, the EPA asked EJAG to help build the Portland Harbor Community Advisory Group (PHCAG). According to the EPA, Superfund Community Advisory Groups (CAGs) entail community members coming together "to serve as the focal point for the exchange of information among the local community," as well as "the EPA, state regulatory agencies, and other relevant agencies involved in cleanup of the Superfund site" (EPA, 2017c). Such groups, in the EPA's eyes, deliver a crucial public service: they provide "a public forum for community members to present and discuss their needs and concerns related to the Superfund decision-making process. A CAG can assist EPA in making better decisions on how to clean up a site. It offers EPA a unique opportunity to hear - and seriously consider - community preferences for site cleanup and remediation" (ibid.).

At first, EJAG leaders appreciated the opportunity to weigh in on the cleanup. They quickly realized, however, that the reality of the CAG did not align with the EPA's stated intentions for the group. "We went to help them - but they didn't really listen," Jeri remembers in a 2016 interview, recollecting how the CAG's convening felt more like an official checkmark on a public participation worksheet than a process that truly would allow for community members to inform the Superfund decision-making process. She continues:

We sat on the advisory group, maybe two years, and our member - who was an African-American man named Billy Washington - he used to 
play for the Oakland Raiders, and he had played [music] with Parliament for a while. He had also cleaned up messes in Kuwait - environmental messes in Kuwait. He knew, he had the expertise. And after about two years he was saying, "They've [the CAG] gone in a different direction, this is not good for the community ... This isn't going to benefit us, so [let's] get out of it."

One of the chief issues for EJAG leaders was that representatives from potentially responsible parties - "PRPs" in EPA terminology and "polluters" in EJAG parlance were also members of the CAG. "Business was at the table," Jeri flatly stated. "The polluters were at the table, and they were running everything." Based on EJAG's experience fighting Evraz/Oregon Steel, community leaders found it unreasonable to expect that impacted communities would be able to participate in the $\mathrm{CAG}$, alongside PRPs, and substantially influence the cleanup of contaminated soil and sediment.

Frustrated by the EPA's presumption that industry and impacted communities could productively work together under the CAG model, and realizing that EJAG's energy would be better spent engaging its base rather than spending hours every week at CAG meetings, EJAG leaders withdrew from participating in the EPA's officiallyrecognized advisory body. Instead, in the mid-2000s, EJAG continued its focus on air pollution. At that time, there was discussion of adding four lanes to the I-5 freeway, which cut through Portland's historically Black Albina neighborhood. Although Albina had by this point already lost many of its African-American residents to gentrification (Gibson, 2007), Jeri recognized the immediate connection between expansion of the 
interstate freeway and EJAG's constituents' lives, and the work the group was already doing on air toxins: "This is our campaign, the I-5 freeway, and not expanding it, for all of these different reasons," she said. EJAG clearly had its hands full as it was, without participating in the CAG.

In the years between EJAG's exit from the CAG and the nascent days of PHCC, EJAG wrapped up its air pollution campaign, and leaders scattered to begin new nonprofits and take on other projects. Dorceta Taylor, for one, began "writing these gigantic books about environmental justice," explains Jeri. ${ }^{14}$ Others stayed closer to home. Jo Ann Hardesty is now the president of the Portland branch of the National Association for the Advancement of Colored People. Several people initiated a local chapter of Protocol for Assessing Community Excellence in Environmental Health, a coalition of government agencies, nonprofit groups, and community organizations focused on building a campaign around various environmental issues with human health impacts. Eventually, Jon Ostar, who had worked with EJAG as an intern attorney under Jeri, started OPAL, an organization focusing on transit justice and other EJ issues. Kevin Odell also left EJAG to help start OPAL, and eventually founded a Portland branch of Groundwork USA. Groundwork Portland (GWPDX) came to focus on environmental workforce development and leadership development for young people of color who were experiencing poverty, as well as advocacy around environmental justice issues more

\footnotetext{
${ }^{14}$ Taylor wrote two landmark books about environmental justice, Toxic Communities: Environmental Racism, Industrial Pollution, and Residential Mobility (2014) and The Environment and the People in American Cities, 1600s-1900s: Disorder, Inequality, and Social Change (2009).
} 
broadly. Much of GWPDX's early work revolved around community-led redevelopment of neighborhood brownfield sites, such as defunct gas stations and other pieces of land that are contaminated with hazardous substances.

Although EJAG had disbanded, Jeri remained deeply committed to grassroots organizing around environmental justice issues. In 2009, when GWPDX's program director position opened, she encouraged someone she knew from the City, Cassie Cohen, to apply, unknowingly laying the first concrete steps for PHCC to take shape. Jeri recalls encouraging Cassie to submit her resume for the position that would eventually transition into GWPDX's executive director: "I knew Cassie from the City, and then I knew [her] from the Center for Intercultural Organizing board, and she was looking for work, and I sent her the Groundwork job announcement." At first, Cassie was reluctant to apply, arguing that her background was in social work rather than environmental justiceoriented community organizing, and that as a white woman she might not be the best person to lead a primarily community of color-serving organization. Jeri was adamant, insisting that Cassie was more than capable of carrying on EJAG's legacy of bringing marginalized groups together around environmental justice issues: "I'm like, 'but you know how to organize because you organized all these people'." Jeri was referencing Cassie's work with the City as an intern from 2005-2007 and then as an employee from 2007-2009. Cassie worked on the visionPDX and Vision Into Action campaigns, both part of the City of Portland's pre-Comprehensive Plan community visioning process. Jeri told Cassie, “'If you apply, I'll support you."” Cassie got the job, and she and Jeri met 
periodically for Cassie's whole tenure at GWPDX, from November 2009 through March 2015.

In the interim: "They're trying to bamboozle us"

While Portland's environmental justice leaders worked on air, transit, and smallscale contaminated properties in low-income neighborhoods, Superfund cleanup planning moved forward with little to no input from members of impacted communities. Starting in late 2011, however, PRPs began doing their own direct outreach to those most likely to suffer the ill effects of harbor pollution. At this point, Jeri became less concerned that members of vulnerable groups were being excluded from the cleanup planning process, as she had been in the early days of the CAG. Instead, a phone call in winter 2012 from a representative of a local Latino-serving non-profit left her much more concerned that impacted communities were actually being paid off to adopt the perspectives of the polluters. The caller described outreach to communities of color that the Portland Harbor Partnership (PHP) - a group of PRPs - was conducting. Jeri recalls the conversation: "He said, 'Can you come watch this presentation, because I think they are trying to bamboozle us."

The PHP consisted of nine core PRPs: the Port of Portland, the Oregon Department of State Lands, Calbag Metals, Evraz Portland, Gunderson LLC, NW Natural, Schnitzer Steel, Vigor Industrial, and Portland General Electric. These PRPs worked with the Metropolitan Group. According to their website, the firm is a "fullservice strategic and creative agency" that "directly impact[s] social change" and "build[s] the power of voice and capacity of the people, organizations, and communities 
that drive social change" (Metropolitan Group, 2016). These nine PRPs also worked with the National Policy Consensus Center, a program of Portland State University's (PSU) Hatfield School of Government. Together, these entities designed and carried out a public engagement campaign around the Superfund site cleanup from August 2011 to March 2012 (Rome and Bell, 2012). The PHP aimed to "raise awareness about the importance of the EPA-led process and to encourage involvement by all parts of the community in the upcoming decisions" (ibid.) via public events, meetings, and other outreach avenues. According to the Metropolitan Group, the PHP implemented a "groundbreaking new public education and engagement effort" around the Portland Harbor Superfund site cleanup.

A final report prepared by master's degree students attending PSU's Hatfield School described the PHP's outreach campaign as multifaceted and extensive. It included a survey and focus groups, public events and community meetings, and development of social media and web-based tools (Rome and Bell, 2012:5). The survey garnered 1,870 responses, and the focus groups included 72 participants. Over 1,500 people attended meetings from fifty-four community, business, and other groups, including fourteen neighborhood associations, and over 25,000 "direct impressions" collected from tabling and other signage at various events. The campaign also included an "On the Waterfront" educational series, featuring lectures by local historians and other experts, developed with the support of the Oregon Historical Society, PSU, Oregon State University, the PHCAG, Freshwater Trust, and Willamette Partnership. More than 650 people attended the lectures. Finally, the survey campaign included a component called a "Charity 
Challenge"; upon completion of the PHP's survey, survey-takers were invited to vote for one of four organizations - Oregon Food Bank, Friends of Trees, Oregon Historical Society, or Freshwater Trust - that would receive a $\$ 10,000$ donation from the PHP (Rome and Bell, 2012:8 and Appendix E).

The Metropolitan Group website highlights outreach to communities of color and immigrant/refugee groups as a core part of the PHP's campaign: "A special emphasis has been placed on engaging a wide array of ethnic and cultural community groups through established community organizations" (Metropolitan Group, 2016). By working with three local, well-established community-based organizations - Immigrant Refugee Community Organization, Latino Network, and Urban League - to "tailor culturally appropriate engagement plans to the specific constituencies" (Rome and Bell, 2012:5), the PHP aimed to demonstrate a commitment to impacted communities' priorities. Activities with these groups included focus groups, presentations, information booths at cultural events, surveys, and translation of feedback into English. Outreach resulted in input from over 500 community members connected to these three groups.

According to Rome and Bell's (2012:1) final report, four overarching themes emerged from the surveys and focus groups conducted with communities of color and the general population:

1) Concern over river contamination coupled with an appeal to clean the Willamette River quickly; 2) A request for more community parks and other forms of public access (e.g., fishing and boating docks, trails for hiking and biking, and community centers); 3) Restoration and 
preservation of wildlife and the natural environment; and 4) Responsible economic development.

The report summarizes one key takeaway from the nine-month outreach campaign: "It is clear from the data that residents of the Portland Metro Region would like a more publicly engaged, responsive, and effective cleanup process to begin" (ibid.). But what was to follow was, from environmental justice leaders' perspectives, anything but that.

As soon as Jeri got wind of the nature of the PHP's presentations, she decided to attend a presentation to see for herself what was going on. She describes her first impression:

"Oh my gosh, yes this is so bad"... For more than 30 years, the governments - meaning state and county - are putting these fish advisories on, not in languages that the people who were eating the fish [spoke]. And that was a really clear picture, and so then when this [PHP representative] comes and does a presentation, he's like, "Pregnant women can eat one ounce of fish a month." And so [audience members] are like, "What, are they supposed to eat the rest of the month?" So that scared him, but he didn't educate the Spanish speakers. He's talking about fish, and they're thinking about the fish you buy in a store. Not fish you take out of the river!

In addition to misleading audience members, Jeri remembers that the presentation - to mostly Spanish speakers - was entirely in English, and that it obscured who would be implicated in paying for the cleanup. "He [the presenter] was speaking to Latino people, 
[but] he wasn't speaking in Spanish," Jeri recalls. "He's dumbed down his presentation, with the end of it saying, 'Well, you're the taxpayers. It's going to fall on you, so whether we spend a million or a hundred million, it's going to fall on you, so it's your decision.' And I'm like, 'Oh my God!'” Jeri understood that City of Portland ratepayers would likely be on the hook for some of the cleanup costs, given that the City was a PRP, but she also knew that the full tab would be shared amongst dozens of entities. Jeri emphasized, "It was a really stupid presentation. It was so dumbed down. It was so dumbed down." For Jeri, the presentation was nothing but a scare tactic to get environmental justice communities to advocate for a less-costly cleanup.

Little did Jeri and others know, however, the ratepayer theme would emerge down the line again as a quiet but powerful fulcrum around which the cleanup planning process would pivot. When PHP representatives mentioned "ratepayers", they were not just talking about ordinary residents who paid sewage and water bills for their homes. They were also talking about corporate ratepayers - many of them PRPs - that paid one of the highest rates in the US for incoming clean water and outgoing discharge. In fact, at the time, the Portland Water Users Coalition was embroiled in a lawsuit against the City and BES, filed on behalf of utility ratepayers for the illegal expenditure of ratepayer revenue. The PWUC included several PRPs, including Siltronic Corporation, Vigor International, and Harsch Investment. Kent Craford, a lobbyist behind the lawsuit, explained in a 2014 interview with the Oregonian that he is simply "speaking up for both residential and big industrial users. Water and sewer rates ... affect everyone" (Theen, 2014). I return to the implications of the ratepayer lawsuits in Chapter 7. 
A call for new grassroots involvement: "It just seemed like there were a lot of voices that were not at the table"

Although outreach to communities of color and immigrant/refugee groups was a source of pride for the PHP, Jeri and others expressed extreme skepticism about the process. For Jeri, the last straw came when one of the PHP's presenters advised a majority Spanish-speaking audience, many of whom likely consumed resident fish from the Portland Harbor on a regular basis, to essentially imagine away any possibility of bodily harm coming from the toxic sludge at the bottom of the river. "'Don't think of them as chemicals," Jeri recalls the presenter suggesting of the deadly toxins subsumed in the sediment that qualified the Portland Harbor for federal Superfund listing. Rather, he suggested the audience think of these toxins as "little bugs in the mud." Jeri could not believe what she was hearing. "My biggest concern was, they're out there, flimflamming communities of color, and [the PRPs] spent a whole bunch of money to create a lie that [they] think will work." She immediately called Cassie at GWPDX.

With a home base in Albina, Portland's historic African American neighborhood, and given that that Cassie had developed relationships in years past with several grassroots community of color-representing groups, Jeri felt that GWPDX was uniquely positioned to convene impacted community groups around the Superfund Site cleanup. And unlike other social and environmental justice-focused organizations in Portland, GWPDX concentrated on community-controlled remediation and reuse of brownfield sites. One of GWPDX's early projects, in 2010, for example, entailed facilitating the transformation of a lead-filled residential lot into a community garden. An Albina neighborhood house had burned to the ground. Dangerous lead paint residue 
remained in the soil where the structure once stood. GWPDX worked with Oregon Sustainable Agriculture Land Trust (OSALT), an organization that "holds farmland and urban gardens for the purposes of research and education on sustainable agriculture," to navigate land acquisition and cleanup permits (OSALT, 2016). GWPDX then led a community redevelopment planning process, and worked with African American youth and elders to build and maintain the Emerson Street Garden on the site. When Jeri called, Cassie made the connection to the Superfund cleanup: "We [Groundwork] did brownfields work, and Superfund cleanup is kind of similar, kind of related," Cassie explains. In particular, GWPDX was familiar with the paradoxes involved with environmental remediation in gentrifying neighborhoods. Given the swiftness with which the development of green amenities (like community gardens) was contributing to rising rents in inner Portland and cities across the US, Cassie knew that, without specific provisions to mitigate displacement, such as community-controlled development, community benefit agreements, and permanently affordable housing, communities of color and lower-income households of all races and ethnicities were at risk of being forced out of their neighborhoods (Gibson, 2007; Goodling and Herrington, 2014). Jeri and Cassie both predicted that the Superfund Site cleanup, likewise, would require a substantial fight in order to ensure that impacted communities would have a say in shaping the harbor's next chapter. It would also take a monumental effort to ensure that those who have suffered from contamination over the last several decades, and who continue to suffer today, are prioritized for cleanup jobs, and that they are not further 
priced out of inner-core neighborhoods as land values and rents rose following remediation and redevelopment.

Cassie recalls the catalyst that inspired her to call other community leaders, alerting them to the toxins that lingered in the Portland Harbor: "Really, it was just two people, two environmental justice oriented people that came to me saying they were concerned." Jeri was one of those people. The other, a federal level employee, was similarly concerned that people affected by harbor pollution were being excluded from the cleanup decision-making process: "It just seemed like there were a lot of voices that were not at the table. Because it's such a long drawn out legal process, it's so hard for a community member ... it's really hard to figure out how to have meaningful involvement." Cassie recalls her first impression after speaking with these two key government employees - "inside activists" (Olsson and Hysing, 2012) - in the spring of 2012: "The PHP was reaching out to community of color groups, and they were paying them," Cassie recalls. "It seemed like a public relation campaign that the PRPs were facilitating." Like Jeri and the federal staff member she spoke with, Cassie was particularly concerned that, since the PRPs were the ones framing the issues during the focus groups, members of impacted communities were being exposed to only one perspective: that of the polluters, whose primary interest lay in keeping cleanup costs as low as possible. Recognizing a clear need for grassroots groups to insert themselves into the cleanup process on their own terms, separate from the PHCAG (given Jeri and EJAG's experience several years prior), Cassie began alerting representatives from other community organizations. Representatives from a wide variety of groups began to 
convene to discuss what a coalition of underrepresented communities might look like, including representatives from larger Portland-area social service agencies and Tribes, as well as smaller grassroots organizations.

\section{A Coalition Takes Shape}

The first meetings: "We had a full room"

While the PHP outreach campaign was wrapping up in early 2012, PHCC was just getting started. Cassie, Jeri, and a dozen community and Tribal leaders gathered at a coffee shop in the back of the former Talking Drum Bookstore, located in the heart of Albina, just a short walk from GWPDX's Emerson Street Garden. A few of those in attendance at the initial meeting were affiliated with larger non-profits, a few represented local Tribes, and the majority came from small grassroots groups. Jeri describes the crowd: "We had a full room," she said, recalling that leaders from African-American, Latino, Native, and Eastern European communities attended.

It was in this meeting that a clear picture of the PHP outreach process began to unfold, and attendees started to understand what was at stake for environmental justice communities in the cleanup of Portland's beloved waterway and riverfront land. While the polluter-led outreach campaign's official report portrayed the PHP as operating with the best interests of "the public" in mind, analysis at Talking Drum painted a different picture: "The general sentiment about those focus groups was kind of shock at how bad the contamination was - people didn't realize [the extent of] it. And concern, and that they wanted to do something about it, and that they didn't trust the PRPs to keep 
facilitating these outreach and engagement plans," explains one participant. Another expresses a similar critique: "[The outreach campaign] seemed like this huge wave of greenwashing that didn't have any community voice in it, that was really just being paid for and well-marketed and advertised by folks whose voices were already really wellrepresented in the whole process." Those in attendance at that first meeting started thinking about mounting a community-led outreach campaign of their own. "[Discussion] was sort of like, 'What do we do? What's being done?' - an assessment of the situation," recalls one attendee.

While the majority of those assembled expressed criticism of the PHP's outreach campaign, there was some disagreement amongst meeting participants about the implications. "Some people were like, this seems like a buy-off. What's happening here? And then others were like 'No this is great. We need to be involved in this one way or another," remembers one person. Urban League leaders, in particular, voiced approval for the PHP's campaign, citing the PHP's outreach as just the first step in what promised to be a valuable opportunity for Portland's African-American community to be engaged in a high profile environmental issue. The Urban League ultimately declined continued participation in the group that would become PHCC.

From Jeri's perspective, however, there was more to the story. "Oh, [Urban League leaders] had to say that," Jeri explains, "to save face." As reported in local media at the time, the PHP had paid $\$ 20,000$ to the Urban League, $\$ 10,000$ to Latino Network, and $\$ 12,500$ to IRCO for participating in the outreach (Mesh, 2012). Yet, rather than focus criticism on the PRP's misleading presentations, the media condemned community- 
based organizations for taking money from polluters. The Willamette Week quoted Jeri, airing her critique of the three community groups that accepted payment, as well: "I was shocked to hear that the groups I work with were taking money from these people...That was alarming, to think that somebody's spending a lot of money so they don't have to spend a lot of money" (quoted in Mesh, 2012). Jeri explained that Urban League's employment program leaders were upset that she had called them out publicly. Jeri reflects on the controversy: “They weren't our community engagement people [at Urban League]. They took the money because they were a jobs program and then [they] got called out ... I'm like, 'Whatever, you did the wrong thing!'...People were pissed at me, and I'm like, 'Get over it, you shouldn't have taken money from them."' While Jeri was disappointed in the community groups' decisions to accept payment from PRPs, she is clear that her main ire was reserved for the PRPs themselves. "But of course, for the Willamette Week, that's the part they want to play on," she laments.

While more critical of the PHP than Urban League representatives were, leaders from Latino Network, IRCO, and a few other larger organizations serving communities of color were also resistant to joining the coalition in its early days. One organization's executive director told Cassie that the harbor cleanup just was not a high priority compared with other urgent matters. Cassie remembers him saying, “I think it's great what you're doing, but we have too much else going on. Definitely, when the time comes, we can put our name down as endorsing." Cassie surmises that lack of resources, identity politics, and personality conflicts with others involved may have influenced some 
organizations to pass. She summarizes her conversation with leaders of the handful of groups declining participation in PHCC:

"Your organization's constituents are the ones most affected by the polluted fish, and it sounds like when you had the focus group that people were concerned and interested and wanted to be involved or to know more about it. And do you have plans to follow up with those folks? Or can we help?" For whatever reason - maybe I just didn’t press hard enough, or - it just didn't happen.

Jeri offers another perspective: "Because most of those organizations have a list of what they're supposed to do, what they get funded for ... if there's anything that's not what they get funded for, then they don't participate. That's pretty common ... Most of those groups [that declined participation] ... were social service agencies, not social justice agencies. They're paid to provide services, not to cure the system.”

In April and May 2012, Cassie also reached out to several Tribal representatives, including all those involved with the Portland Harbor Natural Resource Trustee Council. ${ }^{15}$ The Tribes, too, declined participation with PHCC by and large. One leader

\footnotetext{
${ }^{15}$ Formed in 2002, the Portland Harbor Natural Resource Trustee Council is an entity responsible for assessing and restoring public natural resources - birds, water, fish, wildlife - in the Portland Harbor Superfund Site. CERCLA empowers Trustees to "obtain compensation for harm to trust resources and to plan and carry out actions to restore injured resources through a process called natural resource damage assessment". Eight Trustees currently sit on the Trustee Council: National Oceanic and Atmospheric Administration (acting on behalf of the US Department of Commerce), US Fish and Wildlife Service (acting on behalf of US Department of the Interior), Oregon Department
} 
from the Umatilla Tribal Council attended an early meeting. Cassie remembers his assessment: “'We don't know what our role on the coalition would be, but keep us on the email list." The Grand Ronde Tribal Council, which had recently begun to be more assertive around decisions about ceded lands in the Portland Basin, also decided not to join the coalition. Cassie explains the Tribe's decision to pass on participation: "It did not make sense for a Nation to join the coalition," she said. The Grand Ronde Tribe did, however, agree to support PHCC through its Spirit Mountain Casino Community Fund, and awarded crucial funds to PHCC early on.

The making (and re-making) of political subjects: "Of course water's important to us"

Although the Tribal Councils and some larger community of color-serving organizations passed on participation, several smaller grassroots groups representing urban Native people, African Americans, immigrants and refugees, houseless people, and working-class Portlanders of various races and ethnicities wholeheartedly signed up. Jeri offers a summary: "What was interesting was, leaders from those communities [of color] came. The [larger] organization staff didn't come, but leaders - Native Americans came, Latinos came, African Americans came - leaders, the people on the ground, came.”

of Fish and Wildlife (acting on behalf of the State of Oregon), Confederated Tribes of the Grand Ronde Community of Oregon, Confederated Tribes of Siletz Indians, Confederated Tribes of the Umatilla Indian Reservation, Confederated Tribes of the Warm Springs Reservation of Oregon, and the Nez Perce Tribe. The Trustee Council's legal authority for natural resource damage assessment activities in the Portland Harbor derives from "a wide variety of federal and state statutes and regulations, tribal treaties, agreements and regulations, and land ownership" (Oregon Department of Fish and Wildlife, 2016). 
Many were affiliated with smaller organizations with 501(c)(3) status, while others were part of groups with no formal designations beyond a Facebook page and the allegiance of a handful of members. Most, like Wiconi International, the Czech School of Portland, and Wisdom of the Elders, had memberships of between twenty and a hundred people. Two groups, the East European Coalition and Right 2 Survive, each joined on behalf of several thousand people, although their core leadership teams delegated to PHCC remained small.

Ultimately, a dozen organizations, give or take, representing diverse perspectives on the contamination and cleanup, came together to form the Portland Harbor Community Coalition. Jeri reflects on the organic process of assembling such a wide variety of participants:

We had several meetings, we talked to different funders and everything else ... So [GWPDX] did organizing to bring all these groups together, to get people from all these different walks of life. And pretty soon you're bringing in Eastern Europeans and all these people are going, "Of course the river's the most important thing to us, of course water's important to us, of course having fish is a cultural thing for us and a spiritual thing for us." So you brought together all of these people who historically have a much deeper understanding with the land, than many Americans do. And so it was just the perfect group of people, and to go organize and to say, 'Hey, wait a minute, you haven't talked to these people. You say you're done but you haven't talked to these people, and 
they're right here!" And they're concerned, and we're telling you, "You have to stop what you're doing and talk to them." It was brilliant, and to keep moving on that and finding more people, and even if you're not finding people, the stories that are going out are hitting people's ears, and they know it's true. The African-American community - my husband's family lives on Albina near Beech - they always, always fished in that river.

Indeed, as I mentioned in the introduction to this dissertation, PHCC was beginning to look like the original Rainbow Coalition.

Jeri alludes to the spectrum of reasons for which such a broad range of participants joined PHCC, and Dubet's $(1994,2004)$ theory of political subject formation (PSF) helps to categorize these reasons, and to examine how the myriad rationales for joining influenced the actions that PHCC would take in the years to come. In nearly all cases, motivations for getting involved with PHCC align with Dubet's proposition that people join justice-oriented causes for three main reasons: feelings of connection or community that comes with being part of a group with a larger purpose; a tangible metabolic need (e.g., for food, shelter, safety, etc.) that is ongoing or previously went unmet; and concern about one particular social or environmental justice issues. While few if any of the groups would go on to prioritize the Portland Harbor as their primary area of focus in the years to come, each had core priority areas that overlapped enough with the river cleanup to join the coalition. For all of these core participants, the river that cuts through the heart of Portland was a central unifying concern, and indeed it ultimately 
became the factor that stitched seemingly disparate groups together to work in solidarity during the four years leading up the Environmental Protection Agency's (EPA) June 2016 release of the Proposed Plan and beyond.

The categories driving engagement outlined here - connection, survival, particular social/environmental justice concerns, and the river itself - are neither neat nor mutually exclusive categories. Moreover, political subjects are "made and remade" (Rutland, 2013), ever changing and always evolving in relation to shifting internal dispositions as well as to other people. Political subject formation, indeed, is a process that occurs at the interrelated individual and organizational level: "The organizations which aspire to greatest impact have to raise their consciousness, situate themselves in the broader social struggles, and understand the underpinning ideologies and analysis, as well as the stakes involved and the contemporary opportunities of the present moment" (DeFilippis et al., 2010:166). As I show here, examining PHCC, and especially paying attention to the confluence of factors that brought grassroots groups together at the outset, leads to a revision of just green enough theory.

"I'm helping bring people to PHCC, so that they can inform themselves... so that they can spread that information among their communities"

PHCC members cite relationships and community connections as one key reason for joining the coalition. In fact, in nearly all cases, groups joined because one or more of their members had an existing relationship with Cassie or Jeri. Similarly, many individuals became involved with PHCC through their already-existing relationships with groups that joined up. In many cases, both Cassie and Jeri played crucial networking roles. Cassie would go on to quietly steward the coalition from its inception through 
spring 2015 via her position at GWPDX, and then beginning again in winter 2016, this time as an unaffiliated community member. Ibrahim Mubarak, founder and leader of Right 2 Survive, recalls the fundamental influence of these two women:

How I heard first about PHCC was through Jeri, and she was talking with Cassie and they figured out it would be a good connection, seeing as Right to Survive is a houseless direct action advocacy group, and they were finding a lot of houseless people on the Willamette. And so I went and talked with Cassie and we made the connection, and it felt really good because a lot of people, they were afraid to talk to the houseless community because of the stereotype that they hear.

Ibrahim recalls that it was somewhat unique that Cassie, and PHCC more generally, included houseless people as peers from day one:

I've interacted and witnessed coalitions that invite Right 2 Survive and then don't really know what they are getting themselves into and then change their minds ... What I love about Cassie was, she was open, and she never showed no fear. Her concern was, "Was I comfortable, or was Right 2 Survive comfortable?" And then my concern was, "Are you comfortable?" because we are secure within ourselves. And she opened up the doorway, she said, "Do what you need to do, let me know, and we will follow your first step."

For Ibrahim and many others, Cassie's facilitation helped PHCC meetings become sites where people from a wide variety of class, race, and ethnic backgrounds felt comfortable. 
Right 2 Survive's model involves members' involvement in dozens of social and environmental justice groups, weaving a web of houseless activists and advocates throughout the city. One Right 2 Survive member, a middle-aged white man named Mike Summers, recalls Ibrahim encouraging him to attend a PHCC meeting just a few weeks after arriving at Right 2 Dream Too, the houseless rest area that Right 2 Survive runs: "We knew what we were expected to do ... Ib said, 'I need you guys to go tonight and see if this is something you'd be interested in." Mike has attended nearly every PHCC meeting and event since, and has at times taken on important leadership roles. Another Right 2 Survive member adds, "I was just like, 'Well, okay, let's just see what it is all about, and if I don't necessarily like it I don't have to go to another meeting.' But almost a year later, I'm still going.”

Native groups got involved through similar existing relationships. Although Native American Youth and Family Center (NAYA) did not join until a few years later, a NAYA leader encouraged Cassie to get in touch with several smaller Native groups in the Portland area in 2012. The Portland Youth and Elders Council, the Portland chapter of the American Indian Movement (AIM), Wisdom of the Elders, and Wiconi International joined up from the get-go. As with Right 2 Survive, relationships were key for Wiconi, a faith based organization "geared towards Native Americans that pushed the conversation about decolonization and about our role in the community," according to JR Lilly, Wiconi's interim executive director at the time. JR explains how his relationship with Jeri was central to Wiconi's initial involvement: 
I was invited by Jeri to come to a—she just said a community meeting and that it was important that I be there. And since Jeri is part of the Native Community, whenever an aunt or an uncle asks you to do something, you just do it ... We [Jeri and I] had done some work with Wiconi International. She was a real good friend of Richard, the [Wiconi] founder. And so we just became friends and community members. There's like a million ways [we are connected].

Like Wiconi, Wisdom of the Elders joined because Cassie and the organization's director had worked together over the years and had developed a mutual respect for one another. The leaders of Wisdom, an organization that "records and preserves traditional cultural values, oral history, prophesy and other messages of guidance from indigenous elders in order to regenerate the greatness of culture among today's and future generations of native peoples" (Wisdom of the Elders, 2016) found affinity with likeminded people at PHCC.

Several other local groups connected as well, many by word of mouth, through community leadership networks. Cassie knew one of the founders of the East European Coalition (EEC) from her earlier days doing outreach for the City of Portland, and called him. Another EEC leader encouraged Cassie to contact the Czech School of Portland, which also joined the coalition early on. Impact Northwest, an organization that supports low-income and houseless people in Portland, heard about the fledgling alliance via EEC, and leaders started attending meetings. Asian Pacific American Network of Oregon and the Iraqi Society of Oregon also joined up, as did Líderes Verdes, a group with 
connections to Latino Network via several of its members. Several youth, adults, and elders from Portland's Black/African-American community participated through Groundwork Portland.

At the heart of relationship-oriented reasons for connecting with $\mathrm{PHCC}$, for many, is a desire to serve their communities, now and in the future. A member of Líderes Verdes says simply, "I participate because I like helping." Rodney remembers helping his mother haul construction debris to houseless people when he was growing up, for fires to keep people warm. Now, as an adult who is experiencing houselessness himself, he continues that tradition through his involvement in Right 2 Survive and PHCC: "I get a lot of satisfaction from helping people no matter what it is, so from when I was fifteen until now it has always been like that. You need a shirt, I'll give you my shirt. It may be a little stinky but you can have it." Many PHCC members cite becoming more aware of the pollution and its impacts - and being able to spread that information within their communities - as a key motivation for participation: "I've been living here for a long time and I didn't know that the water was polluted. It's surprising to me, because my children like to go swimming [in the Willamette]. And I'm also here to learn more and share it with my neighbors," explains one participant, a member of Líderes Verdes. Another Líderes Verdes member frequently talks about fishing in the Portland Harbor with her children before she knew about the health risks. She was horrified to learn about the contamination, and now works to let others know: "The more we are informed the more we can inform our communities." The leader of another group says, "I'm helping bring people to PHCC, so that they can inform themselves about what is going on as far as 
pollution. And so that they can spread that information among their communities." One participant, who works with an organization serving the African American community around issues of wellness, explains her relationship-based commitment to PHCC in this way: "I joined this group and decided to do this work because of the generations that came before me, the generation of people that are here now, and those that are still to come, who will have to fight the issue of poisonous water and air."

"It was a pastime and a feeding"

In addition to relationship- and community-based reasons for allying with PHCC, many people and the groups with which they are affiliated joined PHCC out of concern for the survival of vulnerable people relying on the Portland Harbor for basic sustenance, whether in the form of food or shelter. Contamination in the harbor has rendered an important food source unsafe to eat for Native people, Latinos, Eastern Europeans, Iraqis, Black and white Portlanders, and others. One African-American elder, Wilma Alcock, reflects fondly on her childhood, eating fish from the Willamette alongside hush puppies, potatoes, onions, and salad. Fish provided vital sustenance for Wilma's family, and the whole process of fishing and cooking was a source of leisure and comfort for her community in a time of intense racial discord, during and after World War II:

We fished all up and down the river, wherever there was a bank you could get to ... It was a pastime and a feeding. We ate fish probably once a week because it was just healthy for you ... We weren't Catholic but we ate fish on Friday ... And we also would be out at Sauvie Island and 
after I got older, [my parents] had a little trailer, it was called a Teardrop, and it would attach to the back of a car. There was a place for a stove, and a place to sleep, and they would catch fish out in the river. We would use clean water and clean [the fish] and use salt and pepper and cornmeal and fry it in that black cast iron skillet. Oh my god, there was nothing any better than that... Fresh fish, you can't get any fresher than that. (PHCC, 2015)

Wilma and many others now recognize that relying on the Willamette for regular nourishment came with a long list of health risks, some of which likely compounded existing health conditions for some people. This recognition helps fuel participation in PHCC. Similarly, one participant, from the East European Coalition, explains, "[There are] a lot of [Eastern European] fishermen out there, who don't know about why you cannot fish there from the river; that's why we got involved." Many Líderes Verdes participants also come to PHCC meetings because they are concerned about the health of members of their communities who rely on the river to feed their families: "The water is very polluted. We nor our children nor our grandchildren are able to eat the fish. And that's why I like to participate." Mike, from Right 2 Survive, recalls growing up in Portland in the 1960s, cutting Steelhead that his father caught into one-inch thick steaks. His family added slices of lemon, salt and pepper, and onion rings, and "hobo cooked" the fish over a campfire, in aluminum foil packets. A concern for the health and safety of fellow houseless people living along the river today - some of whom are not aware of the 
dangers of consuming toxic fish, and others who eat it because they have few other options - drives Mike's present-day participation in PHCC.

Subsistence fishing is not the only survival-related motive for joining PHCC, especially for advocates for the houseless community. As a "direct action group that educates both houseless and housed people on their civil, human, and constitutional rights," and that works to "bridge the gap between housed and un-housed people by clearing away misconceptions and stigmas associated with houselessness and empower houseless people to stand up for themselves when their rights are violated" (Right 2 Survive, 2016), it made good sense for Right 2 Survive and its members to join PHCC out of a concern for the confluence of ways that harbor contaminants affect the health of houseless people. Lisa Fay, one of Right 2 Survive's leaders, summarizes the assemblage of threats to houseless people seeking shelter along the river:

[Groundwork] noticed what we already knew, that there were many houseless people that lived along the river, and that were being impacted with every aspect of their daily life along the river, health issues, environmental issues. They were worried about their health. They knew that there were toxins in the river. They knew they couldn't drink, or cook from the river. They knew that they shouldn't - although in many cases they didn't have a choice - clean their clothes from the river. They used the river to bathe and were concerned that that was an extra health risk being brought in through their pores. 
For houseless Portlanders, in addition to toxic fish, the riverbank soil in which some people grow vegetables is also an important consideration: "They've been drinking that water, growing vegetation on there, where the soil gets toxic water, so they eat toxic vegetables," explains one Right 2 Survive member. Right 2 Survive representatives are also especially concerned about people being exposed to dangerous substances, such as dioxin and lead, lurking in the soil where people pitch their tents. One Right 2 Survive leader explains how, on top of short-term survival concerns, the pollution that adds a layer of stress about longer-term survival drives Right 2 Survive's involvement in PHCC:

[Houseless people] were worried about the soil contaminants on the surface on the shores and in the vegetation. Some had pets that had gotten sick from running through the vegetation. So, a lot of people were aware there were hazards; they just didn't know the extent of the hazards until we would do outreach, and we would walk and talk with people, and find out about their situations. We knew that there were groups out there that were involved [in the cleanup], but we just hadn't made any strong connections with anybody to see where our group could fit in [prior to joining PHCC].

While some people set up rip-stop nylon tents complete with poles and rain covers beneath the black cottonwoods, willows, bigleaf maples, and Oregon ash trees lining the Willamette, others ingeniously lash logs and branches together, weaving blue and brown tarps and scraps of particle board into makeshift shelters nestled into the riverside underbrush. Many camps include laundry lines, scraps of wood for shelves stocked with a 
few tins of beans or tuna and a can opener, and fire pits flanked by boulders and logs for sitting. These structures and provisions are the only things insulating their inhabitants from cold, wet winters and scorching hot summers. For houseless advocates, then, as well as members of a wide variety of other grassroots groups, concerns about food and shelter alike attracted them to PHCC.

\section{"Something that actually benefits the displaced people"}

Finally, concerns about overarching and interrelated social and environmental justice issues, including intergenerational health, workforce development, housing, displacement, and more motivate involvement in the harbor cleanup for PHCC members. Overlapping with harbor-related threats to survival, outlined above, members of nearly all PHCC member groups talk about a desire for healthy fish and habitat linked to broader human health and cultural traditions to be at the heart of their participation. One Latina participant describes intergenerational impacts of pollution as a key motivating factor for her:

The environment's important to me. I grew up fishing with my dad. I like to do that with my son. Beyond the fact that this isn't just- the pollution's not just going to affect my kids, this is generational. Every single person that's come into contact with Portland is affected by this, to what degree we don't know, because they're not doing studies on that. But Portland does have high rates of cancer and a bunch of other health problems going on, and we just don't know where they connect. 
A middle-aged white woman from the nearby working-class St. Johns neighborhood explains, "I'm really interested in the lower Willamette river, and whether it's safe and healthy or not. And I'm particularly interested in the people that fish, the people that swim, and the people that are getting more exposure to pollution."

For others, it is the prospect of "green jobs" that promise to accompany a robust cleanup that drives their involvement. Leaders with the East European Coalition and Wisdom of the Elders, in particular, were very keen to learn more about the youth employment opportunities that might come out of the cleanup. And, serving Portland's African-American community as well as lower-income residents from a variety of backgrounds, GWPDX's employment program focused on training young people for jobs at the intersection of environmental and environmental justice issues. For Cassie, it was an obvious decision to initiate a conversation with other community leaders about starting PHCC.

For members of Portland's Black/African-American community, jobs and housing, as well as a host of other issues, are inseparable, and this nexus of concerns motivates participation in PHCC. One participant references how the harbor cleanup impacts the Black/African-American community, in particular, in relation to several overlapping issues: "I am here to make sure that we facilitate and leverage this Superfund site into something that actually benefits the displaced people who have been suffering not only from the toxins, but from the job loss, from displacement in housing, education, employment, children, the whole nine yards." And a local community organizer explains, "I'm just happy to be taking it in for the African-American community...getting the word 
out about this awesome work ... [of] PHCC. And so I'm still learning, and as I'm learning, I'm also bringing awareness around the opportunities of work and housing."

But it is not just a desire to see the harbor cleaned up that motivates involvement. PHCC members care about the cleanup process as well, which threatens to exacerbate the challenges faced by those living in precarious shelters along the riverbank. Right 2 Survive leaders know all too well that throughout the city, police periodically force houseless people to pack up and move in the name of environmental remediation. In fact, in summer 2016, authorities conducted sweeps along Johnson Creek, a tributary of the Willamette in southeast Portland, forcing over 500 people to find shelter elsewhere (Smith, 2016). Concerns about habitat and the health of the connected waterway, in part, motivated Mayor Charlie Hales' decision to order the forced removal of so many people with nowhere else to go. "Move to where?" Right 2 Survive members ask. Advocates fear that, as harbor cleanup gets underway, remediation will similarly become a convenient excuse to conduct "sweeps" with even more urgency along the river - what Dooling (2009) refers to as "ecological gentrification". Environmental advocates condemn those with few other options for living along the river, fixating on their trash (Rodriguez, 2014). From Right 2 Survive's perspective, however, refuse associated with desperate attempts to survive on the margins of the city is nothing but a minor annoyance when compared to the heavy metals and other substances deposited over the course of more than a century of industrial activity in the harbor. Right 2 Survive member Loretta Pascoe articulates the contradiction that houseless people living along the river face: "People along the river need a safe place to go, and we need to be able to afford to get 
that [housing] so that we can be away from the river while the cleanup is [taking place]" (PHCC, 2015). Indeed, Right 2 Survive members - and many others associated with PHCC - cite the basic right to sleep as one primary motivation for working for a cleaned up harbor on behalf of impacted communities.

JR explains similarly layered connections between several issues for Wiconi when the organization joined PHCC. Although small in numbers, Wiconi's concerns were expansive, linking spirituality to international and local environmental justice issues alike, and tying the past to the future:

A large part of the organization was around Christian faith, however, it wasn't exclusive to that. [We emphasize] all areas of spirituality and the sacred. So even in the Sun Dance, there are different elements of teaching that are ... involved in it. So there's this big overarching conversation of, how do you-what degree, what percent of ceremony needs to be traditional, and what percentage of it needs to move forward and evolve, and grow with the changing times and elements. When you are carving a pipestone, do you use traditional methods of doing it that takes hours, or can you just use a drill? And what is traditional about it and what is not traditional about it? So a lot of those conversations we were pushing ... And we were trying to find some areas to focus on. What role does Wiconi have in Portland - we have such an international and national reach - but what are we doing here locally? ... But we also were trying to bring the local issues — bring more awareness of it because 
we have a huge following just around the world and the nation ... So when we heard about Portland Harbor, and the challenges, like that there is no environmental justice [element being recognized], that [could be] part of our scope of what we were doing. So I proposed to the board that we get involved more. They agreed, so we began talking with Cassie. We became a core partner.

Like Right 2 Survive and Wiconi, for nearly all PHCC member groups, then, a medley of issues, from jobs to housing, spiritual connection to sustenance, intergenerational concerns to the river itself, are woven throughout analysis of the Portland Harbor Superfund Site cleanup, inspiring involvement in the coalition.

\section{"Please, you have to take care of the rivers"}

But it truly is the river, in relation to the concerns mentioned above, that serves as a convergence point for PHCC's participants. As a prominent feature of the landscape, as a reminder of home for those who have moved to Portland from afar, and as a spiritually sustaining, "life-giving" element, the river stitches PHCC's core groups together. The coalition's tagline on its website and letterhead even reads, "The River is Our Lifeline, Our Future". Abdulhadi "Hadi” Muhammed, a leader with the Iraqi Society of Oregon, puts the river at the center of his organization's concerns about the Portland Harbor: "Nobody, no rules or [regulations] ... told companies not to harm the river and what is inside the river, like fish. Even the plants, when you water the plants with pollution, they die." Hadi, like other Iraqi Society members, finds intimate connections between the Willamette River and waterways running through his home country: 
I remember my country, we have two rivers ... Tigris and the Euphrates ... old rivers ... yes, they come from Turkish mountains, very clear water, very clean, and one of them passed into Syria lands - Arab country, and passed into Iraq ... Any city or town past the river ... When [the rivers] reach the south of Iraq, it is polluted heavily ... Many diseases, the water become bitter or salty ... not good to drink, or not good to water even the plants ... So, it continues even now, when you see the river now the color of the water becomes green or brown. Many living things or creatures disappear ... So now every family has a filter at home. [Otherwise, people get] diarrhea, and different diseases because it is full of germs.

For Hadi, convincing public agencies to clean up rivers is of paramount importance, and drives his group's involvement in PHCC:

Scientists, doctors write in the newspaper or go on TV and ask the government to please see what happened to the rivers, they are full of pollution. But no one here [in Iraq] acts to change it. They are busy in their personal things, and they drink pure water - bottled water, or they have systems [so the pollution doesn't affect them]. I make a comparison between the Tigris and Euphrates and Willamette. And we are suffering the same thing, like you, maybe worse. Why? Because, as you know, our rivers come from the north to south, crossing the cities and towns. And all these towns, messy with their areas, pour into the river ... I think that 
if the government make the operation with the societies or the specialist environment they will solve this, even might not take much money, to the health of the people ... The beaches on the river, even the trees and land. So I think they take care, the government, if they warn them or notify them, 'Please, you have to take care of the rivers', not for Portland only, for all American states.

Irina Phillips, a member of the East European Coalition, is similarly concerned about the Willamette River because of her experiences growing up on another continent. Speaking about the Neva River in St. Petersburg, Russia, Irina says, "I watched the river of my birth city and how it was polluted. From age five or six to age twenty, I saw sand getting dirtier, water getting more oily. There were no warnings." The daily ritual of drinking tea and serving it to visitors is what really brought the problem of the polluted river to the forefront for Irina. Her family's friends and relatives lived all over the region, including in what is now Ukraine and Moldova. People came to visit periodically, and Irina's family served them tea. "The tea we drank as a little girl was really good," she recalls. Others relatives came from Uzbekistan, Kazakhstan, and Tajikistan, which "lie on the Silk and Tea Route from China," Irina explains. "They brought really good green and caravan teas." By the time she was a teenager, however, the city's tap water - from the Neva - had taken a turn for the worse. Irina remembers, "I was embarrassed to give [our guests] tea. The water tasted terrible ... The water did not allow us to enjoy the flavors." Irina connects her experience with this profound shift in drinking water quality to her work with PHCC: "I do not want Portland to go this direction," she says. 
Like representatives of the Iraqi Society and East European Coalition, leaders with the Portland chapter of the American Indian Movement (AIM) put recovery of the river at the heart of their participation. AIM leads seasonal ceremonies on the banks of the Willamette, as well as other nearby waterways. "People can be healed, rivers can be healed," succinctly explains Art McConville, an AIM leader (PHCC, 2014). And one African-American elder similarly explains the linkage between the work of healing the river and healing her community:

My hope is that [the river] gets back to where it once was where it can be life sustaining for people. Because really, actually, progress just-it doesn't sustain people, it just—well, ok, progress, if I'm talking about progress when you're displacing something and putting something else, it usually doesn't last ... I said, "Portland has never had a ghetto, so now they are building one." And they said, "Where?" and I said, "Williams and Vancouver, all of those, they are building a ghetto." "They're not building a ghetto. They are putting in all those new buildings and things," dah, dah-dah, dah-dah. Give it twenty-five years, those are going to be housing that people with no income and little income will be living in. Because [developers] will go on to the next cherry. ${ }^{16}$

\footnotetext{
16 North Williams Street and North Vancouver Street, former hubs of the African American community and main thoroughfares through the formerly disinvested neighborhood, are now ground zero for gentrification and displacement in Portland.
} 
Contrasting the so-called "progress" of city-building with the restoration of a landscape and waterway that could actually support human life, and in particular the health and spirit of the Black community, this statement encapsulates the collective thinking of many PHCC members: development, green or otherwise, is futile without attention also to life-giving elements of the landscape, such as the river. At the same time, river remediation is in vain if only white people of means steer the process and benefit from the outcome, especially if profits come at the expense of those who have suffered from pollution, displacement, and other forms of oppression and exploitation.

Participants' myriad reasons for joining PHCC, with the river stitching them all together, informed a collective process to articulate guiding principles. With the help of the Resolutions Northwest facilitator, PHCC members outlined its first set of guiding principles in late 2012. This would evolve throughout the years. By early 2014, the coalition's list of values included an explicit statement about the intersecting issues at stake in the Portland Harbor cleanup:

We all need to learn from the Native traditions of living in harmony with the river

Everyone has the right to clean water in the Portland Harbor Everyone has the right to safe land along the Portland Harbor Everyone has the right to consume healthy fish in the Portland Harbor A clean Portland Harbor will attract clean, green industry and jobs 
The Native belief that the river is gifted to us by the Creator; spiritual healing of the river is required.

The coalition's guiding principles document also outlined a series of concerns, many of them specific to particular groups, echoing the sentiments voiced earlier in this chapter: that food grown near the river may not be safe to consume; that the cultural and historical tradition of subsistence fishing by Native communities is not possible without exposure to toxins; that although Eastern Europeans are not explicitly reflected in census counts, this population's perspective ought to be considered in the cleanup process; that people experiencing homelessness and "forced off of downtown streets" should be able to "find safe refuge along the river." More generally, at this time, the coalition called on the EPA and DEQ to implement "environmental justice policies" and "ensure the health and wellbeing of minorities and other affected communities." PHCC's preliminary recommendations included everything from "Remove all highly and moderately contaminated sediments from the river and banks" to "Ensure Portland Harbor cleanup job training for locals, and especially low-income communities and communities of color that disproportionately suffer from unemployment;" "Increase tourism and site seeing from exemplary cleanup" to "Require diesel filters on all cleanup equipment and trucks." One bottom-line recommendation stated, "Support an environmental justice analysis that more fully recognizes numbers of individuals that consume resident fish and their cumulative impacts."

Like rain making its way downhill to the river, the Willamette drew together a diversity of constituents - Native, Black/African-American, Latino, Iraqi, Eastern 
European, and white - despite divergences in the ways that harbor pollution has affected members of these groups. But, unlike water running downhill, the convergence of these groups was anything but "natural". Key people, like Cassie and Jeri, convened diverse organizations, and dozens of people invested time and energy to keep the coalition functioning. The coalition's analysis would continue to evolve over the next few years. Importantly, coalition members maintained a firm commitment to viewing ecological remediation as inextricably linked to redressing social and environmental injustices.

\section{Just Green Enough?}

The case of PHCC reminds us that communities of color and those with no and low income are, in fact, very keen to address environmental issues, particularly insofar as ecological concerns are intertwined with social and environmental justice matters. This way of thinking is common sense to many members of impacted communities. And this mindset actually aligns with scholarly understandings of socio-ecological relations:

Contemporary scholars increasingly recognize that natural or ecological conditions and processes do not operate separately from social processes, and that the actually existing socionatural conditions are always the result of intricate transformations of pre-existing configurations that are themselves inherently natural and social. (Swyngedouw, 1999:445)

Although urban political ecology (UPE) scholars "know" that the social and ecological are inseparable - and although grassroots activists on the front lines take this perspective for granted - scholarly understandings of grassroots efforts to enact change do not yet 
fully reflect this orientation. One of the things that PHCC members (and previously Groundwork Portland and Environmental Justice Action Group) have done is to localize and personalize environmental concerns, particularly for those who have suffered the effects of pollution and are least likely to benefit from status quo remediation and green development. This opens space for a sophisticated yet common-sense socioenvironmental understanding, rooted in personal experience, to emerge for PHCC participants.

When we consider PHCC members' rationales for joining the coalition as well as coalition priorities articulated in early visioning sessions, we can see that PHCC's perspective contradicts the rationale detailed in "just green enough" (JGE) theorizing. Recall that Curran and Hamilton (2012:1028) contend that environmental cleanup should be "just green enough" for it to improve "health and quality of life for existing residents, but not so literally green as to attract upscale 'sustainable' LEED-certified residential developments that drive out working class residents and industrial businesses." PHCC certainly is concerned with the potential for the harbor cleanup to contribute to the displacement of vulnerable Portlanders. And yet, rather than eschew robust environmental remediation, the coalition whole-heartedly embraces it as well as provisions to ensure that the cleanup will benefit impacted communities. The case of PHCC therefore offers an alternative example to the JGE model, one that illuminates the evolving collective consciousness of a group seeking to transcend the (green) development-displacement contradiction and remake Portland's waterfront according to a grassroots vision. 
Three areas of evidence presented in this chapter undergird this argument. First, recall the early history of the involvement of communities of color in the EPA's cleanup planning process via EJAG and the PHCAG, which preceded PHCC's formation. When EJAG pulled out of the PHCAG, it essentially spelled little to no meaningful involvement of impacted communities in the cleanup planning process-leaving space for polluters to analogize deadly substances like DDT and PCBs with bugs living at the bottom of the river in conversations with impacted community members, with little recourse. Second, recall which community groups ultimately joined PHCC, seeking to counter the polluters' narratives, and which did not. The Urban League, for example, decided that working for social equity via cleanup jobs was adequate at the time; partially in step with JGE theory, a focus on the river, itself, was not part of UL's mission. In contrast, a dozen smaller grassroots groups became core members of PHCC, pointing to a third area of evidence that directly contradicts JGE theory. As we see in the rationales given by PHCC members for joining the coalition, a river cleanup that leads to the lifting of fish consumption advisories, so that people can safely depend on the river for interrelated cultural and subsistence purposes, is of prime importance. Coalition members have a host of other concerns, as well. At PHCC meetings, people bring up concerns about paying for cleanup, displacement of houseless people, and rising rents. On the surface, these might seem irreconcilable with PHCC's platform of a cleaned-up river. Rather than advocate for a less robust cleanup, PHCC folds these concerns into a holistic analysis that is uncompromising in its demands of a thorough cleanup of the river-and one that benefits, rather than excludes and displaces, those most impacted. 
PHCC is therefore not the group we would expect, based on JGE theorizing. What is crucial to understand about PHCC is the way that categories of social equity, environmental justice, and "the environment" hold little meaning; PHCC members treat issues in these areas as interconnected, inseparable concerns. In fact, when I asked a few coalition members how they understood the concept of environmental justice, they indicated little knowledge of the environmental justice movement writ large, and offered a take that differs from what is commonly understood by the term. One Líderes Verdes member, Ana Mendoza, explained that for her environmental justice means "just taking care of your environment, so like, where you live, the air you breathe, the water you drink. It's justice for all the environments that can't take care of themselves or that the people can do a lot more for. I guess they don't have a mouth or anything to say, 'Hey don't do this to me.' We need to act upon it." This statement indicates that PHCC leaders (myself included) might have done more to help newcomers contextualize the coalition's work within the deep roots of the environmental justice movement more broadly. And yet, it also indicates an evolving openness to read the contamination and cleanup of the harbor in inherently non-binary ways that inform PHCC's efforts to ensure that marginalized groups actually steer and benefit from the river's remediation. This deep, innate understanding emerged for PHCC members from lived experience and collective discussion about present-day circumstances.

In closing, as we see here (and again in Chapter 6), coalition members discuss interconnected social and environmental justice and ecological concerns in narrative fashion, invoking stories and memories in planning and carrying out the coalition's 
activities. Nothing less than full remediation will be green enough for PHCC. And, as we see in the next chapter, nothing less than full participation in the cleanup planning process will be good enough for PHCC, either. 


\section{A Public Opinion Poll ... And a Webinar!: Holding Public Agencies AcCountable}

With a mission to "raise the voices of those most impacted" by pollution in the Portland Harbor, PHCC members spent the next four years, from 2012 through mid2016, engaging fellow community members. PHCC's work revolved around building a collective understanding of the pollution in the harbor and its effects on various groups over the last century and a half, as well as developing an understanding of the cleanup planning process itself. Hosting dozens of popular education-style workshops and events, the coalition's activities were designed to ultimately help prepare people to testify during the Environmental Protection Agency's (EPA) public comment period. The comment period was the official channel for "the public" to influence the Superfund cleanup plan. In the years leading up to this crucial time, PHCC representatives also made a consistent effort to participate in EPA programs aimed at involving ordinary residents. Activities included meeting with City officials, communicating with EPA officials via email and phone as well as in person, and engaging with public officials from these and other agencies at coalition meetings and other events. PHCC members hoped that communications with the City and EPA would sway the planning process to better account for the needs and perspectives of impacted communities.

As we will see in this chapter, early interactions between PHCC and government agency representatives were, on the whole, personable - "Portland nice", as one PHCC member described them. But after struggling to "play their games" for over four years, as 
another long-time coalition member put it, PHCC representatives grew weary of what seemed like a series of false promises that never came to fruition. In spring 2016, the coalition shifted to take more of a conflict-oriented approach in its engagements with the City and EPA: the coalition submitted a letter to the City alleging infringement on the civil rights of those least likely to benefit from a status quo cleanup, and showed up en masse at City Hall, demanding that officials do more to authentically involve the public, and especially underrepresented groups. PHCC's shift to taking a more explicitly confrontational approach resulted in the City of Portland allocating resources that helped support the coalition's work through the EPA's public comment period. Ultimately, PHCC's mobilization played a key role in forcing the federal agency to be more accountable to the needs of marginalized groups.

What challenges did PHCC face with regard to the public participation processes initiated by the City of Portland and the EPA? What organizing approach did PHCC take? The empirics detailed in this chapter contribute insights around my second overarching research question: What obstacles do grassroots groups mobilizing for social and environmental justice face in the green city? They also continue to help answer my third research question: How do grassroots groups mobilize to ensure that underrepresented groups have a say in the shaping of green cities, and that they partake in benefits (e.g., jobs, affordable housing, green space, etc.) emerging from urban sustainability initiatives?

In this chapter, I examine PHCC's interactions with public agencies through the lens of oppositional community development. I first outline PHCC's mobilization 
approach throughout the coalition's early years. In the second and third sections, I then give accounts of the coalition's engagements with the City of Portland and the EPA, the two main public agencies with which PHCC interacted from 2012 through 2016. I emphasize the events that unfolded around the public comment period, starting in late 2015 and going through summer of 2016. In the chapter's fourth and final section, I address how, together, these accounts demonstrate the tokenizing and depoliticized public involvement processes that PHCC experienced at the local and federal levels. Government agencies' exclusion of impacted communities from the planning process directly influenced PHCC's decision to take a more confrontational approach. This shift entailed grassroots actors pushing a re-politicization of the planning process, opening space for those left out of formal channels to meaningfully sway outcomes.

\section{Oppositional Community Development, PHCC-Style}

From the outset, a handful of key PHCC members (i.e., Ibrahim from Right 2 Survive, and Cassie from Groundwork Portland, as well as JR Lilly from Wiconi, Steve Goldstein from the Sierra Club, and leaders from Wisdom of the Elders and the Portland chapter of the American Indian Movement) encouraged the coalition to adopt various aspects of an implicitly OCD approach. As I outline in Chapter 2, in OCD-style work, those involved understand "the community" to be a crucial scale at which to work, possessing immense potential as well as constraints. There is an emphasis on working "within a place", situated in a broader context, rather than merely "about a place". An OCD approach also involves an openness to conflict when necessary; organizers recognize that institutions are often not predisposed to progressive change through polite 
conversation. Finally, political education, the mechanism that facilitates ordinary people developing a political analysis, is at the heart of OCD work. While PHCC did not take any explicitly conflict-oriented steps in the coalition's early years, the political education that transpired from 2012 through 2015 laid an important foundation that prepared members to activate the oppositional in OCD when the need arose.

\section{Prioritizing impacted communities: "It's not hijacked by someone's agenda"}

For PHCC, a scalar analysis transpired through the coalition working in solidarity with groups in other places and at other scales (above and below that of a citywide coalition), but always putting the development of PHCC member groups and their constituents front and center. Through advocating for a more robust cleanup, PHCC prioritized developing the capacities of those most impacted; there was an explicit recognition that power would come from "the community" - rather than from outside experts. Representatives of Right 2 Survive and GWPDX, in particular, helped set this community-led tone for PHCC. Most of PHCC's meetings for the first few years took place at GWPDX's headquarters, on Martin Luther King, Jr. Boulevard in northeast Portland. At the first coalition-wide meeting in mid-2012, attendees helped themselves to slices of cheese pizza and cups of root beer, and sat down in folding chairs arranged in a circle around the room. The green carpet was stained, and the mini-blinds hung at funny angles. The toilet down the hall periodically ran throughout the meeting. Ibrahim, from Right 2 Survive, remembers that the coalition's openness - and to a certain extent, its lack of established order - allowed houseless people from Right 2 Survive to take a core leadership role within a coalition of majority-housed people: "Because [we were] 
creating an organization that I guess wasn't used to organizing different people, and we were used to it, we took the lead and started facilitating [meetings], started doing things, modeling how to do things." Similarly, JR Lilly describes PHCC as an "undefined thing", and explains the coalition's meandering style:

Sometimes you'd show up and it would really just be educational ... or we would have a presenter, or somebody that would just talk about, "Here's how different things are going." And then you get into the community concerns, which, since nobody is there consistently, somebody will be there and complain about something. A few months later a new person will come and they will bring up the same concerns, but those of us that are consistently there are like, "No, we have already talked about this, we already dealt with this.” ... Or new people would come in and be like, "We should be doing this and this," and we would say, "No, we actually already have a plan about how we are going to do all this." But now, because their voice comes in, we have to adjust the plan, and it is always a-we were never able to figure out what we were actually doing ... We would start a plan and be moving forward, and then it would stop and - no one will take leadership, no one will take initiative, there's no core committee that can ask people to do things, or oversee a project, or make sure it happens. There's always things that happened, but just not consistently. 
Rather than viewing the coalition's haphazard modus operandi as a problem, however, JR saw it as inherent to community work - and as a desirable way to operate:

That's just sort of the way it is. And for me, that's fine. There's no desire that this needs to be fixed, or I'm frustrated or upset, you just sort of know that dealing with community work is messy, and you just sort of have to accept that ... There's no like, "Oh there needs to be a board, or there needs to be select people, and we actually need a plan and stick to the plan." No, I think we are fine, we are sort of accomplishing what we set out to do, maybe not as cleanly as — and it's not a full on professional thing, it's really community driven at the core of it. And because that's where it stays, the message stays, the messaging and community advocacy, the grassroots approach to it stays the same. It's not hijacked by someone's agenda, or some group of people that control everything.

For JR, a loose dynamic, without strict rules, was particularly important for Native groups to meaningfully participate:

That's the political drama that gets to the play of all this. So now there should be some ambiguous and loose and whatever, it's like, "Yeah, it's fine." But then it becomes like rules, and it becomes like, "Okay, what are the rules?" Because Natives have a long history of being tokenized or being - "We are going to invite you to the treaty table and make you feel like you are involved, and like you are part of the decision-making 
process." But we are really not, so- - the visions of community [at PHCC] being ambiguous, yeah, count us in.

While keeping participation and leadership roles malleable, which made a wide variety of people feel welcome and opened space for Right 2 Survive and other groups directly run by those who have been and continue to be affected by harbor pollution, coalition members also decided to bring some structure to the group in order to ensure the development of community members' capacities and skills. Early on, the coalition invited a facilitator from Resolutions Northwest to help members collaboratively devise a structure for making decisions and distributing funds, articulate a mission, and set goals. "We decided we would be consensus-based. We came up with a mission statement. We decided this is the power structure. We did power mapping. We did a lot, actually, and it was very intentional. We were trying to be very intentional. This [was] not Groundwork as the only ones leading or making decisions," explains Cassie.

Rooted in a deep faith in the possibilities that emerge when ordinary people coming together to make change, PHCC members focused most of their energy directly on the harbor. Occasionally, however, the coalition connected with grassroots groups working in other places, as well as with broader movements that overlapped with PHCC's mission. In fall 2014, for example, PHCC jointly hosted an event with Columbia Riverkeeper, called "Two Rivers, One City". The event brought together a broad network of river users to discuss threats to the Willamette River as well as the Columbia, the major river into which the Willamette flows. At this event, two local lawyers spoke about the Superfund cleanup process, helping attendees connect the Portland Harbor with 
environmental justice movements more broadly. One PHCC member frequently references this event as key to helping him learn about the wide variety of contaminants in the harbor.

Also in 2014, PHCC hooked up with Jobs With Justice and a handful of other organizations to sponsor the Clean River March in connection with the Pacific Northwest Social Forum (PNSF). The PNSF is an annual event that entails social movement organizers, artists, activists, and others converging to "practice participatory democracy and create cohesion between all the attendees." Fifty or sixty PNSF attendees gathered in Pioneer Square and, guided by a leader from the All Africa People's Revolutionary Party, marched through downtown Portland and up onto the Hawthorne Bridge. Coalition members dropped a banner off the bridge. In bold black letters on a white background, it said, "Clean Rivers = Good Jobs + Equity." By connecting with PNSF, PHCC drew on the energy of a number of social and environmental justice organizations from around the region, connecting the Portland Harbor to broader movements for progressive change.

Another important way that PHCC hitched its work to the wagons of other likeminded groups was through participation in the Anti-Displacement PDX (ADPDX) coalition, an alliance of local service providers and community organizations focused on instituting a variety of anti-displacement provisions in the City's new Comprehensive Plan. Representatives from Right 2 Survive and Groundwork Portland played particularly key bridging roles between ADPDX and PHCC, including giving updates at meetings to keep the two coalitions abreast of each other's work. Recognizing the important ways that the City's land use laws would shape the possibilities for PHCC's constituents to 
access land for community-controlled housing, food production, restoration, and more (and wanting to contribute to stemming the tide of racialized displacement), the coalition signed on to ADPDX. Wearing the hat of PHCC representative, I attended nearly all ADPDX meetings from January through September 2015, and also met with key City officials and Portland Sustainability Commission members. A few other PHCC members also frequently attended these meetings on behalf of the coalition, and several Right 2 Survive members participated on behalf of both PHCC and the houseless community more broadly.

Finally, PHCC formed important connections with a handful of local environmental groups, most notably the Audubon Society of Portland, Willamette Riverkeeper, Columbia Riverkeeper, the Oregon Chapter of the Sierra Club, and the Portland Harbor Community Advisory Group. For several months, PHCC leaders and representatives from these organizations met to discuss "technical" aspects of the cleanup planning process. The general intention of these meetings was to work together ahead of release of the EPA's Proposed Plan to devise a response that encompassed conservation and community concerns alike. Willamette Riverkeeper, in particular, held an important position: the EPA awarded the organization a "Technical Assistance" grant, which allowed access to Peter deFur, a national expert on Superfund cleanup programs. Riverkeeper staff members, however, were not always responsive to PHCC representatives' requests for transparency. Most of the environmental groups mentioned here continued to send representatives to PHCC meetings through the public comment period. Although PHCC members expressed that, at times, these representatives took up 
more space at PHCC functions than was appropriate, local environmental groups were generally supportive of PHCC's work. The Sierra Club and Columbia Riverkeeper, in particular, contributed important resources, including staff time and expertise, funds for food, other resources for PHCC's monthly meetings, and space to gather.

While the coalition came together precisely because of a concern about a particular place - the Portland Harbor - with an intense belief in the power of ordinary people to shape that place, PHCC simultaneously adopted an analysis of scale that incorporated issues and places beyond the harbor. The coalition thus moved somewhat beyond the "militant particularism" that has driven (and stalled) so many struggles (Williams, 1989; see also Harvey, 2001; Stehlin and Tarr, 2016). The relationships developed through this approach would become important for the coalition's work down the line, particularly in summer 2016 when PHCC worked to mobilize as many people as possible to submit comments calling for a substantially more robust cleanup plan. At the same time, by prioritizing the development of impacted community members' capacities first and foremost, PHCC built internal power, as well as a base that protected against outside agendas taking over the coalition's work.

Political Education: "We were opening people's eyes"

Political education has been at the center of the coalition's efforts to draw on and build the strength of its members from the start. From 2012 through 2016, PHCC representatives facilitated dozens of opportunities for members and the public at large to collectively acquire an understanding of the policy and technical aspects of the cleanup, as well as to develop analysis of relationships between the polluters, public agencies, 
mainstream environmental and other community groups, and impacted communities. Political education has occurred through a number of activities, including the march and event mentioned above. PHCC representatives have also convened monthly meetings; created visual information guides and short films; organized rallies, festivals, potlucks, cookouts, harbor tours, and water ceremonies; hosted panel discussions; wrote articles and letters; held organizing and media trainings; and much more, all with an eye toward developing PHCC members' (political) understandings of the harbor cleanup process.

In the course of these undertakings, learning often takes place formally. In spring 2015, for instance, PHCC produced a film that facilitated learning, much of it in a political education vein, on several levels. At a monthly PHCC meeting, a sub-committee of members convened to brainstorm ways to communicate about the Superfund site in coalition member's own words, rather than relying on EPA handouts. I was preparing to teach an undergraduate class at Portland State University (PSU), called "Justice, Environment, and the City" at the time, and suggested that my students could assist PHCC with creation of popular education materials. PHCC members agreed to work with students, and decided to wait and see what media students might be comfortable working with before deciding whether to pursue the creation of a film, re-vamped website, pamphlet, comic book, music video, or some other project. Given that one of my students was majoring in film production, PHCC members, together with students, settled on 
producing a short film: A People's View of the Portland Harbor. ${ }^{17}$ Through a series of discussions, PHCC members decided that the film should do several things: 1) communicate a brief history of the harbor and Superfund site; 2) illustrate the origins, mission, and membership of PHCC; 3) give voice to PHCC members discussing their main concerns about the contamination and cleanup process; and 4) summarize PHCC members' hopes for the future. ${ }^{18}$

The film production process opened space for learning to occur in several ways, some of it overtly political and at other times laying groundwork for future analysis and skills to develop. The lone student enrolled in PSU's film production program helped all of us develop our understanding of everything from developing "B-roll" (background footage) to copyright issues involved with using stock photos. Other students in the class were enrolled in PSU's community development (CD) program. This project required that they draw on their abilities to facilitate good community processes - and teach their non-CD major classmates how to do so as well - using Stoecker's Research Methods for Community Change (2012) as a guide. CD students were also responsible for learning

\footnotetext{
${ }^{17}$ See Bakan (2016) for a discussion of integrating the process of film production into research.

${ }^{18}$ The documentary-style film has two main narrators: Wilma Alcock, a PHCC member, and Faduma Ali, who worked as a part time PHCC community organizer from January 2014 through mid-2015. Providing a humanistic, lyrical element, throughout the film Wilma reads from two poems she wrote about the river from her family's perspective as African Americans living and working in the harbor from World War II onward. Faduma narrates historical background material about the harbor and provides transitions between speakers. About a dozen clips of PHCC members interviewing each other make up the bulk of the film's contents. Visually, the film is comprised of footage of interviews, spliced with photos and film clips of the river and people working in the shipyards, fishing in the river, and more.
} 
how to facilitate interviews so that they could then teach PHCC members how to interview each other.

Learning in all of these areas converged one foggy Saturday morning at Cathedral Park, when thirty PHCC members convened to interview one another for the film. PHCC members brainstormed questions to ask each other, and our film student filmed each interview as participants asked each other about their experiences with the harbor. This process itself allowed PHCC members to learn about and from each other, contributing to PHCC's collective understanding of the ways that pollution has impacted different groups. ${ }^{19}$ (In Chapter 6, I examine in greater detail the impacts of learning that is rooted in personal histories on the coalition's work.) The film, itself, has become a powerful political education tool for PHCC. Coalition representatives have used it to orient newcomers to the coalition, to communicate with elected officials, and to share PHCC's story more broadly, in coalition members' own words.

In another example of formal political education, in February 2016, PHCC participants learned how to testify in preparation for the upcoming public comment period. Jasmine Zimmer-Stuckey, a Senior Organizer with Columbia Riverkeeper, led the training for two dozen PHCC members. She explained to the audience that public agencies often solicit formal public comment prior to making big decisions. People can

\footnotetext{
${ }^{19}$ Students filmed the interviews, and together we chose excerpts to include in the film. While this was a very subjective process, we were guided by two parameters: every single person who participated in interviews would be included (even if it meant that the content was redundant at times), and we would strive to accurately represent PHCC's stated mission, concerns, and visions.
} 
submit comments in writing, via audio or video, or in person. Those giving oral testimony were really speaking to two audiences at the same time, she explained: decision makers and their neighbors. It is therefore important, Jasmine emphasized, that testifiers deliver messages in a way that not only influences the decision-making process, but that also influences others in attendance. The rest of the training was devoted to PHCC members crafting their own testimonies. Participants learned to keep their stories short, make it personal, and end with a clear demand. The following week, PHCC members practiced giving testimony in front of a friendly audience, and then taught their neighbors how to develop their own testimony. (I elaborate on this event in Chapter 5.)

Other education-oriented undertakings have taken an even more explicitly political stance, overlapping with outreach, organizing, and other activities. Right 2 Survive members decided to conduct outreach to people living along the river in late 2012 and early 2013, for example. While connecting with those living in polluted areas, the group interviewed people and ultimately made a short film documenting pollution and discussing its impacts on houseless people and their pets. Lisa Fay explains the impact of the film: "We were opening people's eyes to what the houseless people were going through, how they were suffering, how they were drinking the water, bathing, eating toxic fish." Ibrahim Mubarak explains one explicitly political motive for producing the film: "The industrial capitalists are blaming the houseless communities for the toxicity in the rivers. And so we wanted to prove a point. They've been doing this for hundreds of years, dumping lead, waste, and stuff into the river." Importantly, the film has not only served as a rallying point and political education tool for Right 2 Survive and PHCC 
constituents more broadly, but it has also had an impact on public agency staff. Ibrahim reflects on the film's influence on government officials at several levels at a Right 2 Survive meeting in June 2016:

Because of the film Right to Survive folks made [that] we already shared months ago with the EPA, and with the city, and with the state, it scared them enough and made them aware enough that they started doing early cleanup on the Willamette Cove beach area that was so toxic for families and for houseless folks that were staying there. This is an early win that all of us can actually claim as a victory because of the work of the video and getting our issues out that otherwise the agency wouldn't have cared about or known about or seen.

A few years after making this initial film, Right 2 Survive took on another project that would also have a dual impact, helping Right 2 Survive directly support houseless people and bring awareness to public agencies alike. Fueled by dozens of cups of coffee and countless self-rolled cigarettes, Right 2 Survive members and I met six times in July and August 2014 to put together a pamphlet to then distribute to houseless people living along the river. Every other week, Right 2 Survive members and supporters conduct outreach throughout downtown Portland and on the waterfront. And a few Right 2 Survive members and I had begun walking along the river north of downtown, near Cathedral Park, where many houseless people lived beneath the tree canopy. In addition to passing out socks, granola bars, and other supplies, these walks allowed Right 2 Survive members to check in with fellow houseless people and circulate a bi-monthly 
newsletter. The idea was that a pamphlet that specifically addressed the hazards of life along the river would supplement this newsletter.

The process of producing the pamphlet was one of true collaboration. Gathering in one corner of Right 2 Dream Too, the rest area that Right 2 Survive runs for houseless people in downtown Portland, participants sat on buckets, rusty chairs, and wooden benches. Tacked to the plywood wall behind Roy, one of Right 2 Survive's most enthusiastic PHCC members, was a political poster that the Western Regional Advocacy Project had produced: "House Keys, Not Handcuffs!", it demanded. A core group of six of us met nearly every week, and other Right 2 Survive members and residents who were around joined us from time to time as well. Over the course of our work, we discussed: which categories of information to include; the "tone" of the pamphlet - ("It shouldn't look like a government form you gotta sign!" one person declared); and what to call it. Throughout this dialogue process, all involved learned from each other. One person, for example, had extensive experience as an angler, and another had become an expert on statutes dictating the rights of houseless people in engagements with law enforcement agents; we all learned from each other.

We eventually settled on a title for the guide: "Staying Safe and Healthy on the Rivers" (see Appendix A). The trifold leaflet contains information about which fish are safer to eat than others, what to do if police violate one's rights while living outdoors, how to mitigate health problems from exposure to toxins in water and soil, and news about the superfund cleanup process. The process of creating the pamphlet entailed much discussion, allowing individual and collective learning to occur for all of us, and the 
output of this learning - the guide itself - has in turn fueled additional political education within and beyond Right 2 Survive. "Staying Safe" communicates in a succinct way the cumulative and interconnected ways that houseless people are impacted by pollution in the harbor, as well as the way in which other threats to people's health and safety (i.e., police violence) compound environmental challenges. Several public agency staff have commented to PHCC representatives that the guide helps them understand more about what is at stake for houseless people, and that it contributed directly to Oregon's Department of Environmental Quality's decision to pursue early remediation in Willamette Cove, one area particularly popular with houseless campers.

Formal, organized political education is not the only way PHCC members have learned, however. Learning also happens informally on a near-constant basis, through the dialogue - the coming together, telling stories, sharing ideas, planning, disagreeing about strategies, reflecting, mourning, and celebrating - that arise unceremoniously between PHCC participants and others during harbor-related activities. Incidental, tacit learning might happen on the bus on the way to a meeting, via text message or email, or on the sidewalk during the course of saying goodbye after an event. "Oh, hey - Did you hear that the EPA pushed the public comment period back again? What's up with that? I think..." is an example of the casual information sharing and critical questioning typical of PHCC participants' conversations.

From 2012 through 2016, nearly all PHCC events incorporated some combination of formal and informal learning such as the activities outlined here, some of it by design and much of it by accident. In many of these instances, learning incorporated 
a political element, in large part because learning was often rooted in culturally specific contexts. The Iraqi Society of Oregon, for instance, hosted a festival at Cathedral Park just a few months after PHCC came together. About eighty people attended. "During this party we educate the people how to treat the river," remembers Hadi Muhammed. "We made the party, singing Iraqi songs." Similarly, Wiconi infused an element of political education about the harbor into an annual powwow in Turner, Washington, attended by about 1,000 people, during PHCC's early days. JR Lilly explains:

I gave a talk about environmental justice [at the powwow], and just talked about how as indigenous people we always talk about how it's important to protect mother earth, to do all these things - we preach about it all the time, but what are our actions that we actually do for it? And getting involved with coalitions like the Portland Harbor Community Coalition, and environmental movements, and doing all these things. A least being aware as a minimum, but taking action and showing up would just be - was what we really needed to do.

Events such as the Iraqi Society's celebration and the powwow signify the kinds of engagement activities that people have orchestrated through PHCC, featuring multiple opportunities for participants to learn about the harbor, the impacts of pollution, and the cleanup process. As we will see in the sections to come, this was learning that tended to be off-limits to people through officially-sanctioned public engagement activities.

The relationships, activities, and orientations outlined here help illustrate PHCC's emphasis on developing the perspectives and skills of those most impacted by 
harbor pollution through political education and other means. Through prioritizing the development of PHCC members while also maintaining connections with likeminded groups, as well as making political education the center of the coalition's work, PHCC implicitly adopted an OCD-style approach. Crucially, as we will see in the next two sections, this orientation informed the coalition's eventual response to public agencies' reluctance to authentically engage PHCC members.

\section{Engagements with the City of Portland}

At the same time that Portland's most vulnerable residents were at the heart of PHCC's work, City officials did not meaningfully engage impacted communities - or any residents, really - in the cleanup planning process during most of the time between the harbor's listing as a Superfund site and the EPA's release of the Proposed Plan. In late 2015, the City at first seemed prepared to finally support PHCC's work engaging underrepresented communities. But by winter 2016, it became apparent to coalition leaders that dissemination of a public opinion poll would be the City's main form of public engagement around the Superfund cleanup - a clear indicator of the City's tokenizing treatment of marginalized groups in these years, and sign of depoliticized sustainability discourse, more broadly. In this section, I describe PHCC's interactions with the City, focusing closely on the period when the coalition activated the "oppositional" in OCD. 


\section{Early Communications: A 'Tricky Situation'}

From the coalition's inception, PHCC leaders were well aware that the EPA's Record of Decision (ROD) would ultimately dictate the terms of the cleanup from an ecological standpoint. PHCC leaders also assumed that the City's position on the cleanup would likely influence the EPA's course of action to some extent, and understood that the City and other local agencies (rather than the EPA) had jurisdiction over what would happen to the waterfront following remediation. Starting in 2013, Cassie and other coalition leaders were therefore in touch with City officials, pushing them to begin a public involvement process. PHCC leaders hoped that the City would provide some funds for the coalition to conduct outreach as part of the City's community engagement. This approach would simultaneously support PHCC's work and help the City meet its own public involvement obligations, mandated by both federal Title VI statutes and the City's own policies. The EPA accepts written, oral, or video testimony submitted via email, online portal, postal mail, or in person at formal public hearings. To ensure that all people can meaningfully participate in this process, the EPA and any entity receiving federal funding, including the City of Portland, are governed by Section 601 of Title VI of the 1964 Civil Rights Act. This statute states:

No person in the United States shall, on the ground of race, color, or national origin, be excluded from participation in, be denied the benefits of, or be subjected to discrimination under any program or activity receiving Federal financial assistance. (U.S. Department of Justice) 
Furthermore, EPA's Section 602 regulations prohibit activities "which have the effect of subjecting individuals to discrimination." In other words, it is the outcome of the participation process - not simply the intent - that matters.

At first, coalition leaders met with staff in the now-defunct Office of Healthy Working Rivers (OHWR). Since OHWR was under the purview of the mayor at the time, PHCC leaders and members also periodically met with staff in Mayor Sam Adams' office, and, later, Mayor Charlie Hales' office. When responsibility for the cleanup changed hands yet again, this time shifting to the Bureau of Environmental Services (BES), PHCC representatives met with Commissioner Nick Fish and his staff. ${ }^{20}$ Cassie Cohen, PHCC's founder, recalls:

From the beginning, we were always asking: "Has the City sent something out? Any updates? How are you [the City] letting people know what's going on, or asking for input?" This went on for years. "This is a huge decision about a critical element that everyone should have access to - the river - but people are in the dark about it. Why the void in communication?" It kept going. Two years out from when they said the comment period would happen - the end goal - still nothing. Oh my god. One year out? Nothing. Six months? Still nothing.

\footnotetext{
${ }^{20}$ Portland's unique Commission form of government entails the mayor appointing responsibility for City bureaus to City Council members; it also means that each time a new mayor takes office, responsibilities for the bureaus are often shuffled.
} 
In addition to the City's own public involvement policies, three other important reference points factored into PHCC leaders' assumptions that the City would conduct (or at least contract with another entity to lead) a public involvement campaign that solicited input from underrepresented communities. The first was a report commissioned by the OHWR, which detailed economic outcomes from different cleanup scenarios. "We continually reminded them [City officials] of research conducted by EcoNorthwest on the positive economic development impacts that a thorough cleanup would result in," Cassie recalls. This seemed like the kind of win-win that PHCC leaders assumed City leaders often sought in politically fraught circumstances. Second, since Cassie had worked for the City and had served on the City's Public Involvement Advisory Council for three years, from approximately 2008 to 2011, she was familiar with the City's public engagement obligations, as well as the City's growing capacity to design and conduct outreach in a way that would meaningfully involve vulnerable groups. "I helped write the rules for how each bureau should be tracking public involvement," Cassie explained. She expected the City to follow those rules. Finally, PHCC participants were well aware of the City's track record in catering to environmental interest groups, and figured the Superfund cleanup would follow past trends. Taken together, these factors indicated to PHCC that, theoretically at least, the City would advocate for a thorough cleanup and would engage its residents in a good-faith effort to ensure this outcome. PHCC leaders reasoned that, although it would likely require a fight for them to gain traction, the coalition's other concerns around jobs, housing, and more could surface through the City's public involvement process. 
Starting in 2012, PHCC leaders conveyed to City officials that the coalition was prepared to assist the City with outreach, especially by leading communications with underrepresented groups. Elected officials and their staff members indicated eagerness to work with PHCC, in due time. By 2014, however, City officials began reminding PHCC representatives that, as a potentially responsible party, the City of Portland was on the hook to help pay for the Superfund cleanup. Discussions insinuated that the City was leery of anything that might increase its liability to pay for remediation. When pressed by PHCC representatives, officials acknowledged that, as a public agency, the City had a responsibility to keep its residents informed. Nevertheless, they continually emphasized that this dual role put the City in a "tricky situation", implying that they were in no hurry to conduct public outreach. PHCC leaders maintained the perspective that the City was still responsible for engaging its residents in the cleanup process and held out hope that it would eventually happen.

After years of inaction, in June 2015, conversations with the City finally became somewhat more concrete. Commissioner Fish's office encouraged PHCC to submit a memo outlining the coalition's plan to continue engaging underrepresented communities around the cleanup, as well as a budget requesting funds from the City to carry out the work. His office also indicated that the City would be especially keen to see what sorts of community economic development ideas PHCC might propose. City staff further suggested that the Commissioner might be willing to help sponsor community events, like the upcoming Willamette River Revival Festival that PHCC was co-organizing with the Portland Harbor Community Advisory Group. PHCC leaders got the message: 
couching PHCC's request for City funding in terms of workforce development and community celebrations would be the most likely route to garnering City support for the coalition. PHCC leaders submitted a memo to Commissioner Fish, as requested. In addition to outlining components of a workforce development plan, communications explicitly referenced the City's Title VI civil rights responsibilities:

PHCC views City support of green jobs development and training as one substantial way that the public sector can steward not just ... Portland's environment, but also its people. Support of PHCC's efforts will also assist the City with meeting its federal Title VI obligations related to the Superfund Site, ensuring that marginalized groups have an opportunity to meaningfully participate, influence, and benefit from cleanup.

But the memo had little immediate impact. A City staffer called PHCC representatives in the first week of July, encouraging them to check back again in six to nine months. In the eyes of PHCC members, the City was yet again evading its public involvement responsibilities.

In 2012, the EPA had announced that it would release the Record of Decision (ROD) in 2014 (Profita, 2014). Delays pushed the timeline back several times. Nevertheless, by early summer 2015, less than a year away from what would ultimately become the public comment period, PHCC leaders and members found it unacceptable that the City had still done no outreach. They worried that the City and the EPA would hear Portland's mainstream environmentalists loud and clear during the comment period (from June $8^{\text {th }}$ to September $6^{\text {th }}, 2016$ ), and that these largely white, middle- and upper- 
middle class voices would muffle those demanding an environmental cleanup that also incorporated important social and environmental justice issues.

At this point, in early summer 2015, PHCC's future was unclear. The coalition's funding had run out. There was no money to continue paying an organizer's salary. No resources for childcare or bus tickets for coalition meetings. No funds for printing or other basic costs. GWPDX, the organization that had stewarded PHCC and served as its fiscal sponsor from its inception, was also out of funds. Cassie had stepped down from GWPDX's executive director position when her daughter was born in March 2015. Edward Hill took over at GWPDX, and, despite his experience with environmental justice work in the Pacific Northwest, the tiny non-profit - and PHCC - lost some of its momentum in the transition. It did not help that a few of GWPDX's board members also transitioned out at this time, and that the still-young organization was competing with hundreds of other community groups for scarce funding.

Moreover, Edward's partner also gave birth to a little girl that summer, and I was about to scale back my involvement in PHCC for a few months to care for my own newborn son. PHCC's paid organizer for the previous year and a half was looking for other work. One key PHCC leader was facing a no-cause eviction, and another was battling stage-four lung cancer. Right 2 Survive members were devoting nearly all of their attention to negotiating a City-mandated relocation of Right 2 Dream Too, as well as continuing to battle the City's relentless sweeps of houseless people from the City's inner-core neighborhoods and surrounding green spaces as winter approached. More generally, PHCC member groups were totally overwhelmed by a housing crisis that was 
making it nearly impossible for working-class and even middle-class households to afford rent in Portland; communities of color - the majority of PHCC's constituents were particularly hard hit.

At the same time that PHCC's activities nearly ground to a halt, the City continued to operate on its own timeline and according to its own priorities. In August 2015, Commissioner Fish's office invited PHCC leaders to a meeting. The Commissioner explained that the City had finally changed course in terms of its decision to conduct a public engagement campaign around the cleanup. He explained the shift this way: with Michael Jordan at the helm, BES had a new - and "very competent" - leader. Furthermore, a "ratepayer scandal" surrounding the City's provisions of sewage and water utilities had died down, taking pressure off BES. It was now time for BES to strengthen partnerships and "support equity", the Commissioner explained. What economic development, employment, and other brownfield-related opportunities did PHCC see? he asked. PHCC representatives conveyed the coalition's overlapping concerns about jobs, job training, housing, the City and EPA community engagement processes, and more. Anything related to food, health, and sustainability had his deep commitment, Commissioner Fish stressed. The meeting concluded with enthusiastic but loose conversation about solidifying points of contact with BES, figuring out a communication plan, and including a range of voices in the planning process.

PHCC representatives and I huddled in the City Hall lobby following the meeting with Commissioner Fish. Although the conversation seemed to represent a substantial shift in the City's willingness to take responsibility for funding public 
engagement, several points remained unclear. We agreed that the Commissioner seemed to be feeling us out, trying to figure out where PHCC stood in terms of shifting the burden of cleanup costs to ratepayers, in particular. In mentioning the "ratepayer scandal", Commissioner Fish seemed anxious that the City might be expected to pick up more than its fair share of the cleanup tab. Did officials worry that more public involvement would somehow increase the City's financial liability? On this point, PHCC members were clear: residents should not pick up more than their fair share of the tab. "The polluters should pay to clean up the mess," flatly stated one PHCC meeting attendee. Little did we know at the time, but this was just one small piece of the ratepayer lawsuit story; I return to the implications of the lawsuit in Chapter 7.

As we talked in the City Hall lobby, I sat down on the heavy wooden bench and fanned my face with my notebook. I was nearly nine months pregnant, and taking the bus all over the city to attend PHCC-related meetings during the hottest summer on record in the Pacific Northwest was taking its toll. I apologized for not contributing more during the meeting, particularly in helping to set concrete next steps before the meeting concluded. Nevertheless, we agreed that this was a "sure opening" to secure some funding from the City for PHCC to continue to connect with impacted communities, while simultaneously holding the City accountable to its public outreach obligationsregardless of whether we agreed with the Commissioner's rationale for turning to public engagement so late in the planning process. It seemed that the Commissioner's decision to finally conduct public outreach at this juncture hinged entirely on a political calculation; he was still worried about the rate-payer scandal, and would justify doing or 
not doing public outreach based on what was politically expedient. But given the precariousness of PHCC at the time, we did not feel that we were in a position to question motives. We laid out our plan: within thirty days, the coalition would prepare an updated proposal outlining priority areas for $\mathrm{PHCC}$, as well as a revised budget, ready to send to BES.

In retrospect, given that officials never made any concrete promises, we should not have been so confident that the City's support would be forthcoming. We also should have been more conservative in estimating our own abilities to maintain open communication with BES through the fall, much less sustain consistent contact with coalition members, given that so many people taking leadership roles within the coalition were spread so thin at the time. In fact, from June through November 2015, no general PHCC member meetings took place. This lull points to the fragility of what Cassie and others had begun in 2012 and sustained for over three years. ${ }^{21}$

Nevertheless, a few decisive events transpired in fall 2015. Perhaps things played out as they did in large part because the coalition momentarily lost cohesiveness; without organized outside pressure, the City's decisions went unchallenged. Edward engaged in a series of communications with the City and its contractors, but he operated

\footnotetext{
${ }^{21}$ This lull also points to the importance of paying attention to the agents of change involved in particular campaigns and movements, rather than only to structural components. As the famous Margaret Mead quote says, "Never doubt that a small group of thoughtful, committed citizens can change the world; indeed, it's the only thing that ever has." In the Portland Harbor, people working together are unequivocally the only factor interrupting the inertia of an otherwise status quo planning process, largely influenced by polluters.
} 
alone given the circumstances. City officials explained to him that they were contracting with Oregon Kitchen Table, a program of Portland State University's National Policy Consensus Center (NPCC), to design and carry out a public engagement process around the Superfund cleanup. Then, in November, Edward received two emails, one from the City of Portland's Bureau of Environmental Services and one from the NPCC, identifying him as a stakeholder in the Superfund cleanup process and asking if he was interested in being interviewed "to explore a possible community engagement process around the EPA's preferred alternative cleanup plan for the Portland Harbor Superfund Site." Beyond these communications, most other developments that fall happened behind closed doors.

\section{The City's Survey: 'Positive and/or Negative Impacts on Jobs'}

Then, in an email sent on January 12, 2016, Commissioner Fish officially invited Edward and others to participate in a survey design process. The Commissioner explained that the City aimed to "understand the community's perspective about tradeoffs in the proposed cleanup plan, and about Portlanders' top priorities for the cleanup." $\mathrm{He}$ continued, "We'll use a survey to do that, and what we learn through the survey will inform our official comments to the EPA." Commissioner Fish concluded:

We have a limited timeframe to gather input, but we believe this is an important opportunity for Portlanders to participate in helping the City respond to EPA's proposed plan. We also hope our survey will help get the word out about EPA's process, so that more people understand how to weigh in on their own ... Because it is so vital to hear from a broad 
diversity of community members, [our contractor] will be contacting you separately to discuss the possibility of a contract to help with outreach and organizing efforts.

Despite PHCC's efforts to push the outreach conversation for nearly half a decade, the City of Portland seemed to dismiss its own public involvement policies, turning to what would essentially amount to a public opinion poll to both educate residents and solicit input on the largest environmental cleanup undertaken in the city's history. Commissioner Fish's invitation implicitly communicated the City's perspective that not only would the survey suffice for engaging the public at large, but it would be adequate for engaging those most impacted, namely environmental justice communities who had suffered from the effects of harbor pollution for generations.

At this point, Cassie, Edward, and I all began to reengage more fully with each other and PHCC member organizations. Edward had been forwarding his communications with the City to Cassie throughout the fall, and she felt that she could no longer remain silent. My little boy was a few months old, and I was ready to start attending meetings again. Cassie caught that the Commissioner seemed to acknowledge the limits of the survey in his email, noting the "limited timeframe". Given that the City knew that disparately impacted communities existed - but had largely ignored them since at least 2000, all the while engaging with PRPs - Commissioner Fish's reference seemed especially egregious to her. For the first time in nearly a year, Cassie interjected in the conversation with City officials and their contractors working on the survey. Cassie noted 
that the survey's only job-related item implied that a thorough cleanup would have a negative impact on jobs, and she emailed the City's contractor:

Jobs training/cleanup jobs attached to the Superfund site cleanup ... is separate and unique from the issue of preserving existing Portland Harbor jobs. The City conducted an economic development report a few years ago, under the guidance of Ann Beier-Director of the Office of Healthy Working Rivers, that indicated the potential for greater job growth in correlation to a robust Portland Harbor cleanup, but this report was not well received by PRPs at the time, so it did not get publicized nor utilized. But it is a risky to insinuate to the public (whether intentional or not) that a robust cleanup will result in overall job loss. I am afraid leaving the questions as is will not give the public any choice to imagine the potential for a substantial increase of environmental cleanup jobs. Groundwork Portland as the lead, with the Portland Harbor Community Coalition already gave feedback to EPA 2 years ago that one high priority of community groups is to have EPA's Superfund Jobs Training for the Portland Harbor cleanup.

But Cassie's concerns fell on deaf ears. Despite her email taking issue with the framing of workforce development, the only reference to jobs in the final version was a likertscale statement, which said, "It is important to me that the cleanup plan considers potential positive and/or negative impacts on jobs" (City of Portland, 2015). What, exactly, would marking "strongly agree" indicate? A concern for the cleanup plan's 
impact on existing industrial jobs? Impact on future cleanup jobs? It was impossible for survey-takers to know what was meant by this statement, and equally impossible for survey analysts to know how responders interpreted the statement.

Moreover, despite the scope and complexity of the cleanup, the City had marched forward with its survey-as-sole-public-outreach undertaking on the eve of the public comment period, leaving little time to follow up with other forms of engagement. In essence, the City's outreach process landed squarely on the "degrees of tokenism" rung of Arnstein's (1969) classic ladder of public participation, vacillating between "informing", "consultation", and "placation" activities. And despite clear environmental justice implications, which obligate extra care in public participation processes, the City of Portland had done little to authentically engage impacted communities. In lieu of an actual public education campaign about the cleanup process, the City's survey contained three pages of background text—far too much to expect the average person to read prior to answering questions, and far too little to expect the average person to actually be prepared to engage in such a complex issue. In addition to the poorly-worded jobs question, the survey contained other misleading and confusing lines. Questions in the online version of the survey were not numbered, contained typos, and included undefined words that were likely incomprehensible to many Portlanders, such as "aggregated" and "sediment". According to one local social service provider, the Vietnamese translation was unintelligible.

Despite the lull in PHCC's activities through summer and fall 2015, the coalition's flame had not fully extinguished. With Cassie back in action, and several 
coalition member groups taking note of the impending comment period, participants met in December, and again in January, to revitalize planning for outreach to impacted communities. The City of Portland's tokenizing treatment of impacted communities, exemplified by the poorly designed survey, precipitated a clear shift for the coalition. For PHCC members, the survey was indicative of a cleanup planning process that benefited polluters while ignoring the perspectives of those most impacted. PHCC leaders and members felt that Portland residents - and particularly members of impacted communities - deserved far more than what amounted to a public opinion poll. The coalition had interacted in good faith with the City since 2012. PHCC members presumed that City officials would engage residents in a meaningful way in due time, in return. The survey, however, emerged as proof that this would not happen prior to the public comment period. But for the coalition to continue to engage residents - essentially doing for free what the City was legally obligated to do on its own or via a contract with a group such as $\mathrm{PHCC}-$ it would need resources.

\section{Taking a Stand: 'We Want a Clean River Instead of a Cheap Cleanup'}

PHCC began to convene in full force around the matter of the survey in February and March 2015. The coalition launched a name-blame-shame campaign, a tactic designed to expose egregious behavior of public agencies and push them to make amends, against the City. Holding a sleeping baby against my chest during meetings, I encouraged coalition members to consult the City of Portland's Title VI Civil Rights policy, "designed to remove barriers and conditions that prevent underserved groups from accessing programs and services" (City of Portland, 2013), to gauge possible recourse. 
From PHCC's perspective, the City was erecting barriers for underrepresented groups rather than taking them down. Other passages from the City's Title VI policy bolstered PHCC's position: "Historically excluded individuals and groups [should be] included authentically in processes, activities, and decision-making. Impacts, including costs and benefits, [should be] identified and distributed fairly" (ibid.). From PHCC's perspective, despite communicating with officials for years about the need for outreach to underrepresented groups, the City of Portland had done virtually nothing to "authentically" include "historically excluded individuals and groups" in decisionmaking related to the Superfund cleanup.

At a Líderes Verdes-led event in March 2016, the first concrete steps of PHCC's campaign against the City took shape. Líderes Verdes members organized a dinner at the Sugar Shack to introduce community members, many who had recently emigrated from the Yucatán and elsewhere in Mexico, to the Superfund cleanup. A handful of neighborhood-based community organizations had recently purchased the former strip club, and had begun turning it into a hub of activity for nearby residents. The chipped black-and-white tiled walls and stained red carpet had yet to be replaced, but the setting worked perfectly for PHCC's purposes that evening. Right 2 Survive members also attended the event in solidarity, as did a handful of people not affiliated with any particular organization, but who had heard about the event via PHCC's email list serve.

That evening, everyone munched on panuchos while watching the film that PHCC had produced the previous year, featuring the voices of over a dozen PHCC members, including several Líderes Verdes participants. Children shrieked as they ran 
and played in the next room over. After the film, Líderes Verdes participants shared their testimony, as examples for those in attendance. Líderes Verdes members had learned how to give public testimony at a PHCC meeting the previous month. The first speaker stood at the microphone:

The sand, the water, and the fish are contaminated with industrial pollutants, which increases the possibilities of cancer and problems in development. I am really concerned about the state of the contaminants and toxins in the water. My family is directly exposed to that and the possibilities of getting sick from eating the fish. Or even if the kids are just playing in the sand or accidentally swallow some of the water. As a mother and a resident of this area near the Willamette River, I would like a cleaner environment for our children and for the coming generations also. So I would like to request from the EPA ... the highest level of cleaning for the Willamette River because we have a right to enjoy the river, and we have a right to enjoy that river free of contaminants that directly affect our health.

Another Líderes Verdes member followed, sharing her own testimony: I'm concerned about the people who are unaware about the contamination in the river, and that they are concerning fish. My family likes very much to go fishing, and now that I understand that river is polluted, I'm very scared to take them to the river. I will beg of the EPA 
to take into account our worries. It is not just people who eat the fish, it is other animals and birds.

The idea was that these two brave speakers would inspire others in attendance to brainstorm their own stories to share that evening, and to submit them to the EPA via written comment card or video. Líderes Verdes members facilitated conversations in small groups, passing out comment cards.

During the discussion and testimony writing time, I sat off to the side with my son, who was five months old by this point. Kai intermittently nursed and grabbed at my dangling earrings. After a few minutes, Steve Goldstein wandered over. Steve had been involved with PHCC from time to time over the last few years, although somewhat less so in 2015 on account of his wife's health challenges. Given Steve's five decades working as a white community organizer with poor Black and white communities in Louisiana, North Carolina, and other places in the South, both during and following the Civil Rights movement era, as well as having trained at the Highlander Folk School off and on from 1969 to 1973 , he brought an invaluable perspective to the coalition. ${ }^{22}$ Steve was now serving as a volunteer with the Sierra Club, helping the organization follow

\footnotetext{
${ }^{22}$ Myles Horton and others founded the Highlander Folk School in Tennessee, in 1932. The school provided organizer training for the labor movement in Appalachia. It also played a crucial role in the Civil Rights Movement, including providing training to Rose Parks, members of the Student Nonviolent Coordinating Committee, Martin Luther King, Jr., John Lewis, and many other important figures, and continues to influence grassroots movements led by poor communities (www.highlandercenter.org).
} 
through on commitments to bolster environmental justice movements; his main responsibility in this role was to support PHCC.

Steve asked how things were going. I summarized the survey situation, and casually mentioned my concerns about the City's serious violation of its Title VI responsibilities. "Not that the City doesn't violate people's civil rights all the time-just look at Fair Housing law violations," I lamented. Steve ignored my pessimism, declaring, "This is the way to quintuple the funding! I love it when someone lets their bare ass hang out. To me it's like Christmas." He went on to explain his thinking:

What's needed is to shame them [the City] for their shameful conduct that's created an opening for people to demand that they do something significant instead of pretend ... As a community organizing tactic, how do we flame that embarrassment to provide resources for education, and to collect testimony?

Steve broke it down for me, humbling - yet validating - PHCC's work:

Look, we have this pitiful effort, which is magnificent in its selfsufficiency and its grassrootsness. But it's not likely to produce a significant amount of testimony [to force changes]. This is a chance ... Is somebody willing to spearhead this and go to Willamette Week and go on TV, and write a letter to the Oregonian? And - preferably [with] an organization behind them - just have some fun, kick some ass?

I pondered Steve's question. 
At that moment, Cassie and a few Right 2 Survive members wandered over. Others in the room continued to chat amongst themselves at small tables, practicing giving their testimonies. We filled Cassie and others in on the conversation. This was an important moment, in more than one respect. Steve quickly convinced us to think seriously about ramping up action, although we agreed that a final decision about next steps needed to come from coalition members more broadly. We decided to convene an emergency meeting the next day.

As we compared calendars, an attendee of the Líderes Verdes event who had not previously participated in other Superfund-related activities stood up to share his testimony:

I am here to say that any child going to the river now experiences the river as dangerous to their health. This must be rectified for life's sake. The life of humans, the birds, the fish, the plants. Without clean water, and clean fish, we are not going to be healthy people. There are no boundaries between the river and its banks, the river and the air. The birds do not know to not eat the fish or die in a safe place so as not to pollute where they lay down.

This must be rectified for life's sake. This newly engaged participant summarized the way that many PHCC members had come to understand the high stakes of the cleanup. It was becoming startlingly clear that, without more drastic measures, public agencies would do little to take PHCC constituents seriously. Several of us agreed to meet the next day. I shoved Kai's blanket into my backpack, grabbed a few panuchos to go, hugged a half- 
dozen PHCC members who had by now become friends, and went out into the cold, dark night. Kai fell asleep against my chest before we got to the Killingsworth Street bus stop, half a block away.

The next day, a handful of us got together to plan next steps. The day after, an even bigger group - over a dozen people, including representatives from Right 2 Survive, Líderes Verdes, GWPDX, the Portland Harbor Community Advisory Group, Sierra Club, and Columbia Riverkeeper - met again, at Floyd's Coffee Shop in Old Town. Just a hundred steps or so from the Willamette River and two blocks away from Right 2 Survive's houseless-run rest area, Floyd's became unofficial headquarters for PHCC's organizing that spring.

There was a buzz of excitement at the meeting. Cassie, Edward, and I took turns laying out the situation: on the eve of the public comment period, the City had yet to conduct any public outreach beyond the meager survey. And through Oregon Kitchen Table, City officials were now offering $\$ 7,500$ for PHCC to help disseminate the survey. Steve summed up the possibilities of the moment:

We're at that point where everyone is busy, we're at a point of poverty in time, energy, and resources, yet it's crunch time. EPA says we'd be fine with eating eight ounces of fish a month, and yet people are not fishing for sport. They're fishing for supper. It's a big deal, but the people that have to pay for it want to do it on the cheap ... It's up to us to step upwe want a clean river instead of a cheap cleanup. Does anyone have any 
ideas of where to find the time, energy, people to keep things moving forward?

Someone answered Steve's question: "Call the City out on their bullshit and get them to finally do the right thing and support us!" After much discussion, the group came up with a plan. Despite serious flaws with the City's survey, coalition members would distribute it in exchange for $\$ 7,500$ from BES, routed through Oregon Kitchen Table. PHCC members justified accepting funds for what was widely deemed a totally inadequate survey by committing to using it as a political education tool. PHCC members would sponsor more meetings and events to help impacted communities prepare for the comment period, like the Líderes Verdes event. Attendees would receive a link to the City's survey in the process - and would learn about and discuss the egregiousness of the City's actions. At these events, Coalition members and leaders would also help people develop testimony in preparation for the EPA's public comment period.

The $\$ 7,500$ only scratched the surface of the resources needed to fully mobilize people during the comment period, however. We had heard that a few thousand people had turned out to testify about the Duwamish River Superfund Site in Seattle; we knew we would need at least that many, but likely more. Short on money and time, and, thanks to Steve, realizing this was a political moment the coalition could capitalize on, PHCC members and leaders decided to take the coalition's most conflict-oriented measures to date in engagements with the City of Portland.

Out of funds and short on time, and with the EPA's public comment period just around the corner, PHCC sent a letter to City Commissioners and the Director of the 
Bureau of Environmental Services on April 7, 2016. The opening paragraph communicated PHCC's main issue with the City:

Despite a legal and ethical mandate, the City of Portland has failed to conduct meaningful public engagement with underrepresented groups around the Superfund Site cleanup/redevelopment. Without directly engaging those most impacted, it is unlikely that these groups will benefit from cleanup/redevelopment.

The letter went on to explain how Northwest Native peoples, "have inhabited lands along the Willamette River since time immemorial ... Native people were able to sustain their villages and trade with other tribes in large part due to the salmon, lamprey/eel, and other species that traveled in abundance through the river." It also articulated the historical relationship of Black/African Americans to the harbor, as well as immigrants and refugees and houseless people - PHCC's main constituents. The letter concluded with a series of demands, including funds for outreach to underrepresented groups.

The day after sending the letter, about forty PHCC members and supporters representing Native, Black/African American, immigrant, refugee, houseless, tenants' rights, and other groups gathered on the front steps of City Hall for a rally and press conference. Attendees held a variety of signs depicting PHCC's demands. One featured a colorful drawing of a salmon, its eye crossed out with a black X. Following the rally, twenty PHCC delegates crowded into Commissioner Fish's meeting room and took turns addressing City officials. Steve summarized the spectacle and the group's impact: "We spoke twenty different languages, babies and children climbed on the tables, and some 
people hadn't showered since last Christmas. We scared them." The critical mass, bolstered by local news article empathetic to the coalition's cause (e.g., VanderHart, 2016), made an impact. Within a week, the City's Bureau of Environmental Services released over $\$ 60,000$ in grant funds for community organizations planning to conduct Superfund-related outreach to underrepresented groups.

While representing a clear short-term victory for PHCC, the City's grant-making process was far from ideal. Instead of allowing PHCC to receive the entire amount in one lump sum, individual groups could apply for a maximum of $\$ 5,000$ each. City staff said this would make it possible to disburse the money immediately rather than waiting for bureaucratic channels to funnel it through to the coalition, a process that could take months. While better than nothing, this approach forced PHCC to scramble to find fiscal sponsors for some groups, open separate bank accounts, and take other time-consuming steps to ensure that the coalition's cooperative spirit held steady. Some of the money ended up going to groups that PHCC leaders felt were not actually working with underrepresented groups. Nevertheless, the City funds bolstered PHCC's capacity to support impacted communities through the EPA's public comment period.

It is important to reflect for a moment on the key roles played by several people during this time. Steve's experience organizing in other contexts, in particular, is key to explaining PHCC's shift: he helped coalition members recognize a political opportunity to publicly hold the City accountable, which helped garner resources for the coalition to then further organize and mobilize people during the crucial public comment period. Cassie was another key person in this process. She had maintained connections with 
PHCC members even after she left GWPDX, and had followed the cleanup process from a distance. This allowed her to plug back in and help lead organizing and mobilization efforts. Edward had helped keep communications going at a time when few other PHCC members were engaged, and Ibrahim had encouraged Cassie and others to re-convene in December and January. I had time and experience that allowed me to take the lead in writing the coalition's letter to the City, and I had also developed and maintained relationships that helped participants plug back into the coalition (particularly with Right 2 Survive and Líderes Verdes members). The relationships that Cassie and AIM leaders and others had developed over the years made it easy for people to pick back up, even after a hiatus. A handful of key people helped plan the rally at City Hall, including alerting the media, making signs, and speaking to the crowd. Long familiar with flooding City Hall with its members, Right 2 Survive leaders mobilized over a dozen people to attend the rally. Other PHCC members played important roles by attending planning meetings, weighing in on key decisions, and bringing their friends and neighbors to the City Hall rally. And a few empathetic local reporters helped amplify PHCC's demands on the radio and in newspapers. In short, it was a collective effort, with various people taking the lead in ways that suited their strengths, that brought all the pieces together at the right time.

The campaign resulted in critical resources for PHCC, allowing the coalition to hire three part-time organizers for the public comment period. And yet, as we will see later in this chapter, victory was somewhat fleeting. On June $8^{\text {th }}, 2016$, the EPA released its Proposed Plan that, as we saw in the introduction to this dissertation, proposed to do 
almost nothing to ensure the safe consumption of fish in the future. And by September 2016, when Commissioner Fish and Mayor Hales signed and submitted the City of Portland's official public comment letter to the EPA, it was clear where City leaders stood in relation to the Proposed Plan, and therefore in relation to environmental justice communities: the City unequivocally championed the EPA's weak Proposed Plan, stating, "Overall, we are supportive of moving forward with EPA's proposal" (City of Portland, 2016:3). Somewhat unexpectedly for PHCC, the City's letter also referenced some of PHCC's broader concerns, around workforce development and the EPA's own inadequate public engagement process. PHCC representatives worried, however, that unless the EPA mandated a more thorough cleanup, this gesture would have little effect on actual outcomes.

\section{Engagements with the Environmental Protection Agency}

While the City conducted little public outreach, with the exception of the survey, in the lead-up to the comment period, the EPA held several information sessions, and officials attended a handful of PHCC-organized events. But these interactions, too, amounted to tokenizing treatment from PHCC's perspective, serving to further depoliticize the decision-making process. PHCC leaders felt that prior to the release of the Proposed Cleanup Plan, EPA staff members were simply "going through the motions" rather than substantively engaging with the coalition throughout the cleanup planning process. Cassie summarizes: 
The bottom line is that EPA designated one EPA staff at less than half time, to be the sole person responsible in the Portland area for conducting outreach since around 2012. This individual arrived from another city, with little awareness of who community stakeholders were, especially from underserved populations groups. She did meet with our coalition early on, and based on our requests did arrange for EPA staff to meet with the coalition several times. But the coalition found that over time, that EPA had very inconsistent follow-through on communication, was not helpful in collaborating or jointly planning public involvement strategies with the coalition - although this was our request - and conducted isolated outreach to different stakeholders without providing transparency about the plans nor opportunities for collaboration. Several times we requested that EPA staff let the coalition know if they approach new underserved groups or if new groups expressed interest in the Portland Harbor so that we could better coordinate with more populations. This never happened. We even requested early on to see a draft of their community involvement plan and to use the draft as a way to jointly plan our ongoing outreach efforts with EPA, and this never happened.

Three vignettes help illustrate the tokenizing nature of PHCC's experiences engaging with the EPA. When taken together, they reveal how the federal agency's outreach, like that of the City, had little positive impact on the inclusion of marginalized groups in the 
planning process. The first demonstrates how the EPA ignored PHCC's early requests for assistance conducting an Environmental Justice (EJ) Analysis - a formal analysis of the ways in which environmental justice communities are impacted by a given circumstance - and instead enrolled PHCC leaders' precious time and energy in conversations about a web-based tool that would have had little utility for the coalition. The second illustrates the EPA's propensity to adhere to a public involvement checklist rather than meaningfully engaging with impacted communities. The third focuses on the EPA's pattern of inadequately making information available to the public, particularly during the EPA's public comment period.

\section{Wasting time with C-FERST}

Starting in 2013, PHCC communicated with EPA officials regarding concerns about whether the planning process would be accessible to impacted communities. Coalition leaders sent EPA officials an email in September 2013, outlining several ways that PHCC hoped the EPA would support impacted communities. The memo requested that the EPA require a formal EJ Analysis. As far as coalition leaders know, there was no legal mandate to conduct one in Superfund processes. But PHCC representatives had been in touch with Duwamish River Cleanup Coalition leaders, and heard that the EJ Analysis conducted there was integral to grassroots successes in pushing for a stricter cleanup, community benefit agreements, and other positive outcomes for impacted communities.

Partially in response to the coalition's request, in June 2014, PHCC representatives met with an EPA staff member. The meeting's purpose was for the EPA 
to update PHCC on the status of a tool the EPA had designed to help communities affected by environmental justice issues, including exposure to toxins. While not quite the same as an EJ Analysis, EPA staff communicated to PHCC that the CommunityFocused Exposure Risk Screening Tool (C-FERST) was a web-based tool featuring environmental data, graphics, and demographics that would allow for patterns of impact to emerge. For example, C-FERST would allow communities to see pictures of churches, day care centers, or other sites that might be affected by environmental justice issues, correlating health outcomes with land use configurations. EPA officials stressed that CFERST was a good research tool because it allowed user to compare trends happening in multiple places. Knowledge of these patterns might then help groups like PHCC elevate their concerns through official channels.

But PHCC representatives quickly realized that there were major problems with C-FERST. First, they asked how a mapping tool that gives only a snapshot in time would help PHCC. Native and African American communities, in particular, had been displaced over the course of more than a century, and no longer lived in neatly organized zip codes near the river. This tool would not reflect those changes, coalition representatives stressed. Moreover, many people travel from East Portland, Woodburn (an agricultural town forty miles south of Portland in the Willamette Valley), and, in the case of the Nez Perce, even as far as over four hundred miles away in Idaho, to fish in the Portland Harbor. C-FERST would be unlikely to account for such a wide-ranging radius of travel. Finally, the tool would not capture houseless people living along the river, given that they are not counted in databases synced with the tool. EPA officials acknowledged that there 
was indeed a more transient population in the Portland Harbor than in other cases they had seen. While it was not the first time that the EPA had seen such a scenario, officials agreed that this was a problematic variable that C-FERST developers had not yet accounted for.

The second problem compounded the first. Even though EPA officials were encouraging PHCC to use C-FERST, the tool was not actually recognized by the EPA as appropriate for use in Superfund site decision-making processes. At first, officials emphasized that C-FERST could help the coalition focus attention and prioritize where to put its energy. In Portland, for example, there are high breast cancer rates along the Interstate-5 corridor; C-FERST could therefore help PHCC address this health disparity in a "scientific" way, officials said. PHCC representatives asked, "But what about the Portland Harbor? That's what the coalition is concerned about." C-FERST was not designed for high-profile Superfund sites, officials admitted. One PHCC representative summarized what the rest were thinking: "So it could be a valuable tool for EJ communities in some contexts ... but not for PHCC." In essence, the EPA was encouraging PHCC to utilize a tool that would not actually help the coalition accomplish its stated objectives. PHCC representatives left the meeting, shaking their heads.

In the end, despite several more requests to do so, the EPA never pursued an EJ Analysis for the harbor. This left PHCC to piece together its own data and narrative in an attempt to demonstrate disparate impacts during the public comment period, as I describe in Chapter 6. 


\section{Checking Boxes}

The C-FERST conversation was an early indicator of the way relations between PHCC and the EPA's Region 10 office would unfold. In addition to help with an EJ Analysis, PHCC asked for assistance from the EPA in two other areas in its September 2013 email. The list included provisions for outreach to underrepresented groups so that people from impacted communities could participate in the cleanup planning process. PHCC requested the following:

- Support PHCC Portland Harbor info sessions for culturally specific partners.

- Start a conversation [with] PHCC partners about how EPA can recognize and support the urban native groups.

- Include PHCC in EPA/congressional level meetings or other important meetings; inform PHCC of important meeting updates if representatives cannot be invited.

- Work with PHCC to implement request for multilingual outreach material on Portland Harbor and similarly, begin to plan for non-English public hearings.

And, more generally, PHCC sought support to ensure that impacted communities would benefit from outcomes of the cleanup:

- Work with the PHCC to help translate existing PHCC priorities and values into choices and recommendations on cleanup alternatives.

- Help PHCC understand how to qualify for Superfund job training. 
By spring 2015, however, despite dozens of emails and meetings with EPA officials over the previous few years, PHCC leaders and members held out little hope that the federal agency would actually be helpful in these areas. In April 2015, nearly a dozen PHCC members convened for a conference call with EPA's Region 10 and National Environmental Justice Office officials, outlining concerns about environmental justice implications in the EPA's Superfund cleanup planning process.

During the call, EPA officials thanked PHCC for its work on behalf of impacted communities. But instead of responding directly to PHCC's concerns, officials then enumerated a list of all the public involvement activities conducted by the agency over the previous several years. PHCC representatives requested a written response a few weeks later, anticipating a more direct address of PHCC's concerns. Again, however, PHCC received an enumeration of the EPA's public involvement activities. It appeared that EPA officials were more concerned with ticking boxes on a checklist than engaging substantively with vulnerable communities. In contrast to PHCC's assessment of the EPA, which highlighted a lack of meaningful engagement with impacted communities, EPA officials described things another way in an email to Cassie dated June 20, 2016:

Over the past years, informational outreach, community based computer resource tools, as well as grant funds supporting community outreach have been provided to communities. EPA has been in the community offering information and answering questions about risks, cleanup technologies, job programs, Portland Harbor background and next steps. In addition to regular EPA outreach, the PHCC was invited to attend 
quarterly briefings with the EPA, Regional Administrator to hear project updates and to express concerns. In recent months, EPA organized a series of community-wide information sessions, a webinar and conducted in-person sessions with various community organizations in order to prepare people to comment on the Proposed Plan. Translation assistance was provided for the information sessions hosted by EPA. Along with the series of information sessions offered by EPA, the Agency also participated in community forums hosted by community groups.

The EPA's email went on to directly address Cassie, chastising her for questioning the agency's intentions:

Cassie, with your previous role as the convener of the PHCC and Director of Groundwork Portland, you are aware that EPA has been actively engaged with the PHCC since its inception. The Agency has provided training, participated in discussions, provided translated materials and demographic maps to the members. The EPA EJ coordinator also has also been actively involved with PHCC and its members over the years and offered training workshops on EPA based mapping tools to support community engagement. The EJ coordinator also participated in numerous meetings to better understand and offer solutions to requests from the PHCC.

While the EPA did hold several public information sessions, from PHCC's perspective, the agency did not appropriately partner with local organizations, nor did it effectively 
advertise the events; the proof lies in the poor attendance by impacted community members at EPA-sponsored meetings and hearings. One public comment period hearing, for example, took place at a local social service agency catering to immigrants and refugees. Leaders at the center, however, reported that almost none of their clients attended. They said that the EPA only requested to reserve the space, making few moves to actually partner with the organization in the planning process to ensure that the event appealed to service recipients. Although the EPA may have conducted a long list of outreach activities, these had little bearing on the actual capacities of impacted communities to meaningfully participate in the planning process. Cassie offered a blunt conclusion: "These are examples of what EPA refers to as a successful outreach to diverse populations, but we refer to as failed outreach."

\section{"We have offered numerous Informational Sessions (and a webinar!)"}

The EPA's public comment period reveals a third way in which the EPA dismissed the concerns of those who have suffered the most from harbor pollution. The most obvious way, to PHCC, that the EPA ignored the needs of impacted communities during the public comment period was the agency's refusal to grant more than a thirtyday extension to the mandatory sixty-day window during which time the public could comment on the Proposed Cleanup Plan. In early July, after the Audubon Society and other groups requested additional time, the agency extended the comment period to ninety days. Then, on July 19, 2016, PHCC leaders emailed a request to the EPA for an additional extension, for 120 days total. PHCC's letter cited one main reason for the additional thirty-day extension request: "As of July $7^{\text {th }}$ [thirty days into the comment 
period], the EPA did not yet have project materials translated into Spanish ... One of our organizers visited the EPA Portland office, and the only translated material available was a Spanish glossary of terms. This is inadequate for Spanish speakers to be fully informed ... Providing all residents equal access to public participation is required under federal Title VI Civil Rights laws." While the letter did not mention it, PHCC leaders also worried that many coalition members were out of town, particularly Native and Latino members, visiting extended family during the summer months. An additional extension would provide more opportunity for members of these communities to mobilize their friends and neighbors to submit comments.

Ten days later, EPA officials responded with an email, denying PHCC's request. In the same manner that the EPA had responded to PHCC's environmental justice concerns a few months' prior, the email summarized all of the ways that the EPA had conducted outreach to date. The accounting began, "As you are aware, over the past 6 months, we have offered numerous Informational Sessions (and a webinar!) at different locations in the greater Portland area prior to the release of the Proposed Plan, specifically designed to foster robust discussion and information sharing." The email went on to enumerate the four Portland Harbor Proposed Plan meetings that the EPA had organized, describe the translation services that were offered at these meetings, and list the various publications in which the EPA summarized the Proposed Plan and provided information about upcoming meetings. To address PHCC's concern about translated materials being unavailable, the email stated, "On July 6th a member from the PHCC requested and picked up Fact Sheets and a Glossary of Terms translated into Spanish, 
Russian, Vietnamese and Chinese from the Portland EPA Office. While a Spanish Fact Sheet was unavailable at the time (it was being revised to include updated information) everyone may now access both the Fact Sheet and the Glossary of Terms in English, Spanish, Russian, Vietnamese and Chinese." But the Fact Sheets included only a tiny slice of the information contained in the 151-page Proposed Plan, and coalition leaders questioned the utility of translated glossaries when the Proposed Plan itself was only available in English.

The EPA's email also described the various opportunities available for public comment, and explained,

We have worked hard to make each public meeting as accommodating as possible for all communities. After early initial discussions with area groups and individuals, we specifically planned meetings to span work hours and evening hours, offering various locations and formats that allowed for oral comments in a public forum as well as in private for those more comfortable in that setting.

The email ended with an acknowledgement of the sparse attendance at Public Comment meetings:

While there were many opportunities for diverse communities to engage during the comment period, and despite repeated, focused efforts to publicize and communicate with organizations like yours and the PHCC about those opportunities, we hoped there would have been broader turnout to our Public Comment meetings. At this time, the EPA does not 
plan on scheduling additional public meetings. We encourage you and everyone wishing to comment on the Proposed Plan to submit your comments either in writing or by e-mail by the September 6, 2016 public comment deadline. Community input is a very important part of the cleanup planning process and we value public comments on the Proposed Plan. All forms of comment (written, e-mailed and spoken) are treated equally and will receive a written response when the Record of Decision is signed.

Accepting that time was running short and that the EPA was unlikely to grant any more extensions, PHCC leaders began to mobilize people to attend the EPA's fourth and final hearing, scheduled for Wednesday, July $20^{\text {th }}, 2016$. For their part, PHCC leaders had publicized the first three hearings via email and social media, but had not explicitly organized people to attend them. For one thing, some of the Bureau of Environmental Services funds that had enabled PHCC to hire three part-time community organizers were not available until after the public comment period had already begun. Second, PHCC's organizers focused much of their energy on planning culturally specific events, held separately from the EPA's officially sanctioned hearings. PHCC leaders knew that the EPA would treat all forms of testimony equally, and knew that community members were more likely to attend a street party or cookout than a government-sponsored event.

The EPA continued its tokenizing treatment during the public comment period in another way: presenters rarely delivered content during information sessions and hearings in a way that PHCC's constituents could actually understand and use. On the 
evening of the fourth and final hearing, for example, PHCC organizers mobilized a strong showing: a half-dozen Líderes Verdes members attended, as well as a few dozen representatives from East European Coalition, Groundwork Portland's youth Green Team, and local Native and Black-led organizations that had recently become involved with the coalition. We sat in the back of the room, huddled together on conference room chairs upholstered in mustard yellow fabric. The fluorescent lights flattened the windowless room, complementing EPA officials' monotone presentations, resulting in a synesthetic experience.

The first presenter spent twenty minutes of the two-hour session summarizing the Proposed Plan. Her slides included histograms, diagrams, and flow charts that were entirely illegible to the average person in attendance. One slide alone included terms such as "bathymetric survey", "deposition rates", and "anthropogenic factors". A PHCC member who had been learning about the cleanup for over two years, developing plenty of background understanding compared to the average Portlander, whispered to me, "I have no idea what she's talking about." I, too, after spending nearly five years in Portland State University's flagship National Science Foundation IGERT program, designed to help emerging social scientists become proficient engaging in biophysical science conversations and vice-versa, felt disoriented and disengaged.

My seatmates and I squinted to make sense of the rows and columns on a slide depicting eight alternative cleanup scenarios. For each scenario, the table listed associated dredge volumes, dredge areas, dredge/cap areas, cap areas, in situ areas, acres of Enhanced Natural Recovery, acres of Monitored Natural Recovery, construction 
timeframes, and costs. As we exchanged confused looks, a coalition member's phone vibrated against her knee. She whispered, "Oh god," and held her phone up for me to see an image of a Black man lying on his back in the middle of a road, both hands raised straight up. The news headline read: "Cop shoots caretaker of autistic man playing in the street with toy truck" (Rabin, 2016). We skimmed further, and sat in disbelief. The man was unarmed, the article reported. When the shooting victim asked the Miami police officer why he shot him, the officer responded by saying, "I don't know."

I sank into my chair, cheeks flushed. Here we were, watching a dog and pony show, listening to EPA officials utter acronym after acronym after acronym about a cleanup plan that we feared would ultimately be inadequate to lift fish advisories, let alone allow impacted communities to access other benefits of the cleanup, such as jobs and affordable housing near the river. At least three people pointed out in their oral testimony following the official presentation that they would be long gone by the time remediation was complete. I thought about those who, like the man bleeding in a Miami street, might not make it to next week without a serious overhaul of the criminal justice system. Or through the winter without a serious revamping of housing and mental health systems. I had recently read a scholarly critique of the EPA, which cited the federal agency's abysmal record addressing environmental justice communities (i.e., Pulido et al., 2016). I had shared this information with PHCC members, so we all knew that the possibility of a formal Title VI complaint being taken seriously by the EPA was virtually nil. I wondered: Was it worth it for people to turn out to this public hearing to testify 
about a project that will not come to fruition until far into the future, if at all, while so many struggled to survive just one more day?

PHCC members decided against filing a formal Title VI complaint, and instead focused on mobilizing as many people as possible to call for a much more thorough cleanup during the comment period. By the end of the summer, over 5,000 people had submitted comments on the Proposed Plan; the vast majority called for more robust remediation measures. Besides PHCC, the Yakama Nation, Sierra Club, Willamette Riverkeeper, Columbia Riverkeeper, Audubon Society, Portland Harbor Community Advisory Group, and other community organizations had solicited comments from their membership bases. In addition, local housing activist and independent bookstore owner Chloe Eudaly was running for City Commissioner at the time, largely on a tenant's rights platform. She also worked with PHCC members to produce a short, animated film taking polluters to task and encouraging people to speak out during the comment period.

For its part, PHCC submitted an enumeration of its own to the EPA—but of a much different character than the EPA's lists detailing its public involvement activities. In contrast to the EPA's accounting, PHCC's public comment letter highlights a sharply divergent interpretation of the treatment of impacted communities throughout the months, years, and centuries leading up to the comment period. Elaborating on the letter PHCC submitted to the City just a few months' prior, the coalition's testimony letter again opens with a historical narrative about its core members:

We are the Portland Harbor Community Coalition (PHCC), an alliance of over a dozen member organizations and supporting groups. We 
represent those most impacted by contamination in the Portland Harbor Superfund site: Native people, Blacks/African Americans, immigrants and refugees, people experiencing houselessness/homelessness, and working-class Portlanders of all races and ethnicities. The ways that our people have been impacted by Portland harbor pollution are varied and complex, but must be understood by EPA in order to make an informed decision that fulfils its ethical and legal responsibilities.

The letter goes on to outline the specific ways that the groups listed above have suffered at the hands of polluters. ${ }^{23}$ Later, the letter takes the EPA to task for its shoddy participation process:

When evaluating community acceptance, EPA must do more than invoke the concept of the community, or 'the public'. It must acknowledge that the community most affected by toxic contamination is the most important voice when judging the adequacy of a remedy, as it has suffered the most serious harm. This harm is not at all comparable to the financial cost that is properly borne by PRPs; this recognition was part of the original understanding of CERCLA, and is embodied in the very

${ }^{23}$ PHCC's ten-page letter to the EPA was signed by thirty-seven member and supporting organizations and over fifty individuals, including Oregon's Assistant Attorney General, an Oregon State Representative as well as a Representative-elect, a handful of small business owners and university faculty members, retired USDA Forest Service employees, healthcare workers and physicians, the director of Oregon Physicians for Social Responsibility, the co-founder of Portland Tenants United, and many others. 
name "Superfund", which presumed polluters would pay in advance, and would pay the full cost of their pollution to maintain a healthy environment.

It is in this light that we must condemn the extremely short, highly inadequate, and improperly managed public process surrounding this Proposed Plan. After nearly 16 years of intense negotiations between the EPA and the PRPs, the public has been rushed through a very hasty process that has included failure by EPA to translate key documents, failure to maintain a functioning email account to receive public comments, poorly publicized hearings that convey information in an overly technical manner, and are therefore not accessible to average attendees (let alone those most impacted) $\ldots$ and refusal to grant reasonable extensions to the comment period ... All of the issues just listed have been informed by an unrealistic timeline for a ROD [Record of Decision]. Peter deFur, the technical Superfund Advisor retained by the Community Advisory Group, told the public that for the EPA to reach a ROD by the end of the year, they will have to work in record time once the comment period ends, and that, more likely than not, the ROD has already been written.

The ROD timeline and its technical requirements, combined with the procedural failures outlined above, creates serious doubt that what we have witnessed over the last few months was a meaningful public 
process ... We now believe that EPA's handling of this public comment period may violate Title VI of the Civil Rights Act.

The letter then implores the EPA to "uphold our constitutional rights, our civil rights, and our fundamental human right to a clean environment," as well as "to honor the federal governments treaties with tribal nations," and enumerates the ways in which the Proposed Plan currently is likely to be in violation of legally protected rights and treaties.

The tokenizing treatment that PHCC experienced in interactions with the EPA is indicative of a depoliticized planning process that was devoid of opportunity for members of marginalized communities to meaningfully participate. Although PHCC did not engage in direct action or other tactics falling outside of the EPA's established channels as a result of interactions with the agency (as with the City), the coalition nevertheless also did not place faith in the EPA's time-consuming formal complaint process. Instead, coalition members focused on garnering as much public support as possible for a more robust cleanup, in conjunction with placing pressure on the City to support its most vulnerable residents.

\section{Challenging Public Agencies, Making Space for Marginalized Voices}

As we see in this chapter, PHCC participants experienced the City of Portland's public engagement process prior to the comment period as doing little to include members of marginalized groups, let alone to provide a pathway for PHCC's constituents to actually sway outcomes. The City solicited input via a poorly designed survey, with few accompanying opportunities for people to learn about the harbor nor to express 
alternative perspectives in a meaningful way. When PHCC interjected its own perspective outside of the City's established channels, via name-shame-and-blame tactics, officials supported more robust public engagement in a material way by providing grassroots groups with small grants to support collection of comments. But the City doled out funds to individual groups rather than as one lump sum to the coalition. This approach meant that small organizations with limited capacity had to contend with additional layers of bureaucracy in order to pool funds together, putting stress on the coalition's cohesion and taking time away from organizing at a crucial time in the cleanup decision-making process. The City of Portland ultimately included reference to some of PHCC's concerns in its own comment letter. Although the City's overall support of the EPA's weak Proposed Plan somewhat undermined this gesture, PHCC members felt that they had made some incremental headway in opening space for marginalized groups to influence the cleanup decision-making process.

Similarly, at the federal level, the C-FERST tool that EPA officials offered PHCC would have consumed the coalition's time and energy, while contributing little to advance the interests of underrepresented groups in the harbor cleanup. When PHCC expressed discontent with the EPA's outreach process, officials repeatedly responded by giving long lists accounting for all of the public engagement activities the agency had conducted, with no explanation for how these activities actually contributed, if at all, to eliminating disparate outcomes. Overall, PHCC's experience with the EPA's public engagement process was that it was ineffective in providing underrepresented communities the information needed to adequately participate in and sway the decision- 
making process. And yet, after receiving over 5,300 public comments (the vast majority in favor of a stronger cleanup plan), the EPA's final Record of Decision (ROD), released in January 2017, called for nearly double the amount of contaminated sediment to be removed from the river bottom (EPA, 2017a). Following remediation, it is expected that people will be able to safely consume approximately 25 percent more resident fish than the original Proposed Plan would have allowed. PHCC leaders and members consider the ROD an important step forward.

What is important to understand here is how PHCC managed to gain some traction for the coalition's concerns at multiple scales despite a wholly depoliticized planning process. Undergirded by an OCD-style foundation, PHCC members joined together to challenge both the City's and the EPA's unresponsiveness to underrepresented groups. In step with grassroots groups working for progressive change over the last several decades (Piven and Cloward, 1977), the coalition's shift toward a more adversarial approach helped re-politicize the planning process, opening space for those left out of formal channels to have a meaningful say.

In the next chapter, I drill down into the nuances of PHCC's collective politicization process, which fueled the coalition's confrontations with the City and EPA. During the public comment period, one PHCC representative explained the coalition's persistence in pushing public agencies in this way: "We're looking at this as not just an eleven-mile stretch. We see this as a 300-year plus thing. I understand how federal and state budgets are made. But we're not looking at this as a bureaucrat. We're looking at it as life and death ... We're the ones that have to live with the pollution." This reference to 
the long-term - seeing the cleanup as a " 300 -year plus thing" - is indicative of coalition members' broader understandings of who has been impacted by pollution and how, as well as what should be done to redress injustices. 


\section{TAKing Collective ACtion: Historicized LeARning}

PHCC's spring and summer 2016 engagements with the City of Portland and the EPA indicate a clear shift for the coalition. Instead of encouraging constituents to fill in bubbles on a poorly designed public opinion poll, the spectacle at City Hall, in particular, signified a more confrontational approach for PHCC. This campaign helped the coalition garner resources for ongoing work during the crucial public comment period. PHCC's organizing and mobilization efforts also pushed the City to include a wider array of social and environmental justice concerns in its own testimony on the Proposed Plan, and pressed the EPA to mandate a more aggressive cleanup in the final Record of Decision. Ultimately, the coalition pushed both agencies to become more responsive to underrepresented groups moving forward.

Central to PHCC's communications with public agencies in spring and summer 2016 was a collectively produced historical narrative about the ways in which harbor pollution has impacted various groups. As we have seen throughout the previous chapters, a reverence for the Willamette River, itself, is one of the main reasons that participants of all backgrounds connect with PHCC. When speaking about the river, members often reference their own personal histories. They also draw on stories of their ancestors, many of whom felt the effects of harbor pollution during the last several decades and centuries, or who spent a lifetime depending on rivers in other places, far away from the Willamette Valley. Referencing these stories, PHCC members have traced the relationship between the Willamette River and four main groups, collectively 
producing a "people's history" of the Portland Harbor. As I outlined in the introduction to this dissertation, these threads include 1) the endurance of Native Americans in the Portland Basin over the last two centuries, despite exposure to disease, forced removals, and severely compromised habitat for traditional foods; 2) the survival of Black/African American shipyard workers, their families, and descendants, notwithstanding the exploitation, exposure to air and water pollution, and serial displacement that they have endured over the last half-century; 3) the more recent history of exposure of foodinsecure subsistence fishers, particularly immigrants and refugees, to toxins in the Superfund site vicinity; and 4) periodic police sweeps of houseless people living in makeshift shelters on the margins of the city, including along the Willamette, since the turn of the century.

In this final empirical chapter, I examine PHCC members' shared, still-evolving understandings of these histories, addressing my fourth question: What role does (historicized) learning play in the politicization and collective action of people working for social and environmental justice in the green city? Freire's popular education framework provides a useful rubric for articulating how PHCC's historical perspective has become a vital component of a collective, interconnected learning-politicizationaction process for PHCC. As I summarize in Chapter 2, for Freire (1970), popular education-style learning nearly always starts with personal histories; activating memories of prior experience is the first step in learning that might then contribute to the 
dismantling of oppression. ${ }^{24}$ Accordingly, as we began to see in Chapter 4 and as I elaborate in this chapter, potential activists become involved in PHCC because of their own personal histories in relation to the river. Past and present autobiographies of participants frequently surface during PHCC activities, helping people root their work with PHCC in their own lives and inspiring others to join the coalition. Second, Freire emphasizes that critical questioning is a crucial part of developing an analysis about what is going on, and what can be done to change it. At its core, critical questioning contributes to the development of political consciousness. As we will see in this chapter, for PHCC, historicized learning helps participants ask critical questions about patterns of injustice. These questions open space for people to collectively learn about the ways in which seemingly isolated individual histories of oppression actually stem from systems impacting entire groups, often in cumulative and intergenerational ways. Finally, in Freire's framework, engagement and critical questioning rooted in historical context then form a basis for collective action. As we began to see in Chapter 5 and as I highlight in greater detail here, an evolving narrative about the intersecting traumas experienced in and through the harbor's contamination (and cleanup) has been at the heart of the coalition's efforts to re-politicize the cleanup planning process, cracking open room for marginalized groups to have a say in the future of the harbor. It is important to note that

\footnotetext{
24 The Industrial Areas Foundation (IAF, 2016), for instance, roots its organizing activities in the faiths of constituents. This approach recognizes that it is people's own lives, stories, and histories that provide the most powerful entry points into political activity and social change work.
} 
this is a living history; collective understanding continues to evolve as new stories emerge, new people join the coalition, and participants make new connections.

In the sections to come, I address how each of these three popular education stages have played out for PHCC in turn. Throughout, I draw on Finney (2014) for insights into the ways in which historical contingencies - and the act of remembering them - influence consciousness and present-day experience. Finney asks, "How does memory, both collective and individual, shape African American environmental attitudes and perceptions?" Her line of questioning is prescient for thinking about the role of historicized learning (including the activation of memory) for PHCC members, more broadly.

I conclude this chapter with a discussion about what the case of PHCC contributes to UPE theorizing about green city urbanism. Hern writes, "All cities are built on colonial plunder, and most ... have been built on the backs of racist dominations and unearned privilege" (15). I submit that paying attention to what history does for those on the front lines of change - those, like PHCC members, who are fighting to undo the effects of colonialist, racist, capitalist city-building processes - is imperative in order for UPE scholarship to meaningfully contribute to this work.

\section{Historicized Learning}

\section{Engagement: Sharing Personal Histories}

PHCC participants make frequent reference to their own connections to the river as well as those of their ancestors at PHCC-organized events. As we saw in Chapter 5, 
these personal histories often motivate initial engagement with PHCC. They also give personal meaning to continued work with the coalition, and they provide avenues for other potential members to see their own stories reflected in the coalition's work, inspiring more people to join up. Excerpts of two interviews with PHCC members in $A$ People's View of the Portland Harbor, the film that PHCC members and Portland State University undergraduate students co-produced, help illustrate the link between historicized learning and engagement. In these examples, historicized learning entails recalling details of experiences of the recent past, reflecting on personal memories, linking the past to the present, and dialoguing with others.

Like thousands of immigrants and refugees in Portland, Manuela Interián's friends and neighbors rely on fish in nearby waterways as a key source of protein. Many do not realize the potential health risks, nor do they have easy access to other affordable sources of protein. Manuela describes her initial experience of learning about the toxins in the Willamette:

About five years ago, my family and I went fishing. And we did not know that the Willamette River was contaminated because we were not informed about that. We did not catch any fish, thank God. My children were disappointed, but after I became aware that the Willamette River was contaminated, we thanked God that our health was not exposed to those chemicals.

Manuela's personal history has energized her ongoing participation with PHCC. Having first attended a PHCC meeting because of her involvement in Líderes Verdes, her story 
has since become a rallying point of sorts for her, as well as for her friends and neighbors. Each year, Líderes Verdes introduces a new cohort of activists to PHCC's work. On at least a half-dozen occasions, new Líderes Verdes participants have referenced Manuela's personal history as instrumental in their own enthusiasm for working with PHCC.

Similarly, Paul Walters, a life-long Portland-area resident who worked in the harbor for several years, describes two personal points of contact with the river in the film. First, he talks about his Irish grandfather's childhood adventures in the Portland Harbor:

My first introduction to the river was stories from my grandfather. He grew up in North Portland, [and] in the summertime between school sessions he'd take his little rowboat or canoe over to Swan Island, and he'd camp there for a week. He'd live off of what he caught or hunted. If he was to do that today, the fish'd poison him - if there are any fish that are edible at all.

Later in the film, Paul discusses his own experience doing river-related work:

I've worked on the river. I've worked over the river. I've built bridges. I've worked in the shipyards. I've seen the shipyards, where they sandblast the vessels, and before they've completely cleaned up all the sand and the paint chips and everything else that's come off the ships, they lower the ship back into the water, float it out, and everything that's trapped in the sand floats into the river and pollutes the river. 
Like Manuela, Paul's personal connections to the river have fueled his engagement with PHCC. And more broadly, weaving stories like Paul's into the coalition's larger narrative via the film has helped those associated with labor groups to see themselves reflected in the coalition's work. Two unions and a pair of labor rights groups signed on as PHCC supporters in the run-up to the public comment period. They submitted their own comment letters to the EPA and mobilized their constituents to do the same. One person wrote, "I work at Vigor shipyard and they need to get a better system of protecting the river and the wildlife in that industrial area of the Willamette River.” Forging these kinds of alliances, rooted in people's own personal experiences, is key to the power that PHCC has built thus far.

Having space to share personal histories is a foundational part of historicized learning. Like Manuela and Paul, many PHCC members first became involved in PHCC through the act of remembering the past. In activating memories, PHCC members articulate how things came to be through the lenses of those who have shouldered the costs of industrial activity, often tapping into their "preoccupations, doubts, hopes, and fears" (Freire, 1970:96) about the harbor and beyond. In contrast, as we have saw in Chapter 5, there is little space for these sorts of sentiments, tied to the past, to surface in a meaningful way in official Portland Harbor-related events. Leaders from the Port of Portland and other community organizations have hosted a handful of harbor-related "storytelling" events over the years. But these forums offer little opportunity for participants to critically stitch stories together into a conversation about why some people have incredibly painful memories associated with the harbor, while others have become 
millionaires through harbor-related endeavors. Moreover, these storytelling sessions are not connected to opportunities for those recounting their stories to take meaningful action. In contrast, PHCC-organized events provide space for participants to share stories of the past, and to connect these stories to critical analysis and action, as we see in the following sections.

\section{Collective Learning as Politicization: Connecting Histories}

The second way in which historicized learning contributes to PHCC's collective politicization and action builds on the first. As we have seen, sharing personal histories helps engage and solidify the commitments of PHCC participants. At the same time, sharing these personal histories often does something more: it pushes the coalition's collective, critical understanding forward. Freire summarizes the importance of asking critical questions: "No oppressive order could permit the oppressed to begin to question" (1970:74). By drawing on each other's personal histories to ask deeper questions about what is going on, coalition members have begun to co-produce an analysis about the ways in which exposure to toxins, food insecurity, unstable housing, gentrification/displacement, and other issues intersect and diverge in similar and different ways for different groups. Again, excerpts from A People's View help to illustrate. In the first example below, I reference the personal history, in larger historical context, of a Right 2 Survive member. In the second, I show how the stories of one PHCC member associated with Groundwork Portland, and African-American elder, have helped shape PHCC's collectively evolving political consciousness. 
Gesturing to the harbor a hundred steps behind him while discussing his own personal history, Roy Pascoe articulates the challenges of living on the riverbanks after being laid off from his job: "We lived on the river for quite a while, and it had its many challenges. The river goes up and down with the weather. We had the rain to battle with, the snow, the police, the parks, our stuff being stolen from us." Later in A People's View, Roy discusses the direct impacts that depending upon the Portland Harbor for shelter and sustenance have had on his body:

We [found] out about a year or so ago that the river's completely contaminated. A lot of pesticides, leads, mercuries ... I've fished out of these rivers. I've eaten out of these rivers ... Once we found out the river was contaminated ... we found it more complicated ... I just recently beat cancer. I don't know that [the cancer] wasn't because of [living along the river] ... There are a lot of cancer-causing agents that are in these rivers.

A year after filming, however, lung cancer caught up with Roy. He died on May 16, 2016. Our last conversation was a few weeks before he passed away, while he was still able to speak. Roy pounded his shaking fist on the table at Floyd's Coffee, and said, “Damn it! If I wasn't fighting for my life, I'd be fighting for the river" (Goodling, 2016). Roy's story has had a powerful impact on many PHCC participants. His personal history echoes many of the challenges we have heard about in previous chapters.

Like Roy and other Right 2 Survive members, those with few other options have sought refuge along the Willamette for over a century. As early as the 1980s, Roy was 
already thinking about how houseless people might actually live in harmony with urban rivers, without fear of police violence, and with regular access to food, toilets, and places to dispose of trash. One day in fall 2014, when Roy and his partner, Loretta, and I were walking along the Willamette for the first time together, passing out Right 2 Survive's Safe Camping Guide, Roy stopped suddenly, blocking us from walking further down the path. "Holy shit!" he whispered. Loretta and I froze. My arms felt limp as adrenaline swelled into my shoulders. Local newspapers occasionally reported bodies found floating in the river. Had we stumbled across one? "What is it?" I whispered back. Roy's response was not what I expected. Returning to conversational volume, he exclaimed, "I've been here before!" I relaxed. Confused, I asked, "When? Why?" "In a dream!" Roy replied. "Back in 1982. I dreamt I built a marina in this cove. It was a place for houseless boaters to come and fuel up, buy supplies. Dump their refuse. It was a whole business I was runnin'!" Loretta and I looked over Roy's shoulder, and saw three boats tied together about twenty-five steps from the shore. Soda cans and tarps littered the beach, and a recent fire smoldered a few feet above the high-tide line.

As a member of Right 2 Survive, Roy has spent countless hours working with others to improve the conditions he and fellow houseless people face living along the river, as well as in doorways, tucked beneath building eaves and under freeway overpasses, and in myriad other nooks and crannies of the city. In essence, Roy's marina dream involves kinds of the services that houseless people provide for other houseless people at Right 2 Dream Too, the rest area that Right 2 Survive runs. A houseless-run marina serving people making a life along the river would, indeed, make a big difference. 
Roy's personal history has influenced PHCC's collective work in profound ways. Most basically, getting to know Roy and other Right 2 Survive members, witnessing their commitments to PHCC, and learning firsthand about the plights of houseless Portlanders more generally has helped housed coalition members develop empathy for those who are literally living on the margins of the city. This attitude stands in contrast to news reports of environmentalists fixating on trash left in the river, ostensibly from houseless people living nearby (Rodriguez, 2014). Furthermore, Roy's dream has provided inspiration for coalition members to dream big dreams of their own. Whenever coalition members talk about their own hopes for the harbor's future, someone inevitably references Roy's dream. And given that Roy recalled this dream from nearly four decades prior, around the time that widespread chronic homelessness took root in the US for the first time in history, his story almost subconsciously helps infuse a broader historical context into PHCC's evolving collective narrative. An understanding of the deeper history within which Roy's story plays out, including specifics like the mayor's order for City workers to remove scows and other makeshift shelters constructed along the river as early as 1909 (Blalock, 2012), is still evolving for PHCC members. But participants know that houseless people living along the river today continue to fear authorities tearing down their shelters (as they have for over a century), and that many people also now fear the consequences of living amidst toxic sediment and eating contaminated fish, as well as the ramifications of the cleanup process itself. Roy's dream from the early 1980s, as well as the example of Right 2 Dream Too, has helped drive home possible ways to redress this situation. 
PHCC members fold this budding historicized understanding into analysis of how to ensure that houseless people and other underrepresented groups are not further marginalized by remediation and redevelopment. In spring 2016, for example, I invited representatives of Right 2 Survive, Líderes Verdes, and GWPDX to speak on behalf of PHCC in an undergraduate class I was advising at Portland State University. A Líderes Verdes member - someone who has never experienced houselessness herself, and who was not involved in activism prior to joining Líderes Verdes and PHCC - eloquently explained the cumulative impacts experienced by houseless people in relation to the harbor, including the triple-burden of exposure to toxins, police violence, and cleanuprelated displacement. As moderator of the panel, I turned to Mike, from Right 2 Survive, to see if he had anything to add to the Líderes Verdes member's summary. "She pretty much said it all!" he said. This moment serves as evidence of an emergent understanding of cumulative and intersectional impacts of harbor pollution for PHCC members, as well as a powerful demonstration of the type of cross-race, cross-class solidarity that has unfolded through the coalition's activities.

The pre-World War I eradication of scows and more recent sweeps of the houseless, however, are just two moments in a long string of forced removals and other forms of systemic violence perpetrated against those seeking to make a life adjacent to the Willamette River. Here, I turn to another personal history, one that elucidates cumulative, intersectional, and intergenerational impacts of the harbor's pollution. Wilma Alcock, a PHCC member and nearly lifelong Portland resident, narrates A People's View with a poem she wrote that speaks to the experiences of Black Portlanders working in and 
living near the harbor since World War II. Wilma articulates connections between her family's move to Portland as part of the Black Migration - people who migrated to Portland mainly to work in the shipyards in the 1940s - and her community's experiences with workplace racism:

We are the Black Migration who left a place we knew to descend into a place we didn't know./ To experience the same, but different./ To adapt to change, whether weather, or our attitude;/ to blend, and begin again, and not quite blended/ but like whole milk that separated into cream and less bodied full milk./ However hostile the environment, we endured by the weekend/ with Friday night dancing, and spiritual prancing on Sunday,/ to leave our slights on the floor, enabling us to push onto Monday once more./ Hard to verbalize our dilemma, but with a grunt and an "umph" and a stare,/ as we stepped forward to work harder with less reward than the others that were there.

As Wilma speaks, sepia-tone images of segregated neighborhoods from Portland's nottoo-distant-past flash on the screen. Later in the film, Wilma recalls fishing in the river as a girl, while her parents worked as "chippers", shaving lead paint off of ships in the shipyards. This is the same lead that currently sits at the bottom of the harbor, bioaccumulating in the flesh of catfish, carp, and bass, and in turn in the bodies of those who rely on the river for sustenance.

Throughout the film, Wilma's words emphasize the fortitude of her community members as they experience layers of displacement and dispossession, exploitation and 
oppression related to the Portland Harbor and beyond. Wilma's family was one of many thousands of African American households segregated to the Albina area starting in 1948, and then forced to move to make way for Urban Renewal projects in the decades that followed, including construction of the Fremont Bridge over the Willamette. One of the bridge's massive grey pillars now towers above vacant lots down below, right where Wilma's house once stood. Members of Wilma's family and community now face displacement yet again, as City policies that paved the way for new development in Albina without accompanying affordable housing provisions have resulted in the outmigration of thousands of African American residents over the last twenty years (Gibson, 2007; Bates, 2013). Wilma reflects, "It's been a gradual taking over ... It's very subtle, but once you really see the pattern, it's not subtle; it's very planned out."

On top of exposure to toxins in the workplace and the violence of serial displacement, Wilma's personal history alludes to how Black Portlanders have disproportionately suffered from health impacts such as asthma, caused in part by diesel trucks traveling in and out of the harbor adjacent to Portland's historically Black neighborhoods (Multnomah County Health Department, 2014). Wilma's father ultimately died of mesothelioma, likely a result of cumulative exposure to contaminants in the shipyards, his neighborhood, and elsewhere. Wilma talks about the violence, suffering, and premature loss of life that her family has endured:

You can't take back someone's life, and it doesn't even come out until the person is dead. My dad was dead by the time they really started saying mesothelioma is caused by asbestos and all of this. And he 
suffered, and I don't even want to talk about that. It just makes me so angry, because his environment killed him.

Wilma's father and thousands of others came to Portland specifically to work in the wartime shipyards. And yet, when they arrived, they were banned from joining the Boilermakers Union. At the same time that they were excluded from the workplace protections afforded white workers, Black shipyard workers were exposed to extraordinarily toxic substances. And the City took people's homes in the name of blight removal and urban renewal, splintering the Black community over and over. Driving home the weight of this history, Wilma talks about the reparations that would only begin to redress past and present wrongs: "It's almost like, you know, the slavery thing, where they should pay us. It's almost the same thing ... It's not going to happen, but something should happen—-they took so much.”

By highlighting cumulative, intersectional, and intergenerational trauma, Roy's and Wilma's stories have helped PHCC members collectively ask critical questions about the ways in which seemingly isolated incidents are, in reality, linked to broader systems and structures. This is a key element of developing a politicized analysis and laying groundwork for collective action, demanding reparations and other mechanisms to rectify past and present injustices. At one PHCC meeting following the public comment period, PHCC members reflected on the coalition's collective learning over the previous few years, weaving together analysis of the preceding eras with forward-looking action. One PHCC member explained, simply, "There were layers of pre-existing environmental pollution and contamination that we learned about, and we're still learning about how to 
get these communities' messages amplified." Another participant immediately connected this understanding of the past to making change for the future, emphasizing the crossclass, cross-race solidarity that has emerged through PHCC: "We need to band together to get anything accomplished as far as community organizing, getting policy change, anything. I mean, it's up to us to get together ... We've learned to stand up for ourselves and to stand up to injustices built into the system." Freire (1970) asserts, "Dialogue is the encounter between men, mediated by the world, in order to name the world." Linking personal histories to exploitative and oppressive planning and policy decisions throughout the twentieth century - in short, engaging in dialogue via the sharing of personal histories in order to "name the world" - has helped PHCC members begin to make sense of the underlying reasons for various groups' similar and divergent experiences, laying a foundation to take collective action.

It is important to flag here, however, that even though PHCC members are beginning to ask critical questions and link multiple histories together, coalition members are at many different stages in terms of their abilities to view the world through a racial justice lens. PHCC participants have emphasized shared histories of dispossession and displacement, exploitation and oppression. This unified approach has by and large served the coalition thus far. But PHCC has yet to systematically develop a racial justice analysis that delves into the intricacies of power relations between the groups represented within the coalition. Coalition members are beginning to realize that there is crucial work to be done in the months and years to come in order to deepen collective understanding about the differing ways in which groups within the coalition might benefit (or continue 
to suffer) from the cleanup going forward. Such an analysis will be necessary, especially as the coalition moves into a campaign around the actual cleanup phase of the harbor. Whereas the campaign that is the focus of this research was more generally focused on "impacted communities" writ large, the coalition may soon have to address questions about how resources should be divided between impacted communities. Questions around who should receive limited resources, such as job training, contracts, access to land, and more will surely emerge.

\section{Collective Action: "Not all impacts can be measured"}

Learning the histories of diverse groups has helped PHCC participants ask critical questions and begin to outline the contours of cumulative, intersectional, and intergenerational impacts that have roots in the harbor's toxic sediments. In short, it has contributed to the development of members' individual and shared political consciousness, which in turn has been crucial for both the form and function of PHCC's engagements with public agencies. First, without an emerging analysis about the disparate impacts of harbor pollution, it is unlikely that PHCC members would have mobilized so quickly and forcefully to challenge the City of Portland around its tokenizing public outreach. Finney (2014:53) discusses the notion of "collective memory", or "the way a group of people 'remember' the past" and then use this remembering as a "cognitive map to orient people's present behavior." Indeed, the collective memory of the harbor that PHCC members had forged in the years leading up to the public comment period people to respond with enthusiasm when it became clear 
that a more aggressive approach would be necessary to sway outcomes, as we saw in Chapter 5 .

Second, PHCC's collective critical consciousness, arising in large part through historicized learning, has been crucial for the coalition's articulation of demands on behalf of multiple impacted communities. In other words, historicized learning has helped shape the "what" - the content - of the coalition's demands. Recall, for example, PHCC's letter to the City in spring 2015, which ultimately played a key role in PHCC's wide array of concerns gaining traction. The letter says, "City officials have long known that there are serious equity implications in the Portland Harbor cleanup/redevelopment process for historically and present-day marginalized groups, including Native Americans, African Americans, immigrant and refugee subsistence fishers, houseless people, low-income households, pregnant/nursing mothers, children and infants." A footnote gives details about the ways in which harbor pollution impacts each of these groups. Later, the letter demands that City officials meet with coalition representatives immediately to discuss community priorities around jobs, housing stability, support for houseless people, public access and restoration, and Community Benefit Agreements. Included in this list of priorities are "reparations for previously displaced communities."

The coalition's testimony letter submitted to the EPA likewise includes a historical narrative. This time, the coalition included even more details than in the letter to the City, and put all the text in the opening pages of the letter rather than as a footnote. Following an articulation of the distinct past and recent histories of Native Americans, 
Black/African Americans, immigrants and refugees, and houseless people in relation to the harbor, the letter ties these threads together:

Many people fall into more than one of these groups. Many members of these groups have also endured exploitation, oppression, and health disparities from living in other geographic areas, and for reasons that do not originate with Portland Harbor pollution. In other words, many of our people face cumulative and intergenerational impacts from Portland Harbor pollution, and some of these harms are compounding pre-existing harms. Decades and centuries of displacement away from the harbor area also means that impacted communities cannot be easily mapped and tracks-which means that not all impacts can be measured ... This is why we are calling on the EPA to craft a Record of Decision that does far more to protect our communities than the current Proposed Cleanup Plan.

It is worth examining one clause included in this paragraph - "not all impacts can be measured" - more closely, in order to understand the way that historicized learning has contributed to PHCC's collective politicization and course of action. In contrast to PHCC's predecessor, Environmental Justice Action Group, or the organizations that Corburn (2005) examines in Street Science, PHCC representatives rarely communicate with public agencies in numeric terms; the coalition did not rely on health statistics, maps, or environmental data to illustrate the impacts of pollution on Native, Black/African American, immigrant and refugee, and houseless people. This may come 
as a surprise, given the EPA's fixation on mapping and counting (as we saw in PHCC's conversation with EPA officials about the C-FERST tool) and the techno-rational nature of sustainability discourse, more broadly. Would the coalition not want to learn to speak the language of decision makers? On some levels, yes, coalition members have taken steps to learn this language. After all, PHCC has invited scientists and other experts to meetings so that members can learn about toxins and ecological impacts of various cleanup methods on multiple occasions. But in terms of measuring impacts, no studies have directly linked high cancer rates in communities of color to the river, for example, and PHCC lacked the substantial resources required to mobilize the kinds of data that the EPA might have deemed valid and reliable. Moreover, because impacted communities are dispersed across dozens of zip codes and hundreds of miles, and because people suffer from cumulative and intergenerational impacts, the coalition could not have simply hired a GIS expert to make a color-coded map that would effectively illustrate disproportionate impact, let alone communicate in a compelling way.

But, more elementally, PHCC members do not think in histograms and GIS algorithms. Like most people, they think in stories. Finney (2014, quoting Sibley, 1995:132) explains the power of calling upon stories - memories - in fighting for change:

Memory also constitutes a body of knowledge for the individual, and community memory becomes a way its members claim and own their past, particularly when their narratives are relegated to the margins of social and cultural importance. Memory becomes increasingly valuable to a group whose values are perceived to be morally threatening to the 
status quo, particularly when they are "presented as legitimate perspective on social relations."

In putting memories and histories front and center during confrontational engagements with public agencies, PHCC representatives banked on the potential power of these narratives to gain legitimacy for the coalition. Within a broader oppositional community development framework that prioritized political education with historicized learning at its core, coalition participants collectively crafted a narrative that illustrates the complex historical and contemporary ways that pollution has affected different people, echoing the stories featured in A People's View and recounted formally and informally at countless PHCC meetings and events. Learning about and telling a historical narrative, in part by design and in part by accident, was within the coalition's means. During PHCC's meeting with the City, following the spring 2016 rally and press conference, one member summarized:

This is ... about communities not only taking part in the [decisionmaking] process but also actually becoming a part of the river becoming again integrated into the river. For African Americans that were here during the war and now are being moved around the city, it's been historically a problem. For Latino and Chicano populations, who have used the river or been near the river, it's a problem. For First Nations People, for Native Americans who were here originally, not having access to the river has been a problem. 
This statement recaps in short form the historical narrative around which the coalition formulated its demands. The coalition the EPA and the City to make decisions based on historically rooted stories—rather than "distant statistics" (Finney, 2014). EPA officials have been especially vocal about the impact of the over 5,300 testimonies submitted during the public comment period. They have stated that stories from impacted communities, in particular, convinced the agency to strengthen its cleanup plan. In addition to PHCC's collaboratively-written letter, individual PHCC members submitted letters that drew on the kinds of historicized narratives I have outlined here. One person wrote, for instance,

I grew up here in second generation family of (extended 79 members in tribe from both parents) Portlanders. Mama, Vi Suart, will become 100 on April $16^{\text {th }} 2017$, having been born 4/16/1917, making me now $64 \ldots$ We won't let Schnitzer clan or these, any of these, corporations 'off the hook' - they should be prosecuted for criminal activities!!!

Another wrote, "I am 73 years old and was born and raised in Portland. I have eaten fish from the river for years. I have many health problems and want to know if the water and fish have poison in them." And yet another argued, "The river is more than a symbol of the city. People have lived off of the river for centuries, and the current state of the river is a shame." This is just a small sample of the kinds of historical references that informed the EPA's Record of Decision. PHCC's collective historicized learning over the previous four years proved indispensable for the coalition's ability to articulate grievances and make demands to hold the City of Portland and EPA accountable to marginalized groups. 
Because of the foundation built over the years via historicized learning, the coalition was prepared to act, both inside and outside of formal public participation channels, when the need and opportunity arose. ${ }^{25}$

\section{Remaking the City, Remaking Ourselves}

In this chapter, I illustrated how historicized learning has done three things for PHCC participants and the communities on behalf of whom they work. First, as we began to see in Chapter 4 and as I elaborate in this chapter, historicized learning has engaged potential change-makers in social and environmental justice issues related to the harbor cleanup process by tapping personal experiences. Second, historicized learning helped expose cumulative and intergenerational trauma, as well as some of the intersectional ways that different groups are impacted, prompting PHCC members to ask critical questions. This evolving perspective has opened space for participants to link seemingly isolated incidents to oppressive systems, contributing to the development of political

\footnotetext{
${ }^{25}$ It is important to acknowledge here that, as an engaged scholar working day in and day out with the coalition, I played a substantial role in tying together the coalition's various historical threads in the letters to both the City and the EPA. Coalition members asked me to write initial drafts of both letters, based on the histories shared throughout the previous several months and years at coalition activities as well as in A People's View. I shared drafts of the letter at coalition meetings, solicited feedback, made revisions based on coalition members' suggestions, and repeated this process several times until members were satisfied with the final versions. This is an example of the way in which a phronetic research orientation can pave the way for scholars to collaborate with people working on the front lines for change. I reflect on this process in greater detail in the last chapter of this dissertation. It is also important to note that a local journalist with expertise in Native and Tribal histories of the Pacific Northwest played a key role in writing the final letter to the EPA, particularly in drawing attention to the culturally specific importance of lamprey.
} 
consciousness for PHCC members. Finally, as we began to see in Chapter 5 and as I highlight in greater detail here, coalition members' collectively produced historical narrative ultimately helped PHCC infuse a political element into the Superfund cleanup planning process, opening space for members of impacted communities to influence outcomes. PHCC's shared understanding of history formed the backbone of the coalition's name-shame-and-blame campaign against the City of Portland as well as its mobilization during the public comment period, giving context and weight to the coalition's demands. The past, in others words, emerged in the present "through the embodied reactions of individuals as they carry on their daily lives" (Finney, 2015:54, quoting Eyerman (2001:5)).

Collective learning has long played a key part of social and environmental justice mobilization. Indeed, as Freire asserts, "It is when the majorities are denied their right to participate in history as Subjects that they become dominated and alienated. Thus, to supersede their condition as objects by the status of Subjects - the objective of any true revolution - requires that the people act, as well as reflect, upon the reality to be transformed" (1970:130, emphasis added). At its core, (depoliticized) sustainability discourse is about the future rather than the past, tending to erase what came before. Absent from mainstream sustainability discourse is an analysis of past and present oppressive circumstances, such as redlined neighborhoods and multigenerational exposure to air and water toxins-oppressive circumstances that laid a foundation for today's "sustainable development" to occur. Attention only to the present and future does little to disrupt the common sense of sustainability as universally beneficial. Historicized 
learning within a broader community development/organizing approach that is open to confrontation, as we have seen here, has been fundamental to PHCC's efforts to disrupt status quo greening and instead advance a conjoined environmental and social/environmental justice agenda. Historicized learning has been instrumental in changing those who, in turn, are working to change the (green) city.

By examining how those on the front lines come to understand the historical context in which they are working - and by paying particular attention to how they employ this history in fighting for a more just future - the case of PHCC contributes to crucial conversations emerging in urban political ecology (UPE). PHCC is one grassroots group that is attempting to wrestle with the legacy of the "historical spatial logics" (Heynen, 2015:2) of marginalized spaces of years past in the present, in order to shift the balance of power in the future. Yet, it is not enough for scholars, alone, to name names and develop understandings of the ways in the past reverberates in the present. While scholars may have a role to play in the advancement of a more just sustainability, ordinary people coming together are the engines of change (Hale, 2008; Piven, 2006; Piven and Cloward, 1977). In producing a "people's history" of the Portland Harbor, PHCC members are articulating the specific mechanisms that have produced disparate outcomes for marginalized Portland residents, disproportionately residents of color. While I, a scholar of UPE, have had a hand in helping to tie various threads of this narrative together, including writing letters to public agencies and producing popular education materials with coalition members (and in the writing of this dissertation), without building a collective understanding of history that is rooted in people's own 
personal experiences, PHCC members would have been unlikely to show up at City Hall, let alone articulate narratives that would have compelled public agencies to make changes. 


\section{Discussion \& CONCLUSION: GREen City RISING}

In this dissertation, I examined PHCC's internal workings and interactions with local and federal public agencies from the coalition's inception in 2012 through 2016. Beginning with a scene on a downtown sidewalk in Portland, Oregon, a few dozen members and supporters of the Portland Harbor Community Coalition (PHCC) gathered together for a press conference in front of a municipal building in June 2016. The crowd condemned local and federal public agencies for letting polluters off the hook for responsibility to clean up the Portland Harbor. PHCC members and supporters from all walks of life demanded a more comprehensive remediation plan, with provisions resulting in fish that are safe for daily consumption, jobs for impacted community members, land for community-controlled remediation and redevelopment, antidisplacement measures for houseless and working-class people living along and near the river, and more.

Seven months later, the EPA released its Record of Decision (ROD). This final cleanup plan called for a more rigorous remediation approach than the original Proposed Plan, ultimately allowing people to safely eat approximately 25 percent more resident fish per month once the cleanup is complete. Although the City of Portland did not call for a more robust overall cleanup, the City's own public comment letter encouraged the EPA to include provisions for impacted communities around jobs and other areas of concern in the ROD. For PHCC, these shifts represent incremental but important steps forward for grassroots groups working for a more just version of the green city. These 
small victories did not happen without a fight: PHCC led a grassroots campaign to ensure that impacted community members had a say in the planning process, opening space for those previously left out to speak with more authority moving forward.

This research sheds new light on the nature of grassroots mobilization for social and environmental justice in green cities. The case of PHCC illustrates one way that ordinary people are challenging the interconnected domination of land and people. Four research questions guided this research. In dialectical fashion, the first two questions address the problem at hand, and the second two questions address who is doing what to address disparities arising from contamination and cleanup.

1. What historical and present-day circumstances give rise to grassroots collective action in the green city?

As in other contexts, uneven development that is part and parcel of urbanization processes gives rise to grassroots mobilization in the green city. Portland's sustainability successes, which include early river remediation efforts, have indeed come at a cost: working-class households - disproportionately people of color and especially Native and Black people - have experienced de facto evictions from the city's inner-core neighborhoods, in part as a result of the city's green development approach (Goodling et al., 2015). Many of those impacted by displacement have also suffered from the effects of harbor pollution. In the introduction to this dissertation and throughout the chapters that followed, I recounted how four groups have been particularly hard hit by pollution in the harbor over the last two centuries: Native Americans, Black/African Americans, immigrants and refugees, and houseless people. Members of these groups are unlikely to 
benefit from remediation and redevelopment without substantial interventions. To push public agencies to become more responsive to the needs of these groups, a dozen grassroots organizations came together to form PHCC, with a mission to "raise the voices of those most impacted by harbor pollution." Over the last five years, the coalition has advocated for river remediation as well as provisions around jobs, housing, community control of land, and more. PHCC is not only building on the successes of Portland's past stewards of the river, then, but the coalition is also responding to the perhaps unintended but nevertheless devastating consequences of early and present-day sustainable city boosters.

2. What obstacles do grassroots groups organizing for social and environmental justice face in the green city?

As we saw in Chapter 5, one of the most substantial obstacles that PHCC faced from 2012 through 2016 was tokenizing treatment by local and federal public agenciesindicative of depoliticized sustainability discourse, more generally. Indeed, as we saw in Chapter 4, the coalition first came together because members of impacted communities were being shut out of the planning process. PHCC representatives, therefore, focused not only on getting the word out about the cleanup to impacted communities, but they also spent significant time and energy trying to force the City of Portland and the EPA to adhere to legal obligations of engaging members of impacted communities in a meaningful way. A shortage of funds to keep operations running, particularly when leadership changed hands, compounded difficulties, as did the material pressures of daily life. Many PHCC members, including key leaders, gave birth to or were raising very 
young children during the years prior to the release of the Proposed Plan. Other members faced life-threatening illnesses, eviction, and stress related to the daily threat of police violence. And many core PHCC members are houseless, making day-to-day survival a constant struggle. These difficulties exacerbated challenges the coalition faced in attempting to engage with public agencies around the cleanup planning process. As I show later in this chapter, a status quo growth machine - rather than a green machine, as we would expect based on previous theorizing - influenced City officials behind the scenes to refrain from more meaningful engagement of impacted communities.

3. How do grassroots groups organize to ensure that underrepresented groups have a say in the shaping of remediation and redevelopment initiatives, and that they partake in benefits (e.g., jobs, affordable housing, green space, etc.) emerging from urban sustainability initiatives?

Throughout this dissertation, we have seen that PHCC came to take an implicit oppositional community development approach in responding to the obstacles outlined above. As we saw in Chapters 4 and 5, in the coalition's early years, PHCC leaders mainly focused on organizing popular education activities in order to help impacted community members learn about the harbor, its history, and the cleanup process from a “people's perspective". Chapter 5 shows how in spring 2016, however, on the eve of the public comment period, PHCC members and leaders realized that public agencies were unlikely to engage impacted communities in a meaningful way on their own accord. At this point, the coalition shifted to take a more adversarial approach. PHCC members confronted City officials, demanding authentic inclusion of vulnerable Portlanders in the 
cleanup planning process, as well as insisting on City support for a series of provisions that would help redress harbor-related disparities. Then, during the public comment period in summer 2016, the coalition submitted a strongly worded letter to the EPA, accusing the agency of disregarding Title VI Civil Rights laws in its handling of the harbor cleanup planning process. At the same time, the coalition continued to mobilize people to submit comments as part of the EPA's official decision-making process. PHCC's shift toward more adversarial tactics helped re-politicize the planning process, in turn making an opening for those left out of formal channels to sway outcomes. Several individuals were key to the way this process unfolded, pointing to the importance of paying attention to the agents of change in cases of socio-environmental contestation.

4. What role does (historicized) learning play in the politicization and collective action of activists working for social and environmental justice in the green city?

Finally, in Chapter 6, we see the key role that historicized learning has played in the politicization and collective action of activists working for social and environmental justice in the green city. I illustrated how historicized learning has done three things for PHCC and its members: 1) it has engaged new members in the coalition's work; 2) it has helped build members' political consciousness by highlighting cumulative and intergenerational trauma, as well as the intersectional ways that different groups are impacted; and 3) it has enabled PHCC to collectively produce a narrative of a "people's history" of the harbor, which ultimately contributed in a foundational way to PHCC's efforts to make public agencies more responsive to impacted communities. Paying 
attention to what historicized learning does for grassroots groups like PHCC is a necessary step for scholars to meaningfully contribute to this work.

The case of PHCC contributes new understandings about how socio-ecological change happens in cities pursuing green development initiatives to the co-constitutive fields of critical urban studies and urban geography, and the sub-field of urban political ecology. In addition to complementing just green enough theory (Chapter 4), providing an empirical example of the way in which depoliticized sustainability discourse plays out on the ground from the perspective of a grassroots coalition (Chapter 5), and contributing to an emerging body of work around socio-environmental change in the context of the green city, this research as a whole makes two additional theoretical interventions. A central aim of urban political ecology is to articulate the specific interconnected colonial, racist, and capitalist mechanisms that produce cities, and to "disentangle the interwoven knots of social process, material metabolism, and spatial form that go into the formation of contemporary urban socionatural landscapes" (Heynen, Kaika, and Swyngedouw, 2006:8). Again, in dialectical fashion, another overarching goal is to contribute to the dismantling of colonial and racist urbanization processes, in part by "identifying the strategies through which a more equitable distribution of social power and a more inclusive mode of the production of nature can be achieved" (Heynen et al., 2006:13). In the next two sections, I articulate what the case of PHCC contributes to each of these objectives. 


\section{Theorizing Sustainability Postpolitics and the (Green) Growth Machine}

The first intervention addresses the role of depoliticized sustainability discourse in advancing urban growth machine interests in green cities. Recall from Chapter 2 that in recent years, as the capacity to generate a profit through industrial activities has waned, growth machine coalition actors have turned to the arts, the "creative class", and smart (green) growth strategies to stimulate development (Gould and Lewis, 2016; Logan and Molotch, 2007; While et al., 2004). "Sustainability fixes" revolving around the development of bicycle infrastructure, LEED-certified buildings, urban waterfronts, and other green-themed initiatives entail the "selective incorporation of ecological goals in the greening of urban governance" (While et al., 2004:551). Swyngedouw (2007, 2009) argues that depoliticized - postpolitical - sustainability discourse is one of the main features of the green growth machine.

What we see in the Portland Harbor looks different than what we would expect based on these theorizations. As we saw in Chapter 5, City of Portland and EPA officials stressed the need to move on the cleanup as soon as possible, given the decade-and-ahalf-long planning process and the uncertainty of a new presidential administration in 2017. Officials stated that the need to act quickly, at least in part, precluded agencies from conducting more time-consuming (and robust) public participation processes. Drawing on McCarthy (2013), I take this disjuncture as an opportunity to pivot and ask what role depoliticized (sustainability) discourse might be playing in the Portland Harbor 
in order to see where growth regimes working in green cities might be susceptible to progressive challenges ${ }^{26}$ After all, sustainability fixes, like other attempts to avert crisis, are tenuous, prone to fracturing (Hackworth, 2007; Harvey, 1989; While et al., 2004; see also Long, 2014 and Temenos and McCann, 2012). As with other kinds of fixes, a green development approach is "capable of holding for a time, though not necessarily resolving" (While et al., 2004:551) tensions arising between profit-seekers and labor, property owners and tenants, economic growth proponents and environmental and social justice activists.

To this end, it is important to briefly look back in time, to the start of a campaign to clean up the Portland Harbor that began nearly one hundred years before current efforts. As I recounted in the introduction to this dissertation, environmentalists working as early as the 1920s eventually succeeded in establishing the Oregon State Sanitary Authority in 1938, which mandated that pulp and paper industries stop dumping waste into the Willamette. Between 1947 and 1952, state-level officials also required the City of Portland to stop dumping sewage in the river, resulting in the City spending millions on a wastewater treatment plant and other infrastructure improvements. Then, in 2011, the City finished construction of the Big Pipe, a $\$ 1.4$ billion initiative that has substantially decreased urban sewage overflow into the Willamette since its completion in 2011. These advancements came in large part due to activists working on behalf of the

\footnotetext{
${ }^{26}$ Again, McCarthy (2013:19) suggests that instead of fixating on the present as "existing in a 'post-political' condition," "Perhaps we ought to ask broader, more structural questions about the recurring ways in which capitalist modernity consistently creates and frames environmental 'problems' and 'solutions"' (22).
} 
river, as well as a tightening of environmental regulations at the federal level. Despite the non-point source toxins that remain, the activists championing these shifts helped land Portland on the map as a leader in the environmental movement, starting in the 1970s (Hillegas-Elting, 2009). Portland's boosters have since leveraged the city's reputation as a steward of the earth by explicitly encouraging green-themed growth (Goodling, Green, and McClintock, 2015). Susan Anderson, Director of Planning and Sustainability for the City of Portland, puts it bluntly: "We're not doing [sustainability] just to be altruistic ... there's money to be made" (quoted in Minow Smith, 2012).

But now, in the midst of the Superfund cleanup, and despite an ongoing reputation as an urban green mecca, it appears that the City of Portland has somewhat retracted its enthusiasm for tying together environmental stewardship and economic growth, at least in the Portland Harbor. The counterpoint to Anderson's statement is that when there is money to be lost by doing sustainability, environmental stewardship - even of the sort that might promote economic growth in the long run - is prone to taking a back seat. No matter how committed to a green growth agenda a municipality may appear, then, it is far from a forgone conclusion that sustainability is a totalizing force. I argue that what we see in the Portland Harbor Superfund Site, then, is the work of a status quo - rather than green - growth machine.

Based on extant understandings of the tendency for capitalism to internalize its own contradictions (Harvey, 2014), this should not come as a surprise. But the underlying mechanisms by which Portland Harbor-related growth regime actors exert their influence are important to elucidate, if for no other reason than to better understand the obstacles 
that grassroots groups like PHCC face. This is not a case of the City of Portland pandering to business elites hoping to use public subsidies to offset costs of building socalled eco-villages; rather, the City has capitulated under pressure from corporations that polluted the river throughout the twentieth century, and that continue to make fortunes through decisively non-green (or even superficially green) means. ${ }^{27}$

${ }^{27}$ One notable exception is Zidell Corporation. Just upriver from the Portland Harbor Superfund Site, in the South Waterfront area, a dozen glass-encased condominium towers stretch toward the sky. The priciest units overlook the Willamette River. On warm summer afternoons, condo-owners, shoppers, and tourists sit on barstools in ground-level bistros, sipping martinis and slurping oysters while bright red and yellow kayak flotillas glide by. Occasionally, a tugboat pushing a barge mounded with gravel lumbers past, reminding residents and tourists of the Willamette's legacy as a working river (HillegasElting, 2009; Abbott, 1983; Lang, 2010). In fact, the condos and bars of today sit atop and adjacent to land that once hosted a second-hand machinery sales business, and later the largest post-World War II shipbreaking operation in the US, run by Zidell Machinery \& Supply Co.

As in the hotspots dotted throughout the Superfund site just north of the Zidell empire, the lucrative shipbreaking industry in the harbor came with a steep cost to the river and nearby land. In the mid-1990s, Zidell agreed to address pollution along a halfmile of riverfront land, spending \$20 million over twenty years. And yet, court rulings ensured that Zidell "recouped a large portion of their expenses from insurance companies" as well as from the federal government, which provided the ships. Moreover, in classic rent gap form, the subsidized remediation has opened thirty acres for new development. Current plans for Zidell Yards include 1.5 million square feet of office space, 2.2 million square feet of residential housing, and substantial areas devoted to retail and open recreational space (Profita, 2016).

While Zidell voluntarily undertook environmental remediation ahead of an imminent EPA mandate to do so, in many ways, the Zidell tale prefigures what parts of the twenty-two-mile-long Superfund shoreline might look like in decades to come, absent robust anti-displacement and other social equity-oriented provisions. It also serves as a site of comparison that helps illuminate the dynamics at play in the Portland Harbor Superfund Site, which starts just a few hundred yards downstream. At the end of the day, it is many of the same growth machine actors at work, whether the development in question is grey, green, or greenwashed. 
On the one hand, officials continually invoked depoliticized sustainability discourse in public communications about the Superfund site throughout the planning process. A rising green tide will lift all boats, and the sooner the cleanup begins, the better for all stakeholders involved, they said. In particular, local leaders celebrated a newly acquired ability to safely swim in the Willamette (thanks to the Big Pipe), which distracted the vast majority of Portlanders from the harbor pollution's environmental justice implications through the late stages of the cleanup planning process. In spring 2016, during the local election cycle and just before the public comment period began, Mayor-elect Ted Wheeler even delivered his ballot via "tiny triathlon". He ceremonially swam across the Willamette, biked along the waterfront, walked a few blocks to Pioneer Courthouse Square, and dropped his voting card in the box, while reporters and campaign supporters looked on (Acker, 2016a). Then, a few months after his election and during the height of the public comment period, Wheeler joined the Human Access Project (HAP) for the First Annual Mayoral Swim. HAP's mission is to "transform Portland's relationship with the Willamette River" by building "more public spaces, beaches and access points to the Willamette River in downtown Portland, inspiring people to 'connect' with the river," and supporting "conservation, education and stewardship" of the river (Human Access Project, 2017). Thanks to HAP's advocacy, in 2015 the City of Portland allocated $\$ 300,000$ to the creation of an "urban beach" on the Willamette, just across the river from downtown Portland. In an interview with the Oregonian, Mayor Wheeler commented on the First Swim: 
The water quality's actually very good ... The river, in my opinion, based on the facts, the data I've seen, is perfectly safe for people ... A lot of the pollution you're seeing is actually in the soil ... Today we're going to swim in the water, the water quality is very good-we're not going to stop and eat mud on the bottom of the river. (Quoted in Acker, 2016b)

The Mayor's statement eerily echoes the comment made by a PRP representative to members of Portland's Latino community back in 2012, equating PCBs to "little bugs in the mud." For those relying on the river for sustenance, the Mayor's casual dismissal of concerns about the river's ecological integrity - and the City's enthusiastic support for swimming and public beaches, but not for Superfund-related outreach or a thorough cleanup - is illustrative of the depoliticized sustainability discourse that permeated the harbor cleanup planning processes.

But on the other hand, the Mayor's attitude is also illustrative of the precariousness of the pursuit of profit via sustainability fixes. At the same time that Portlanders became accustomed to shouting with glee while jumping off of docks into the cool river on hot summer afternoons over the last few years, in county courtrooms polluters quietly scared City officials away from taking meaningful steps to further clean up the river, including doing public outreach, generally, and engaging with impacted communities, specifically. Schmidt (2015) reported in the Oregonian that Portland's water and sewer rates are now amongst the steepest of all large cities in the US, rising 71percent between 2005 and 2015; construction of the Big Pipe accounts for much of the 
increase. Lobbyist Kent Craford and attorney John DiLorenzo have led suits against the City and BES, alleging illegal expenditures. They were also behind a 2013 ballot measure campaign to reduce utility charges. Representing entities that include Portland Harbor PRPs, such as Siltronic Corporation, Vigor Industrial, and Harsch Investment companies that do little to promote themselves as "green" - Craford notes that water and sewer rates "affect everyone", and that it is through the courts that he is "speaking up for both residential customers and big industrial users" alike (Theen, 2014). In addition to opposing federally mandated infrastructure improvements, Craford and DiLorenzo have put forth a narrative around wasteful spending on several other relatively small "questionable projects", including construction of two buildings, a house that demonstrated water-conservation technology, innovative public restrooms, and decorative park fountains. Superfund-related expenditures are also included in this list of dubious expenses. Despite putting relatively little money toward public outreach, BES put over $\$ 50$ million of ratepayer revenue (and another $\$ 8$ million from the City’s general fund) toward harbor-related expenses, including background studies, since 2001 (Schmidt, 2015).

In December 2016 and January 2017, a Multnomah County Circuit Court judge ruled that most of the City's expenditures in question have been justified—including Superfund spending (Floum, 2017). But in the interim, the lawsuits have had a chilling effect on the City's advocacy for a fully remediated harbor, precluding the City from dedicating resources for outreach to people who are the most affected by pollution. Most elementally, expenditures for outreach fall into the grey area repeatedly targeted by 
Craford and DiLorenzo as illegal uses of ratepayer revenue. An even more substantive area of concern for City officials, however, is likely around the Comprehensive Environmental Response, Compensation and Liability Act's "Joint and Several Liability" clause. According to the EPA, Joint and Several Liability means that "any one potentially responsible party (PRP) may be held liable for the entire cleanup of the site" (EPA, 2017b). In other words, the EPA can hand the entire cleanup bill to a single PRP, leaving it up to that entity to then wrangle money from other PRPs-but with no legal mechanism to ensure that they pay up. The clause is particularly susceptible to being invoked when "the harm caused by multiple parties cannot be separated" (ibid.), as is the case in the Portland Harbor. One Portland Harbor Community Advisory Group member reported that City officials disclosed concerns that if the EPA decided to invoke this clause, the City of Portland would be a particularly vulnerable target; whereas companies come and go, declare bankruptcy, and take other complicated turns, municipalities are constant. The more rigorous the cleanup plan put forth in the ROD, the higher the City's potential bill. City officials feared that bringing more attention to the Superfund site would generate residents' support for a more robust cleanup — but that ratepayers (or taxpayers, depending on the court's decision) would then be liable for the entire bill. Given that the EPA's estimated cost spread went as high as $\$ 9$ billion, the most extreme outcome would have had significant consequences for the City and its residents. Paradoxically, if officials spoke too loudly about concern over the Joint and Several Liability clause, the City also faced the possibility of setting a precedent for its liability. Now that the ROD has been released, it is still possible that the EPA will invoke Joint 
and Several Liability and assign the entire bill to the City, but the ceiling of the City's obligation is now closer to $\$ 1-2$ billion rather than $\$ 9$ billion.

This is the context in which public officials decided against conducting a robust public outreach process, and in which PHCC has been working to transcend the (green) development-displacement contradiction. And yet, through the entire public comment period, in large part because of the lack of meaningful dialogue between public agencies and impacted communities, PHCC leaders and members were mostly in the dark about these nuances. ${ }^{28}$ Coalition leaders were aware that ratepayer lawsuits were under way, but did not understand the implications of the Joint and Several Liability clause in this context. Instead, the coalition operated under the assumption that City leaders were prioritizing the interests of industry over those most impacted by pollution as a continuation of historical mistreatment of communities of color. In essence, that is what was happening. But had PHCC understood the larger picture of the City's potential liability, it is possible that the coalition could have worked more efficiently during the planning process. Instead, postpolitical sustainability discourse muddied the picture for PHCC, masking the durability of a status quo urban growth regime.

The question remains: Is depoliticized discourse that complicates matters for grassroots groups working for social and environmental justice unique to the green city? I

\footnotetext{
${ }^{28}$ It is important to note that, had the City taken a more "collaborative planning" approach (Innes and Booher, 2010), it would have offered no guarantee of more just outcomes given "deep differences" (Watson, 2006) in rationalities between decisionmakers and community members. PHCC, however, might have had more information with which to work had the City followed more of a communicative process.
} 
argue no, this is not a unique situation, writ large. As early as the turn of the century, urban planners pushing for sanitary improvements argued that advancements would benefit the rich and poor alike, when in reality it was people of privilege that gained the most from them. And in process-oriented Portland the question of how to push for more just outcomes have troubled activists for years. The tension between process and outcomes continues to trouble grassroots groups, including PHCC. And yet, as I have shown in this dissertation, there are also particularities that need to be unpacked in the sustainability era that matter for on-the-ground agents of change. A host of factors pose particular challenges, such as navigating both federal Superfund and local land use laws, addressing the contradictions arising from a green development-displacement dialectic in a context of disproportionate historical exposure to pollution, and challenging the actions of greenwashed corporations driving urban development—as well as the public agencies that facilitate them. While a legacy of activism over the past several decades indeed informs the actions of today's grassroots groups operating in the green city, there remain nuances that are unique to this context, begging close examination.

The case of PHCC helps to illuminate the tenuousness of sustainability fixes, shrouded in postpolitical sustainability discourse put forth by public agency officials: there is nothing automatic about economic growth continuing to occur along green lines, even in paradigmatic sustainable cities such as Portland. Returning to McCarthy's suggestion that scholars ask broader questions about the recurring ways in which different actors frame environmental problems and solutions in service to economic growth (instead of fixating, for instance, on what counts as "proper politics"), I argue that 
it is necessary to examine the role that depoliticized sustainability discourse currently plays in advancing urban growth coalition interests, green or otherwise.

\section{Theorizing Collective Action in the Green City}

By examining the relationship between sustainability discourse and growth regimes (green, greenwashed, or otherwise) in broader historical context, it is then possible to sharpen analysis of where current urban growth regimes might be vulnerable to challenges. To that end, the second overarching theoretical intervention that this dissertation makes relates to the way that green growth trajectories are not only susceptible to being undermined by traditional growth machine coalitions, but also by grassroots organizations with social and environmental justice goals. Addressing the contradictory, conflicting, messy relationship between these two dialectical poles is crucial to developing a full picture of how change happens.

Urban scholars have begun to theorize the relationship between grassroots groups working for social and environmental justice in contexts like the Portland Harbor Superfund Site and "the state", but have yet to fully articulate a theory of change that addresses the contradictions involved in challenging green(washed) growth coalitions for groups that do not separate environmental and environmental/social justice concerns. Notably, as I outline in Chapter 2, Pulido et al. (2016) have taken stock of situations in which, like the case of PHCC, public agencies dismiss the concerns of communities of color. Recall that of the 298 Title VI Complaints filed against the EPA prior to January 2014, only one has not been dismissed (Pulido et al., 2016:4). Pulido and colleagues 
argue that environmental justice groups' reliance on the state to check the power of polluters actually inhibits achievement of more just results. They suggest that environmental justice groups follow the lead of groups like Black Lives Matter (BLM) and others keener on direct action tactics rather than relying on official participation channels to convince the state to effectively regulate polluters, including the EPA's grievance process.

The case of PHCC provides an actually existing example of a grassroots group that has engaged public agencies outside of established channels. And yet, notwithstanding the coalition's rally at City Hall, PHCC has not pursued some of the more intense kinds of direct action tactics employed by BLM and other groups, such as marching in lanes of traffic, dangling off of bridges, staging hunger strikes, instituting boycotts, and other more drastic counter-power measures. At one summer 2016 meeting, coalition members discussed how to best sway the EPA to extend the public comment period another 120 days. One participant suggested staging a "die-in" on the Burnside Bridge, as BLM activists had recently done following yet another police shooting of an unarmed Black person. Other PHCC members, some who had been active with Portland's chapter of BLM and other direct action groups working for improved police accountability, disagreed with this tactic. The impact of harbor pollution on people has indeed been horrible, and the exploitation of land for profit is sickening, impacting communities' lives and livelihoods in disruptive and unjust ways for generations, they agreed. But cleaning up the harbor, generally, and extending the public comment period, specifically, are not quite on par with the urgency of addressing the police state murder of 
Black men and women on a near-daily basis, they argued, nor can everyone afford to risk arrest or bodily harm for this particular cause. And more simply, the resources (i.e., time, funds, bodies, etc.) needed to mobilize this sort of action were in short supply. Coalition members instead decided to rely on a mounting strength in numbers of people signing onto the coalition's collective public comment letter as well as submitting their own public comments, many of them invoking PHCC's historicized narrative, to sway the EPA largely from within established channels at that time.

PHCC is a grassroots organization that has been open to taking a more confrontational approach rather than simply engaging through bureaucratic channels, and indeed has employed a combination of the two in its work. This case demonstrates that while adversarial approaches may be needed at times, tactics need not necessarily be of the most drastic sort in order for change to come about in the green city. In the case of PHCC, we see an example of how change has unfolded in "radically incremental" (Pieterse, 2008) ways. PHCC has engaged with several government agencies around one particular project; sought the redistribution of public resources; forced the City and EPA to consider a wider range of issues; and helped dozens of impacted community members - many with little to no prior knowledge of the Superfund site process - learn about all aspects of the harbor in order to bring about progressive change. The coalition has its roots in critique of the cleanup planning process. Through direct action and other means, the coalition garnered funds to continue organizing and deepen members' engagement and critical analysis. In formal and informal communications with local and federal agencies, coalition members articulated grievances that public agencies had previously 
ignored. In large part, this required PHCC members to cut through the depoliticized, science and technology-heavy discourse that permeates sustainability discussion, illuminating the reality that sustainable development often further exacerbates rather than alleviates racialized poverty and oppression. PHCC members ultimately forced officials to begin to acknowledge the social relations that produce and perpetuate disparities, resulting in policy changes - and, notably, public commitments from City and EPA officials to be more responsive to impacted communities going forward. PHCC will face challenges during the implementation phase of these policy shifts, particularly given that the incoming Trump administration has threatened to gut the EPA such that enforcement of existing statutes may become all but impossible (Quirke, 2017), but what is clear is that ordinary people banded together to demand resources and policy shifts, and in so doing gained traction as legitimate players in future decision-making processes at the interconnected city and federal scales.

\section{Limitations}

As with all research, this project is not without shortcomings in terms of approach, methods, and findings. I undertook an intensely ethnographic approach, blending participant observation with participatory action research. Ethnographic research, including participant observation within the extended case method (ECM), allows researchers an intimate look into the day-to-day world under examination that would not be possible through less direct methods. The ECM, in particular, challenges the positivistic view that in order to really know something we have to objectively stand outside the circumstances being studied. At the same time, by positioning ourselves as 
researchers within the world under investigation, we influence that world. Burawoy (2009:9) describes the paradox at hand: "Inescapably," he says, "we live in the world we study." We cannot divorce sociology from history, but rather, "we are living history as we do research" (ibid.).

Over the course of researching and writing this dissertation, my own experience simultaneously "living history" while observing its unfolding was a complex and intensely subjective undertaking. For one thing, I have been explicitly attempting to understand an untold history (of the past and present) that has been largely omitted from official accounts. But more importantly, I have been working to co-produce an understanding of this history with others, including people surviving and thriving in the face of some of the most egregious elements of this history. Our shared commitment to learning this history stems from a desire to collectively remake the city and change history moving forward. In short, I have been attempting to undertake phronetic research, a social science approach rooted in a commitment to actually swaying a given social phenomenon or process.

And yet, many of the strengths of this approach also present challenges that are important to acknowledge. This orientation has allowed me to contribute to PHCC's undertakings. It also necessitates an extra dose of reflexivity in analysis of findings. Despite my best intentions to remain reflexive and responsive to those who have been most harmed by harbor pollution, the reality is that I had much more time to devote to this project than did most of those whose stories contribute to this research. I have been in frequent contact with PHCC representatives about this research along the way, and a 
few people have generously read all or portions of this writing and offered feedback. But, ultimately, coalition members explicitly and implicitly placed great trust in me to discern what should be included, and how it should be interpreted. I have taken this responsibility very seriously, but I know that there is still potential for misrepresentation.

Additionally, I sometimes struggled to discern what exactly my role should be at a given moment. My critical education background solidified my commitment to coproducing knowledge, and I attempted to take to heart the slogan "nothing about us, without us", which highlights the imperative that those who are most impacted by structures and policies have first and last say in how to change those structures. And yet, as I mentioned earlier and as Derickson and MacKinnon (2015) have articulated, resources, time, and energy are often in short supply in grassroots organizing. "The challenges that historically marginalized communities face in producing and enacting [alternative] visions of socionatural futures are material, cultural, and political," they argue. "What might seem to some like the banalities of poverty in the United States present meaningful, material barriers" for marginalized communities "to simply be together in space to reflect on their concerns and develop strategies for the future" (305). They therefore urge researchers not to "seek to produce a theory" of a given topic, but rather endeavor to produce a "politics that seeks to produce the conditions in which just theories ... can emerge" (306). In so doing, they talk about two different but related modes of "resourcefulness", in which researchers undertake both mundane tasks - grant writing, brochure creation, meeting facilitation, channeling university resources - as well 
as in terms of "triangulating" research questions to address both scholarly as well as community priorities.

To this end, and taking cues from Stoecker's (2012) "goose method", I attempted to take on leadership roles within PHCC when asked (i.e., in writing letters to public agencies, in planning for A People's View of the Portland Harbor filming), to assume responsibility for the nuts and bolts of coalition work when necessary (i.e., making copies, stuffing envelopes, writing grant applications) — and to take a step back to let others lead as well. I tried to truly trust that sometimes it is better in the long run to let things unfold slowly and in step with each other rather than steamrolling ahead, even if I felt I could accomplish a task more quickly on my own. The messiness of this work created dramatic tension with allies who were new to the coalition's work at times, but I feel strongly that I have a responsibility to adhere to PHCC's mission to raise the voices of those most impacted in the harbor, and that this requires working hand-in-hand with everyone, quirks and all, as much as possible and desired. At the same time, for example, at ten P.M., two hours prior to the EPA comment period deadline for accepting public comment, I knew that PHCC members were relying on me to get the final draft of the coalition's letter formatted and turned in.

Finally, I came up against the unavoidable limitations of time and practicality in this research. In an ideal world, I would have done a second round of interviews with PHCC members following the comment period, asking people to reflect back over the five years of work leading up to it. I also would have interviewed more public officials to hear about how the coalition's work influenced the decision-making process from their 
perspectives. And although a single case study (especially using an extended case method approach) allows for much more in-depth investigation than in a comparative or multiple case study design, it is impossible for a single person to be fully immersed in two places at once; that said, a comparative case would have added an important relational dimension.

\section{Avenues of Future (Engaged) Inquiry}

All of the limitations mentioned above, however, open space to think about avenues of future inquiry with potential to improve upon and augment this dissertation research. For example, in the coming months, I hope to follow up with several PHCC members, as well as public agency officials to gain a retrospective view that is less possible when researching in the moment. Another possible follow-up component could involve interviewing Steve at the Sierra Club as well as Sierra Club staff to understand more about how the conservation organization has taken a shift in recent years to be much more supportive of and responsive to social/environmental justice-focused groups like PHCC.

As I mentioned in the introduction, I will also work with PHCC representatives to determine exactly how to make the findings here useful to the coalition. We are currently laying groundwork to produce a comic book addressing "A People's History of the Portland Harbor", that will hopefully allow for a much more robust co-production of historical knowledge, as well as inform the coalition's work moving forward. Such a project would build on the historical dimensions of the coalition's film, as well as on the 
cursory historical research I detail here to make much fuller use of local oral history resources (i.e., Vanport Mosaic).

Another possibility for future research in a historical vein is to contribute to the People's Guide series that Laura Pulido initiated, along with Laura Barraclough and Wendy Chang, when they wrote A People's Guide to Los Angeles (2012). The guide is a "radical tourbook that highlights sites of racial, class, gender, and environmental struggle in Los Angeles County's history and landscape" (Pulido, 2017). The University of California Press has commissioned a People's Guide series, and teams are currently working on editions for Atlanta, Berlin, Boston, Chicago, Nashville, New Orleans, New York, Orange County, Portland, and the San Francisco Bay area. I am in touch with the Portland guide authors and may work on this in some capacity with them over the next few years.

Finally, going back to the original inspiration for this research, I hope to draw on this dissertation to write a book about the work of PHCC. My hope is that this book would be helpful to grassroots leaders working in similar contexts in other cities, as well as scholars, students, and practitioners working in the areas of community development/organizing, environmental management, public policy, and urban planning. Taking inspiration from James Tracy's (2014) Dispatches Against Displacement, I will aim for writing that is both theoretically and empirically grounded, and that is written in a way that is accessible and useful to people working on the front lines. One additional possibility for such a book would be to interview leaders working with the Duwamish River Cleanup Coalition, for a comparative perspective. I have already travelled to 
Seattle a handful of times in order to begin to develop my understanding of the Duwamish River Superfund cleanup, which is a few years ahead of Portland; making this comparison explicit could be very beneficial. 


\section{References}

Abbott, C. (1983). Portland: Planning, Politics and Growth in a Twentieth-Century City. Lincoln, Nebraska: University of Nebraska Press.

Acker, L. (2016a). Ted Wheeler to swim the Willamette again. OregonLive. www.oregonlive.com/portland/index.ssf/2016/08/ted_wheeler_to_swim_the_willam.html (last accessed 8 February 2017)

Acker, L. (2016b). We swam across the Willamette with Ted Wheeler and it wasn't even gross at all. OregonLive.

www.oregonlive.com/portland/index.ssf/2016/08/ted_wheeler_to_swim_the_willam.html (last accessed 8 February 2017)

Agyeman, J. (2005). Sustainable Communities and the Challenge of Environmental Justice. New York: NYU Press.

Agyeman, J. (2013). Introducing Just Sustainabilities: Policy, Planning, and Practice. New York: Zed Books.

Alinsky, S. (1971 [1989]). Rules for Radicals: A Practical Primer for Realistic Radicals. Vintage Books.

Anguelovski, I. (2011). Neighborhood as Refuge: Community Reconstruction, PlaceRemaking, and Environmental Justice in the City. Cambridge, Massachusetts: MIT Press.

Anguelovski, I. (2013). New directions in urban environmental justice: Rebuilding community, addressing trauma, and remaking place. Journal of Planning Education and Research, 1-16.

Anguelovski, I. (2016). From toxic sites to parks a (green) LULUs? New challenges of inequity, privilege, gentrification, and exclusion for urban environmental justice. Journal of Planning Literature, 31(1), 23-36.

Arnstein, S. (1969). A ladder of citizen participation. Journal of the American Institute of Planners, 35(4), 216-224.

Atlas, J. (2010). Seeds of Change: The Story of ACORN, America's Most Controversial Antipoverty Community Organizing Group. Nashville: Vanderbilt University Press.

Audubon Society of Portland (2016). [letter] http://portlandharborcag.info/sites/default/files/AudubonSocietyofPortlandCommentsonP ortlandHarborSuperfundPlan9-6-16final\%20(1).pdf (last accessed 8 February 2017) 
Bakan, J. (2016). Integrating Film in Research. www.grad.ubc.ca/about-us/news/facultyfilmmakers-discuss-integrating-film-research (last accessed 8 February 2017)

Banzhaf, H. and E. McCormick (2012). Moving beyond Cleanup. In S. Banzhaf, (Ed.) The Political Economy of Environmental Justice, (pp. 23-51). Stanford: Stanford University Press.

Bates, L. (2013). Gentrification and displacement study: Implementing an equitable inclusive development strategy in the context of gentrification. Commissioned by the City of Portland's Bureau of Planning and Sustainability. www.portlandoregon.gov/bps/article/454027 (last accessed 8 February 2017)

Bates, Curry-Stevens, and Coalition of Communities of Color (2014). The African American community in Multnomah County: An unsettling profile.

http://pdxscholar.library.pdx.edu/cgi/viewcontent.cgi?article=1135\&context=socwork_fa c (last accessed 8 February 2017)

Bayer, I. (2014). Paul Boden and the history of homelessness as we know it today. Street Roots. http://news.streetroots.org/2014/07/02/paul-boden-and-history-homelessness-weknow-it-today (last accessed 8 February 2017)

Bevington, D. and C. Dixon (2005). Movement-relevant theory: Rethinking social movement scholarship and activism. Social Movement Studies, 4(3), 185-208.

Blalock, B. (2012). Portland's Lost Waterfront: Tall Ships, Steam Mills and Sailors' Boardinghouses. Charleston, South Carolina: The History Press.

Boyd, R. (1975). Another look at the 'fever and ague' of Western Oregon. Ethnohistory, 22(2), 135-154.

Boyd, R. (2013). Lower Chinookan disease and demography. In R. Boyd, K. Ames, and T. Johnson (Eds.), Chinookan Peoples of the Lower Columbia (pp. 229-249). Seattle, Washington: University of Washington Press.

Brooks, K., G. Bosker, and T. Gelber (2012). The Mighty Gastropolis Portland: A Journey Through the Center of America's New Food Revolution. San Francisco, California: Chronicle Books.

Bullard, R. (2005). The Quest for Environmental Justice: Human Rights and the Politics of Pollution. San Francisco: Sierra Club Books.

Bunce, S. (2009). Developing sustainability: Sustainability policy and gentrification on Toronto's waterfront. Local Environment, 14(7), 651-667. 
Bunce, S. (forthcoming). Sustainability Policy, Planning and Gentrification in Cities. Routledge.

Bunce, S. and G. Desfor (2007). Introduction to 'Political ecologies of urban waterfront transformations'. Cities, 24(4), 251-258.

Burawoy, M. (2009). The Extended Case Method: Four Countries, Four Decades, Four Great Transformations, and One Theoretical Tradition. Berkeley: University of California Press.

Campbell, S. (1996). Green cities, growing cities, just cities? Urban planning and the contradictions of sustainable development. Journal of the American Planning Association, 62(3), 296-312.

Carter, E. (2016). Environmental justice 2.0: New Latino environmentalism in Los Angeles. Local Environment: The International Journal of Justice and Sustainability, 21(1), 3-23.

Causa Justa/Just Cause (2014). Development without displacement: Resisting gentrification in the Bay Area. http://cjjc.org/wp-content/uploads/2015/11/developmentwithout-displacement.pdf (last accessed 8 February 2017)

Checker, M. (2005). Polluted Promises: Environmental Racism and the Search for Justice in a Southern Town. New York: NYU Press.

Checker, M. (2011). Wiped out by the 'greenwave': Environmental gentrification and the paradoxical politics of urban sustainability. City \& Society, 23(2), 201-229.

Choudry, A. (2015). Learning Activism: The Intellectual Life of Contemporary Social Movements. Toronto: University of Toronto Press.

City of Portland (2013). City of Portland Civil Rights Title VI Plan. Office of Management and Finance, Bureau of Internal Business Services. www.portlandoregon.gov/oehr/article/523687 (last accessed 8 February 2017)

City of Portland (2016). [Letter] www.portlandoregon.gov/bes/article/588692 (last accessed 8 February 2017)

Coalition for a Livable Future (2013). The Regional Equity Atlas: Metropolitan Portland's Geography of Opportunity. http://clfuture.org/programs/regional-equityatlas/maps-and-analysis/ (last accessed 8 February 2017)

Columbia River Inter-Tribal Fish Commission (1994). A fish consumption survey of the Umatilla, Nez Perce, Yakama and Warm Springs Tribes of the Columbia River Basin. CRITFC Technical Report No. 94-3. Portland, Oregon. 
Cook, I. and E. Swyngedouw (2012). Cities, social cohesion and the environment: Towards a future research agenda. Urban Studies, 49(9), 1959-1979.

Corburn, J. (2005). Street Science: Community Knowledge and Environmental Health Justice. Cambridge, Massachusetts: MIT Press.

Curran, W. and T. Hamilton (2012). Just green enough: Contesting environmental gentrification in Greenpoint, Brooklyn. Local Environment: The International Journal of Justice and Sustainability, 17(9), 1027-1042.

Curry-Stevens, Ann, Amanda Cross-Hemmer, and Coalition of Communities of Color (2010). Communities of color in Multnomah County: An unsettling profile. http://coalitioncommunitiescolor.org/docs/AN\%20UNSETTLING\%20PROFILE.pdf (last accessed 8 February 2017)

Curry-Stevens, Cross-Hemmer, Coalition of Communities of Color (2011). The Native American community in Multnomah County: An unsettling profile. http://pdxscholar.library.pdx.edu/cgi/viewcontent.cgi?article=1093\&context=socwork_fa c (last accessed 8 February 2017)

Davidson, M. (2010). Sustainability as ideological praxis: The acting out of planning's master-signifier. City, 14(4), 390-405.

Davidson, M. and K. Iveson (2014). Recovering the politics of the city: From the 'postpolitical city' to a 'method of equality' for critical urban geography. Progress in Human Geography, 1-17.

Davidson, M. and L. Lees (2010). New-build gentrification: Its histories, trajectories, and critical geographies. Population, Space and Place. 16, 395-411.

deFur, P. (2016). [Presentation] http://portlandharborcag.info/node/445 (last accessed 8 February 2017)

DeFilippis, J. (2004). Unmaking Goliath: Community Control in the Face of Global Capital. New York: Routledge.

DeFilippis, J., R. Fisher, and E. Shragge (2010). Contesting Community: The Limits and Potential of Local Organizing. New Jersey: Rutgers University Press.

Derickson, K. and D. MacKinnon (2015). Toward an Interim Politics of Resourcefulness for the Anthropocene. Annals of the American Association of Geographers, 105(2), 304312.

Dillon, L. (2014). Race, waste, and space: Brownfield redevelopment and environmental justice at the Hunters Point shipyard. Antipode, 46(5), 1205-1221. 
Dillon, L. and J. Sze (2016). Police power and particulate matters: Environmental justice and the spatialities of in/securities in U.S. cities. English Language Notes.

Dooling, S. (2009). Ecological gentrification: A research agenda exploring justice in the city. International Journal of Urban and Regional Research, 33(3), 621-639.

Doussard, M. (2013). Degraded Work: The Struggle at the Bottom of the Labor Market. Minneapolis: University of Minnesota Press.

Dubet, F. (1994). The system, the actor, and the social subject. Thesis Eleven, 38, 16-35.

Dubet, F. (2004). Between a defence of society and a politics of the subject: The specificity of today's social movements. Current Sociology, 52(4), 693-716.

Duffy, L. (2014). Portland proves to be 'America's bike capital' in U.S. Census. $O P B$ News Blog. www.opb.org/news/blog/newsblog/portland-proves-to-be-americas-bikecapital-in-us-census/ (last accessed 8 February 2017)

Ellis, D. (2013). Cultural geography of the Lower Columbia. In R. Boyd, K. Ames, and T. Johnson (Eds.), Chinookan Peoples of the Lower Columbia (pp. 42-62). Seattle, Washington: University of Washington Press.

Emerson, R., R. Fretz, and L. Shaw (2011). Writing Ethnographic Fieldnotes. Chicago: University of Chicago Press.

EPA (2013). Portland Harbor Human Health Risk Assessment Summary. https://www3.epa.gov/region10/pdf/ph/sitewide/human_health_risk_assessment_factshee t_aug2013.pdf

EPA (2016). Portland Harbor Superfund Site: Superfund Proposed Plan. https://yosemite.epa.gov/R10/CLEANUP.NSF/ph/Portland+Harbor+Superfund+Site (last accessed 8 February 2017)

EPA (2017a). Record of Decision.

https://yosemite.epa.gov/R10/CLEANUP.NSF/ph/Portland+Harbor+Superfund+Site (last accessed 8 February 2017)

EPA (2017b). Superfund Liability. https://www.epa.gov/enforcement/superfund-liability (last accessed 8 February 2017)

EPA (2016c). Community Advisory Groups. www.epa.gov/superfund/communityadvisory-groups (last accessed 8 February 2017)

Eyerman, R. (2001). Cultural Trauma: Slavery and the Formation of African American Identity. New York: Cambridge University Press. 
Faber, D. and S. Kimelberg (2014). Sustainable urban development and environmental gentrification: The paradox confronting the U.S. environmental justice movement. In H. Hall, C. Robinson, and A. Kohli (Eds.), Uprooting Urban America: Multidisciplinary Perspectives on Race, Class \& Gentrification (pp.77-92). New York: Peter Lang Publishers.

Finney, C. (2014). Black Faces, White Spaces: Reimagining the Relationship of African Americans to the Great Outdoors. Chapel Hill: The University of North Carolina Press.

First Stop Portland (2014). The Weekly Post, 4(29), 7 August 2014. [electronic newsletter]

Floum, J. (2017). Portland OK to spend millions of utility ratepayer money on Superfund cleanup. OregonLive.

www.oregonlive.com/politics/index.ssf/2017/01/portland_okay_to_spend_million.html (last accessed 8 February 2017)

Flyvbjerg, B. (2001). Making Social Science Matter: Why Social Inquiry Fails and How It Can Succeed Again. Cambridge: Cambridge University Press.

Flyvbjerg, B., T. Landman, and S. Schram (2012). Real Social Science: Applied Phronesis. Cambridge: Cambridge University Press.

Foley, G. (1999). Learning in Social Action: A Contribution to Understanding Informal Education. Zed Books.

Freire, P. (2000 [1970]). Pedagogy of the Oppressed. Bloomsbury Academic.

Gamper-Rabindran, S. and C. Timmins (2011). Hazardous waste cleanup, neighborhood gentrification, and environmental justice: Evidence from restricted access census block data. The American Economic Review, 101(3), 620-624.

Gamper-Rabindran, S. and C. Timmins (2013). Does cleanup of hazardous waste sites raise housing values? Evidence of spatially localized benefits. Journal of Environmental Economics and Management, 65(3), 345-360.

Gibbs, L. (1982). Love Canal and the Birth of the Environmental Health Movement. Gabriola Island, BC: New Society Publishers.

Gibson, K. (2007). Bleeding Albina: A history of community disinvestment, 1940-2000. Transforming Anthropology, 15(1), 3-25.

Gilmore, R. W. (2007). Golden Gulag: Prisons, Surplus, Crisis, and Opposition in Globalizing California. Berkeley, California: University of California Press. 
Goodling, E. (2016). Roy Pascoe: 'If I wasn't fighting for my life, I'd be fighting for the river'. Street Roots. http://news.streetroots.org/2016/06/02/roy-pascoe-if-i-wasn-tfighting-my-life-i-d-be-fighting-river (last accessed 8 February 2017)

Goodling, E., J. Green, and N. McClintock (2015). Uneven development of the sustainable city: Shifting capital in Portland, Oregon. Urban Geography, 36(4), 504-527.

Goodling, E. and C. Herrington. (2014). Reversing complete streets disparities: Portland's community watershed stewardship program. In S. Zavestoski and J. Agyeman (Eds.), Incomplete Streets: Processes, Practices, and Possibilities (pp. 176-202). New York: Routledge.

Gould, K. A., and T. L. Lewis (2016). Green Gentrification: Urban Sustainability and the Struggle for Environmental Justice. New York: Routledge.

Griffin-Valade, L., D. Kahn, and K. Adams-Wannberg (2010). City of Portland: 20th Annual Community Survey Results. Portland, Oregon: Office of the City Auditor. www.portlandoregon.gov/auditservices/article/325076 (last accessed 8 February 2017)

Gunder, M. (2006). Sustainability: Planning's saving grace or road to Perdition? Journal of Planning Education and Research, 26, 208-221.

Hackworth, J. (2007). The Neoliberal City: Governance, Ideology, and Development in American Urbanism. Ithaca: Cornell University Press.

Haffner, J. (2015). The dangers of eco-gentrification: What's the best way to make a city greener? The Guardian. www.theguardian.com/cities/2015/may/06/dangers-

ecogentrification-best-way-make-city-greener (last accessed 8 February 2017)

Hagerman, C. (2007). Shaping neighborhoods and nature: Urban political ecologies of urban waterfront transformations in Portland, Oregon. Cities, 24(4), 285-297.

Hale, C. (Ed.) (2008). Engaging Contradictions: Theory, Politics, and Methods of Activist Scholarship. Berkeley: University of California Press.

Hannah-Jones, N. (2011). In Portland's heart, 2010 census shows diversity dwindling. The Oregonian. www.oregonlive.com/pacific-northwestnews/index.ssf/2011/04/in_portlands_heart_diversity_dwindles.html (last accessed 8 February 2017)

Harvey, D. (1989). The Urban Experience. Baltimore: The Johns Hopkins University Press.

Harvey, D. (2001). Spaces of Capital: Towards a Critical Geography. New York: Routledge. 
Harvey, D. (2007). Limits to Capital. London: Verso.

Harvey D. (2014). Seventeen Contradictions and the End of Capitalism. Oxford: Oxford University Press.

Hern, M. (2016). What a City is For: Remaking the Politics of Displacement. Cambridge, Massachusetts: MIT Press.

Heynen, N. (2015). Urban political ecology II: The abolitionist century. Progress in Human Geography, 1-7.

Heynen, N., M. Kaika, and E. Swyngedouw (2006). Urban political ecology: Politicizing the production of urban natures. In N. Heynen, M. Kaika, and E. Swyngedouw (Wds.), In the Nature of Cities: Urban Political Ecology and the Politics of Urban Metabolism. London: Routledge.

Highlander Center (2017). http://highlandercenter.org/media/timeline/ (last accessed 8 February 2017)

Hillegas, J. (2005). Working for the 'working river': Willamette River water pollution, 1926 to 1962. Portland State University. [Master's thesis]

Holifield, R. (2007). Neoliberalism and environmental policy. In N. Heynen, J. McCarthy, and P. Robbins (Eds.), Neoliberal Environments: False Promises and Unnatural Consequences. New York: Routledge.

Horton, M. and P. Freire (1990). We Make the Road By Walking: Conversations on Education and Social Change. Philadelphia: Temple University Press.

Human Access Project (2017). www.humanaccessproject.com (last accessed 8 February 2017)

Hume, S. and S. Hardwick (2005). African, Russian, and Ukrainian refugee resettlement in Portland, Oregon. Geographical Review, 95(2), 189-209.

Industrial Areas Foundation (2017). www.industrialareasfoundation.org/content/mission (last accessed 8 February 2017)

Innes J. and D. Booher (2010). Planning With Complexity: An Introduction to Collaborative Rationality for Public Policy. New York: Routledge.

Knox, P. and R. Florida (2014). Atlas of Cities. Princeton, New Jersey: Princeton University Press.

Lafazani, O. (2012). The border between theory and activism. ACME, 11(2), 189-193. 
Lang, W. (2010). One city, two rivers. In C. Miller (Ed.) Cities and Nature in the American West. Reno, Nevada: University of Nevada Press.

Lawhon, M., H. Ernstson, and J. Silver (2014). Provincializing urban political ecology: Towards a situated UPE through African urbanism. Antipode, 46(2), 497-516.

Lewis, D., E. Thorsgard, and C. Williams (2013). Honoring our tilixam: Chinookan people of Grand Ronde. In R. Boyd, K. Ames, and T. Johnson (Eds.), Chinookan Peoples of the Lower Columbia (pp. 307-325). Seattle, Washington: University of Washington Press.

Logan, J. and H. Molotch (2007). Urban Fortunes: The Political Economy of Place. Berkeley: University of California Press.

Long, J. (2014). Constructing the narrative of the sustainability fix: Sustainability, social justice and representation in Austin, TX. Urban Studies, 53(1).

MacLeod, G. (2011). Urban politics reconsidered: Growth machine to post-democratic city? Urban Studies, 48(12), 2629-2660.

Mank, B. (2008). Title VI. In M. Gerrard and S. Foster (Eds.), The Law of Environmental Justice: Theories and Procedures. (pp. 22-65). Chicago: American Bar Association.

Marx, K. (2012 [1867]). Das Kapital: Critique of Political Economy (Volume 1). Aristeus Books.

McCarthy, J. (2013). We have never been 'post-political'. Capitalism Nature Socialism, 24(1), 19-25.

McFarlane, C. (2011). Learning the City: Knowledge and Translocal Assemblage. West Sussex, UK: Wiley-Blackwell.

Merrifield, A. (2002). Dialectical Urbanism. Monthly Review Press.

Mesh, A. (2012). What the muck? Willamette Week. www.wweek.com/portland/article18986-what-the-muck.html (last accessed 8 February 2017)

Metcalfe, J. (2016). The winners of the C40 Cities Awards for Climate Change. CityLab. www.citylab.com/weather/2016/12/c40-cities-awards-climate-change-plans/509270/ (last accessed 8 February 2017)

Metropolitan Group (2016). www.metgroup.com/what-we-do/ (last accessed 8 February 2017)

Miller, J. (2015). Super Fun Superfund: Polluted Protection Along the Gowanus Canal. [Dissertation] 
Minow Smith, D. (2012). Breaking: Portland sustainability chief admits 'Portlandia' isn't really a parody. Grist. http://grist.org/cities/breaking-portland-sustainability-chief-admitsportlandia-isnt-really-a-parody/ (last accessed 8 February 2017)

Multnomah County (2015). Point-in-time count of homelessness in Portland/Gresham/Multnomah County, Oregon. https://multco.us/file/42320/download (last accessed 12 April 2017)

Multnomah County Health Department (2014). Report Card on Racial and Ethnic Disparities. https://multco.us/file/37539/download (last accessed 8 February 2017)

Nester, P. (1983). First Half of My Life. Salem, Oregon: Willamette University Press.

Nixon, R. (2011). Slow Violence and the Environmentalism of the Poor. Cambridge, Massachusetts: Harvard University Press.

Oregon Health Authority (2017).

http://public.health.oregon.gov/HealthyEnvironments/TrackingAssessment/Environmenta 1HealthAssessment/Pages/phsite.aspx (last accessed 8 February 2017)

Oregon Public Broadcasting (2015). Lift Ev'ry Voice.

http://watch.opb.org/video/2365467028/ (last accessed 8 February 2017) [Film]

Oregon Sustainable Agriculture Land Trust (2016). www.osalt.org (last accessed 8 February 2017)

Olsson J. and E. Hysing (2012). Theorizing inside activism: Understanding policymaking and policy change from below. Planning Theory and Practice, 13(2), 257-273.

Oregon Department of Fish and Wildlife (2016). Trustee Council Fact Sheet www.fws.gov/oregonfwo/contaminants/portlandharbor/Documents/TrusteeCouncilFactS heet.pdf (last accessed 8 February 2017)

Pearsall, H. (2013). Superfund me: A study of resistance to gentrification in New York City. Urban Studies, 1-18.

Pearson, R. (1996). African Americans in Portland, Oregon, 1940-1950: Work and Living Conditions-A Social History. [Dissertation]

Pellow, D. and R. Brulle (2005). Power, Justice, and the Environment: A Critical Appraisal of the Environmental Justice Movement. Cambridge: MIT Press.

Pellow, D. (2016). Toward a critical environmental justice studies: Black Lives Matter as an environmental justice challenge. DuBois Review, 13(2), 221-236. 
Pierce, J. and H. Pearsall (2017). A spoiled well (of data): Addressing the procedural injustice of contemporary environmental justice research through collaborative qualitative data gathering. Local Environment, 22(3), 388-392.

Pierson, P. (2004). Politics in Time: History, Institutions, and Social Analysis. Princeton, NJ: Princeton University Press.

Pieterse, E. (2008). City Futures: Confronting the Crisis of Urban Development. Lansdowne, South Africa: University of Cape Town Press.

Piven, F.F. (2006). Challenging Authority: How Ordinary People Change America. Lanham, Maryland: Rowman and Littlefield Publishers, Inc.

Piven, F.F. and R. Cloward (1977). Poor People's Movements: Why They Succeed, How They Fail. Vintage Books.

Portland Harbor Community Coalition (2014). http://ourfutureriver.org/stories/ (last accessed 8 February 2017)

Portland Harbor Community Coalition (2015). A People's View of the Portland Harbor [Film] www.ourfutureriver.org (last accessed 8 February 2017)

Profita, C. (2014). A guide to the Portland Harbor Superfund Site. Oregon Public Broadcasting. www.opb.org/news/blog/ecotrope/a-guide-to-the-portland-harborsuperfund-site/ (last accessed 8 February 2017)

Profita, C. (2016). Portland's toxic graveyard for World War II ships. Portland Tribune. http://portlandtribune.com/pt/9-news/335347-214776-portlands-toxic-graveyard-forworld-war-ii-ships (last accessed 8 February 2017)

Pulido, L. (2000). Rethinking environmental racism: White privilege and urban development in Southern California. Annals of the Association of American Geographers, $90(1), 12-40$.

Pulido, L. (2008). FAQs: Frequently (un)asked questions about being a scholar activist. In C. Hale (Ed.), Engaging Contradictions: Theory, Politics, and Methods of Activist Scholarship (pp. 341-365). Berkeley and London: University of California Press.

Pulido, L. (2015). Geographies of race and ethnicity I: White supremacy vs white privilege in environmental racism research. Progress in Human Geography, 39(6), 809817.

Pulido, L. (2016). Geographies of race and ethnicity II: Environmental racism, racial capitalism and state-sanctioned violence. Progress in Human Geography, 1-10. 
Pulido, L. (2017). A people's guide. www.laurapulido.org/copy-of-environmental-justice (last accessed 8 February 2017)

Pulido, L., R. Barraclaugh, and W. Chang (2012). A People's Guide to Los Angeles. Berkeley, California: University of California Press.

Pulido, L., E. Kohl, and N. Cotton (2016). State regulation and environmental justice: The need for strategy reassessment. Capitalism Nature Socialism, 1-20.

Quastel, N. (2009). Political ecologies of gentrification. Urban Geography, 30(7), 694725 .

Quirke, S. (2017). Willamette Superfund cleanup expected to proceed under Trump. Street Roots. http://news.streetroots.org/issue/2017-02-03 (last accessed 8 February 2017)

Rabin, C. (2016). Cop shoots caretaker of autistic man playing in the street with toy truck. Miami Herald. www.miamiherald.com/news/local/crime/article90905442.html (last accessed 8 February 2017)

Right 2 Survive (2016). https://right2survive.wordpress.com/about/ (last accessed 8 February 2017)

Robbins, W. (2002). Pollution in paradise. The Oregon History Project. https://oregonhistoryproject.org/narratives/this-land-oregon/people-politics-andenvironment-since-1945/pollution-in-paradise/\#.WIjLS7YrJE6 (last accessed 8 February 2017)

Rodriguez, A. (2014). Growth in illegal camping along Willamette River sparks frustration among environmentalists. OregonLive.

www.oregonlive.com/portland/index.ssf/2014/10/growth_in_illegal_camping_alon.html (last accessed 8 February 2017)

Rome, E. and J. Bell (2012). Community perspectives on the future of the Portland Harbor and the Willamette River. Portland State University. [Report]

Rose, J. (2016). Homelessness: Portland's Great Depression Hoovervilles vs. 'Halesvilles' (photos). OregonLive.

www.oregonlive.com/history/2016/04/homelessness_portland_hoovervi.html (last accessed 8 February 2017)

Rutland, T. (2013). Activists in the making: Urban movements, political processes and the creation of political subjects. International Journal of Urban and Regional Research, 37(3), 989-1011.

Schafran, A. (2014). Debating urban studies in 23 steps. City, 18(3), 321-330. 
Schmidt, B. (2015). Portland explained: How alleged misspending put city on hook for millions of dollars. OregonLive.

www.oregonlive.com/portland/index.ssf/2015/07/portland_explained_how_alleged.html (last accessed 8 February 2017)

Scott, J. (1990). Domination and the Arts of Resistance: Hidden Transcripts. New Haven, Connecticut: Yale University Press.

Shragge, E. (2013). Activism and Social Change: Lessons for Community Organizing. Toronto: University of Toronto Press.

Sibley, D. (1995). Geographies of Exclusion: Society and Difference in the West. London: Routledge.

Slavin, M., and K. Snyder (2011). Strategic climate action planning in Portland. In M. Slavin (Ed.), Sustainability in America's Cities: Creating the Green Metropolis (pp. 2140). Washington DC: Island Press.

Smith, N. (1982). Gentrification and uneven development. Economic Geography, 58(2), 139-155.

Smith, N. (1996). The New Urban Frontier: Gentrification and the Revanchist City. New York: Routledge.

Smith, N. (2008). Uneven Development: Nature, Capital, and the Production of Space. Athens, Georgia: University of Georgia Press.

Smith, E. (2016). As Springwater Corridor sweep continues, Portland tallies cleanup results. OregonLive.

www.oregonlive.com/portland/index.ssf/2016/09/as_springwater_corridor_sweep.html (last accessed 8 February 2017)

Smith, A. and Taylor, Q. (1980). Racial discrimination in the workplace: A study of two west coast cities during the 1940s. The Journal of Ethnic Studies, 8(1). http://search.proquest.com/openview/821f83ccdb6039341db6892abc0ba0e1/1?pqorigsite $=$ gscholar\&cbl $=1821393$ (last accessed 8 February 2017)

Sonnie, A. and J. Tracy (2011). Hillbilly Nationalists, Urban Race Rebels, and Black Power: Community Organizing in Radical Times. Brooklyn, New York: Melville House.

Spores, R. (1993). Too small a place: The removal of the Willamette Valley Indians, 1850-1856. American Indian Quarterly, 17(2), 171-191.

Starbird, E. (1972). A river restored: Oregon's Willamette. National Geographic 141(6), 816-834. 
Stehlin, J. and A. Tarr (2016). Think regionally, act locally? Gardening, cycling, and the horizon of urban spatial politics. Urban Geography.

Stoecker, R. (2012). Research Methods for Community Change: A Project-Based Approach. Los Angeles, California: Sage.

Strom, S. (2003). Oregon Steel settles pollution lawsuit. Portland Business Journal. www.bizjournals.com/portland/stories/2003/08/18/daily10.html (last accessed 8 February 2017)

Sullivan, K. (2016). Lonely Planet's top cities and countries to visit in 2017. Newsday. www.newsday.com/travel/lonely-planet-s-top-cities-and-countries-to-visit-in-20171.12633237 (last accessed 8 February 2017)

Sundling, D. and S. Buck (2012). Fish Consumption in the Portland Harbor. The Brattle Group.

www.brattle.com/system/news/pdfs/000/000/087/original/Fish_Consumption_in_Portlan d_Harbor_Sunding_Buck_Oct_23_2012.pdf?1377791286 (last accessed 8 February 2017)

Swyngedouw, E. (1999). Modernity and hybridity: Nature, regeneracionism, and the production of the Spanish waterscape, 1890-1930. Environment and Planning A, 29(2), 311-332.

Swyngedouw, E. (2007). Impossible 'sustainability' and the postpolitical condition. In R. Krueger and D. Gibbs (Eds.), The Sustainable Development Paradox: Urban Political Economy in the United States and Europe. New York: The Guilford Press.

Swyngedouw, E. (2009) The antinomies of the postpolitical city: In search of a democratic politics of environmental production. International Journal of Urban and Regional Research, 33(3), 601-620.

Sze, J. (2007). Noxious New York: The Racial Politics of Urban Health and Environmental Justice. Cambridge, Massachusetts: MIT Press.

Taylor, D. (2000). The rise of the environmental justice paradigm: Injustice framing and the social construction of environmental discourses. American Behavioral Scientist, 43(4), 508-580.

Taylor, D. (2009). The Environment and the People in American Cities, 1600s-1900s: Disorder, Inequality, and Social Change. Duke University Press.

Taylor, D. (2014). Toxic Communities: Environmental Racism, Industrial Pollution, and Residential Mobility. New York: NYU Press. 
Temenos, C., and E. McCann (2012). The local politics of policy mobility: learning, persuasion, and the production of a municipal sustainability fix. Environment and Planning A, 44(6), 1389-1406.

The United States Commission on Civil Rights (2003). Not in my backyard: Executive Order 12898 and Title VI as tools for achieving environmental justice. Washington, DC: U.S. Commission on Civil Rights.

Theen, A. (2014). Portland Public Water District: Kent Craford pushes for reform as city leaders call him a corporate shill. OregonLive.

www.oregonlive.com/portland/index.ssf/2014/04/portland_public_water_district_6.html (last accessed 8 February 2017)

Tracy, J. (2014). Dispatches Against Displacement: Field Notes from San Francisco's Housing Wars. Oakland: AK Press.

Trahant, M. (2016). Standing Rock Tribe defied history. Indian Country Media Network. https://indiancountrymedianetwork.com/news/politics/standing-rock-tribe-defied-historywhat-happens-next-anything-inevitable/ (last accessed 8 February 2017)

Tretter, E. (2013). Contesting sustainability: 'SMART Growth' and the redevelopment of Austin's Eastside. International Journal of Urban and Regional Research, 37(1), 297 310 .

United Church of Christ (UCC) (1987). Toxic Wastes and Race in the United States.

U.S. Department of Justice. Title VI of the Civil Rights Act of 1964.

www.justice.gov/crt/fcs/TitleVI-Overview (last accessed 8 February 2017)

VanderHart, D. (2016). "Portland's finally going to talk to disadvantaged folks about their filthy river". The Portland Mercury.

www.portlandmercury.com/news/2016/04/13/17877389/portlands-finally-going-to-talkto-disadvantaged-folks-about-their-filthy-river (last accessed 5 May 2017)

Walker, S. (2009). Beyond distribution and proximity: Exploring the multiple spatialities of environmental justice. Antipode, 41(4), 614-636.

Walker, S. (2015). Urban agriculture and the sustainability fix in Vancouver and Detroit. Urban Geography, 1-20.

Warren, M. (2001). Dry Bones Rattling: Community Building to Revitalize American Democracy. Princeton, New Jersey: Princeton University Press.

Watson, V. (2006). Deep difference: Diversity, planning and ethics. Planning Theory, 5(31), 31-50. 
Whaley, G. (2010). Oregon and the Collapse of Illahee: U.S. Empire and the Transformation of an Indigenous World, 1792-1859. Chapel Hill: University of North Carolina Press.

While, A., A. Jonas, and D. Gibbs (2004). The environment and the entrepreneurial city: Searching for the urban 'sustainability fix' in Manchester and Leeds. International Journal of Urban and Regional Research, 28(3), 549-569.

Williams, R. (1989). Resources of Hope: Culture, Democracy, Socialism. London: Verso. Wisdom of the Elders (2017). www.wisdomoftheelders.org (last accessed 8 February 2017)

Wolch, J., J. Byrne, and J. Newell (2014), Urban green space, public health, and environmental justice: The challenge of making cities 'just green enough'. Landscape and Urban Planning, 125, 234-244.

Yin, R. (2009). Case Study Research: Design and Methods. California: Sage Publications.

Zavestoski, S. and J. Agyeman (2014). Complete streets: What's missing? In S. Zavestoski and J. Agyeman (Eds.), Incomplete Streets: Processes, Practices, and Possibilities (pp. 1-14), New York: Routledge. 
Appendix A: Staying Safe \& Healthy on the Rivers
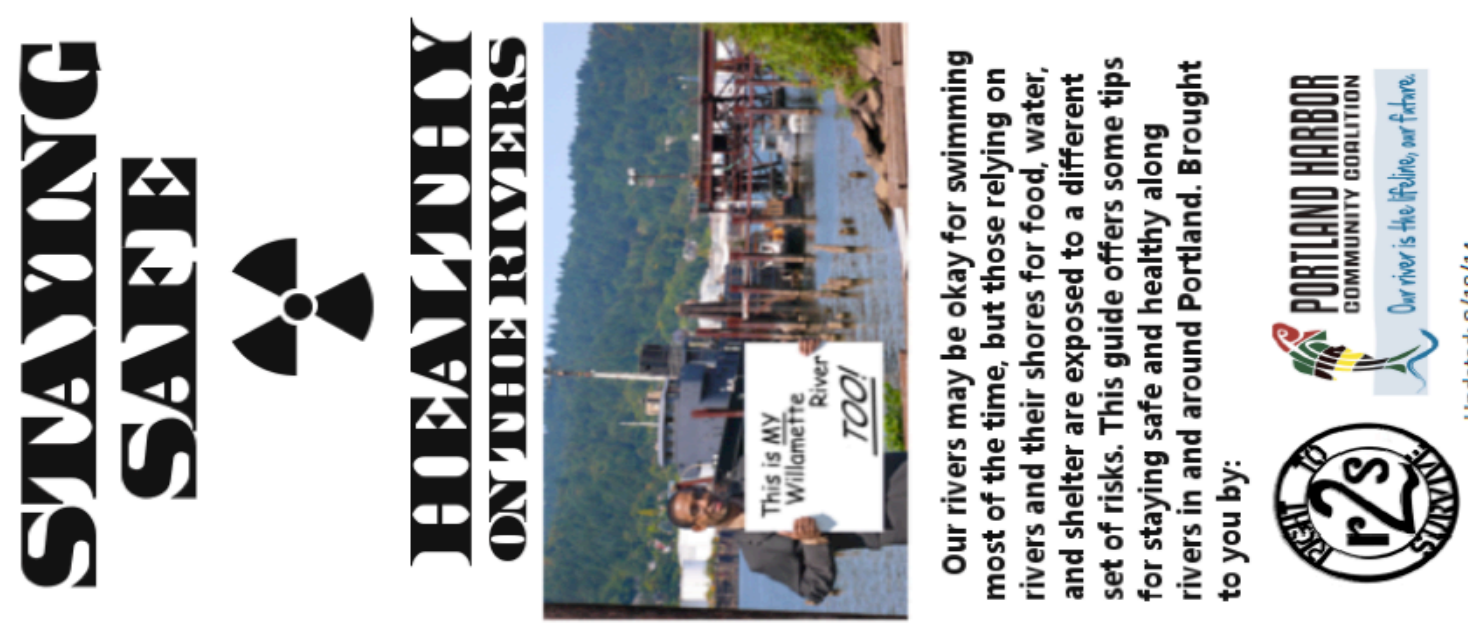

\begin{tabular}{|c|c|c|c|c|c|c|c|c|c|c|c|c|}
\hline 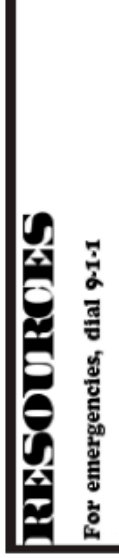 & 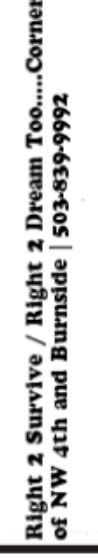 & 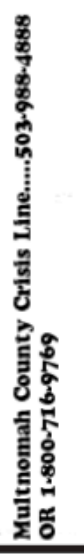 & 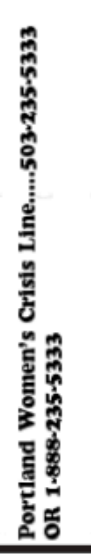 & 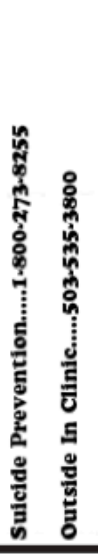 & 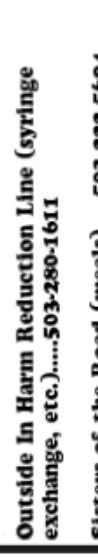 & 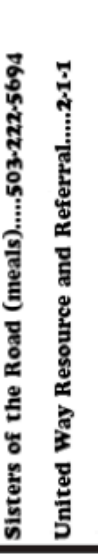 & 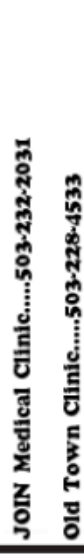 & 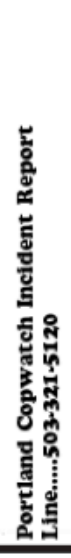 & 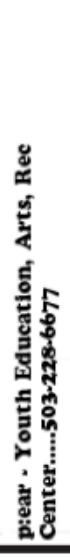 & 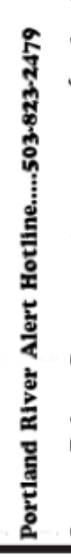 & 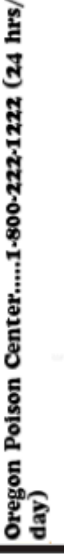 & 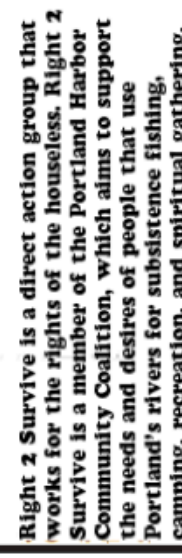 \\
\hline
\end{tabular}

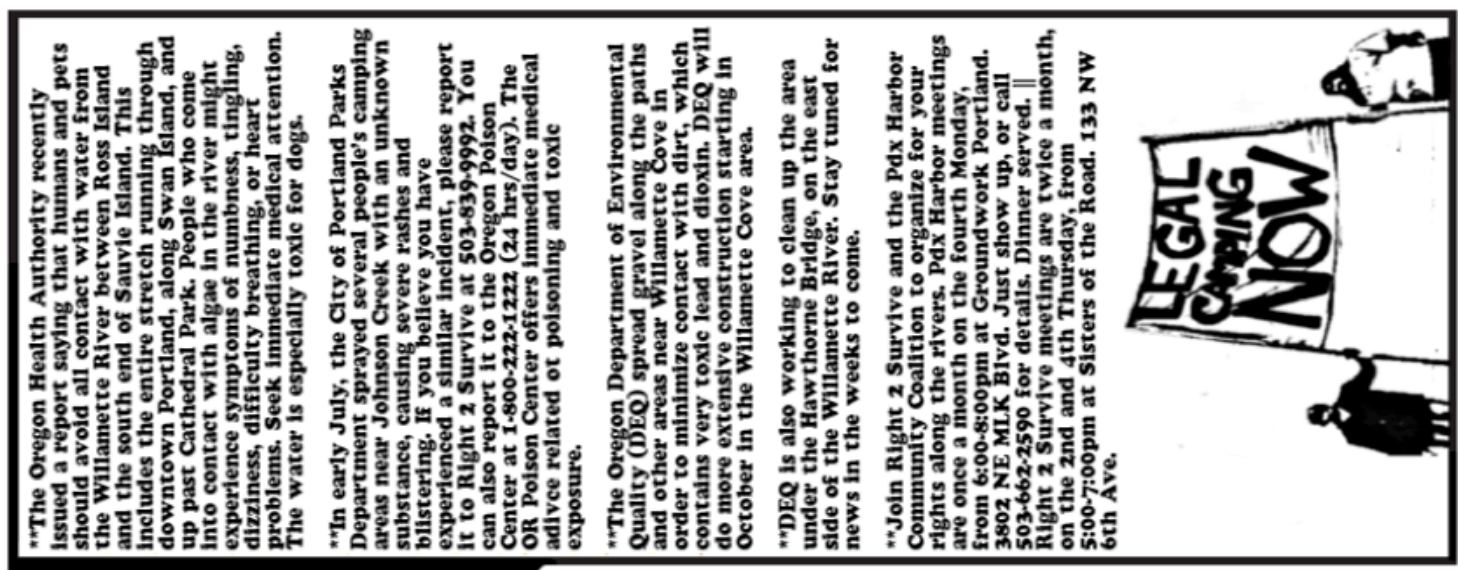

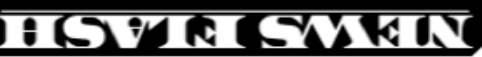



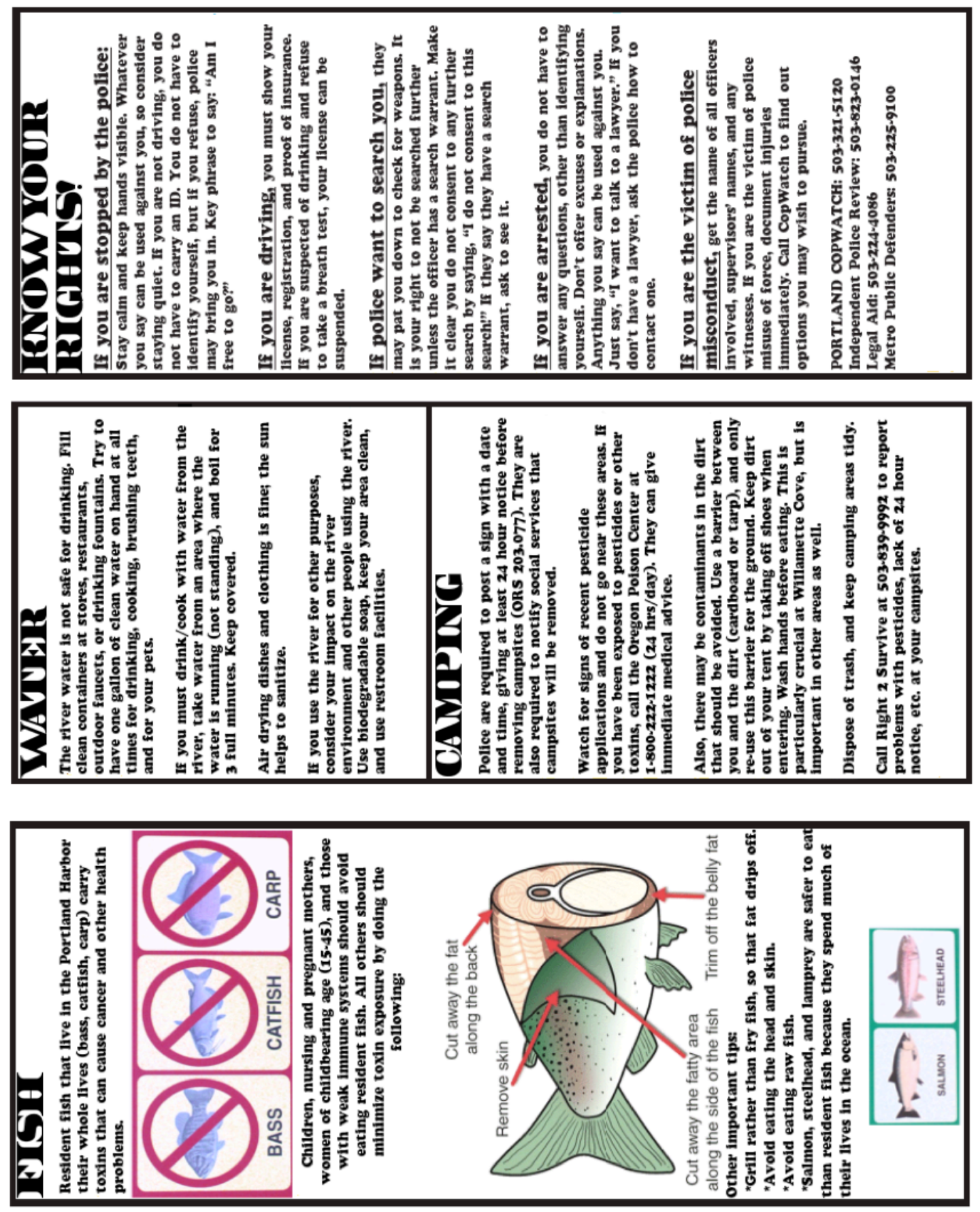


\section{Appendix B: Interview Participants}

Table 1. Interview Participants, Affiliation, Interview Date

\begin{tabular}{|c|c|c|}
\hline Alex Lopez & Groundwork Portland & August 17, 2015 \\
\hline Ana Mendoza & Líderes Verdes & $\begin{array}{l}\text { July } 3,2015 ; \text { July } \\
9,2015\end{array}$ \\
\hline Anonymous & Líderes Verdes & July 9, 2015 \\
\hline Anonymous & Líderes Verdes & July 9, 2015 \\
\hline Anonymous & Líderes Verdes & July 9, 2015 \\
\hline Anonymous & Líderes Verdes & July 9, 2015 \\
\hline Anonymous & Líderes Verdes & July 9, 2015 \\
\hline Anonymous & Líderes Verdes & July 9, 2015 \\
\hline Anonymous & Public agency & July 23,2015 \\
\hline Anonymous & Public agency & January 24, 2017 \\
\hline Cassie Cohen & Groundwork Portland & $\begin{array}{l}\text { June } 6,2015 \text {; June } \\
15,2015 ; \text { July } 18 \text {, } \\
2015\end{array}$ \\
\hline $\begin{array}{l}\text { Abdulhadi } \\
\text { Muhammed }\end{array}$ & Iraqi Society of Oregon & July 20, 2015 \\
\hline Ibrahim Mubarak & $\begin{array}{l}\text { Right } 2 \text { Survive/Right } 2 \\
\text { Dream Too }\end{array}$ & August 14, 2015 \\
\hline Irina Phillips & East European Coalition & February 2, 2017 \\
\hline Jeri Jimenez & $\begin{array}{l}\text { Environmental Justice Action } \\
\text { Group, City of Portland }\end{array}$ & $\begin{array}{l}\text { July } 28,2016 ; \\
\text { August } 8,2016\end{array}$ \\
\hline JR Lilly & Wiconi International & August 24, 2015 \\
\hline Lisa Fay & $\begin{array}{l}\text { Right } 2 \text { Survive/Right } 2 \\
\text { Dream Too }\end{array}$ & August 14, 2015 \\
\hline Loretta Pascoe & $\begin{array}{l}\text { Right } 2 \text { Survive/Right } 2 \\
\text { Dream Too }\end{array}$ & July 2, 2015 \\
\hline Mike Summers & $\begin{array}{l}\text { Right } 2 \text { Survive/Right } 2 \\
\text { Dream Too }\end{array}$ & $\begin{array}{l}\text { July 10, 2015; } \\
\text { July } 17,2015 \\
\end{array}$ \\
\hline Steve Goldstein & Sierra Club of Oregon & $\begin{array}{l}\text { June } 30,2015 \\
\text { July } 8,2015\end{array}$ \\
\hline Rodney Wall & $\begin{array}{l}\text { Right } 2 \text { Survive/Right } 2 \\
\text { Dream Too }\end{array}$ & July 17, 2015 \\
\hline
\end{tabular}




\begin{tabular}{|l|l|l|}
\hline Roy Pascoe & $\begin{array}{l}\text { Right 2 Survive/Right 2 } \\
\text { Dream Too }\end{array}$ & July 2, 2015 \\
\hline Tricia Reed & $\begin{array}{l}\text { Right 2 Survive/Right 2 } \\
\text { Dream Too }\end{array}$ & $\begin{array}{l}\text { July 10, 2015; } \\
\text { July 17, 2015 }\end{array}$ \\
\hline Wilma Alcock & Groundwork Portland & June 1, 2015 \\
\hline
\end{tabular}

